Florida International University FIU Digital Commons

FIU Electronic Theses and Dissertations

University Graduate School

9-27-2016

\title{
A Value-Driven Exploration of Online \& In-Person Learning for Professionals
}

Tammy S. Sanders

Florida International University, tsand024@fiu.edu

DOI: $10.25148 /$ etd.FIDC001181

Follow this and additional works at: https://digitalcommons.fiu.edu/etd

Part of the Adult and Continuing Education and Teaching Commons, Curriculum and Instruction Commons, and the Educational Methods Commons

\section{Recommended Citation}

Sanders, Tammy S., "A Value-Driven Exploration of Online \& In-Person Learning for Professionals" (2016). FIU Electronic Theses and Dissertations. 3053.

https://digitalcommons.fiu.edu/etd/3053

This work is brought to you for free and open access by the University Graduate School at FIU Digital Commons. It has been accepted for inclusion in FIU Electronic Theses and Dissertations by an authorized administrator of FIU Digital Commons. For more information, please contact dcc@fiu.edu. 
FLORIDA INTERNATIONAL UNIVERSITY

Miami, Florida

\section{A VALUE-DRIVEN EXPLORATION OF ONLINE AND IN-PERSON LEARNING FOR PROFESSIONALS}

A dissertation submitted in partial fulfillment of the

requirements for the degree of

DOCTOR OF EDUCATION

in

CURRICULUM AND INSTRUCTION

by

Tammy S. Sanders

2016 
To: Dean Michael R. Heithaus

College of Arts, Sciences and Education

This dissertation, written by Tammy S. Sanders, and entitled A Value-driven Exploration of Online and In-person Learning for Professionals, having been approved in respect to style and intellectual content, is referred to you for judgment.

We have read this dissertation and recommend that it be approved.

Kyle Bennett

Sarah Mathews

Melody Whiddon

Thomas Reio, Major Professor

Date of Defense: September 27, 2016

The dissertation of Tammy S. Sanders is approved.

Dean Michael R. Heithaus

College of Arts, Sciences and Education

Andrés G. Gil

Vice President for Research and Economic Development and Dean of the University Graduate School

Florida International University, 2016 
(C) Copyright 2016 by Tammy S. Sanders

All rights reserved. 
DEDICATION

To All of You

For All of This 


\section{ACKNOWLEDGMENTS}

For their guidance, insight and support throughout my doctoral and dissertation processes, my sincerest appreciation to my Major Professor and dissertation Committee Members, as well as the faculty and staff of the FIU College of Education, the FIU University Graduate School and the Florida Education Fund. This endeavour owes an immense and enduring debt of gratitude to you all.

"If I have seen further than others, it is by standing upon the shoulders of giants." Sir Isaac Newton 


\section{ABSTRACT OF THE DISSERTATION \\ A VALUE-DRIVEN EXPLORATION OF ONLINE AND IN-PERSON LEARNING \\ FOR PROFESSIONALS}

by

Tammy S. Sanders

Florida International University, 2016

Miami, Florida

Professor Thomas G. Reio, Jr., Major Professor

The purpose of this dissertation is to undertake a learner-centered exploration of delivery mode relevance in professional learning. Given the increasing pervasiveness of technology-mediated online delivery in nondegree professional learning at the individual and enterprise levels, this study has a particular focus on learning value ascribed by learners to online and in-person delivery in relation to their professional development.

Qualitative and quantitative methods were used in this study to collect and examine data from adult professionals in an effort to determine how value is ascribed to learning. With this aim in mind, this study focused on the following research questions:

1. Are there differences in preferred learning format between men and women?

2. Are there differences in preferred learning format between professionals in varied age groups?

3. Are there differences in preferred learning format between professionals who have engaged in learning online and people who have not?

4. For participants who indicate learning format preferences, how do they define and describe their preferences and on what aspects of the learning experience do they base their preferences?

5. For participants who indicate learning format preferences, how are these participants describing and interpreting meaningful relevance for learning in their day-to-day professional lives? 
A key driver of this exploration was a scarcity of representative understanding in wider research about the relationship between varied modes of professional learning delivery and professional learning transfer, which has long typified learning value in the adult professional context.

By exploring professionals' learning experiences and delivery mode preferences, this study arrived at several explanatory concepts, to include: learning preference premiums as impactful value-drivers for learners; ubiquitous blend as a comprehensive value-based approach to professional learning design and delivery; and absolute proximity as a deliberate technology-mediated merging of work and learning contexts that supports professionals in achieving full applicability of their learning.

Keywords: absolute proximity, corporate learning, corporate training, edtech, executive education, learning preference, management training, Millennial learning, online learning, ubiquitous blend 


\section{TABLE OF CONTENTS}

CHAPTER

PAGE

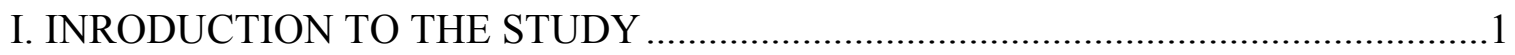

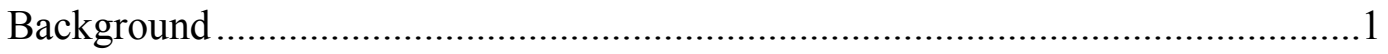

Problem Statement ................................................................................

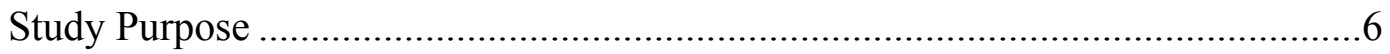

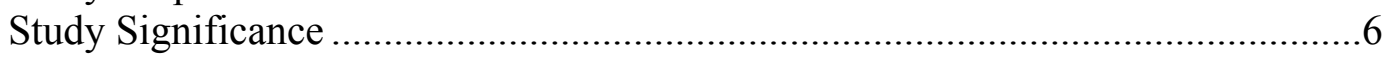

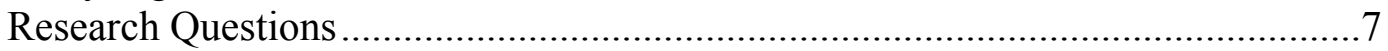

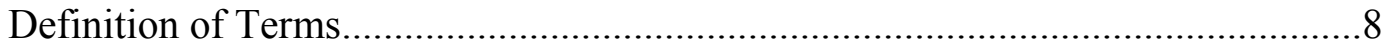

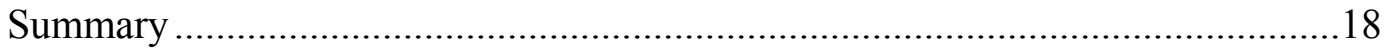

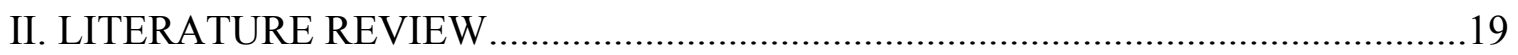

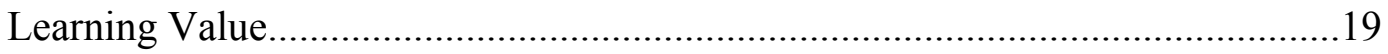

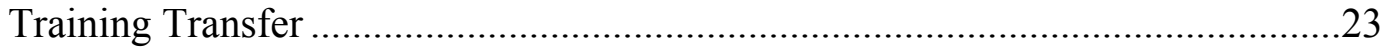

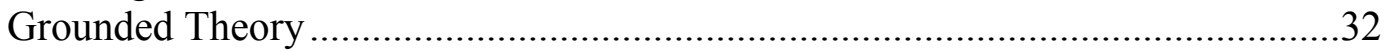

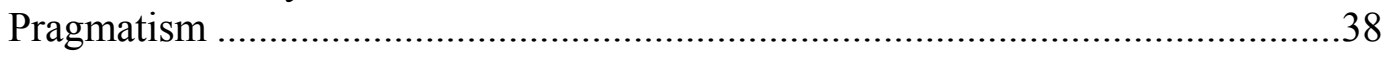

Pragmatism and Grounded Theory …………………........................................4

Pragmatism, Grounded Theory and Mixed Methods.........................................42

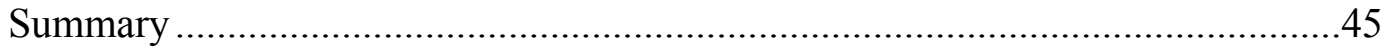

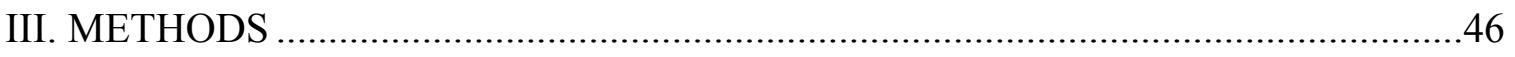

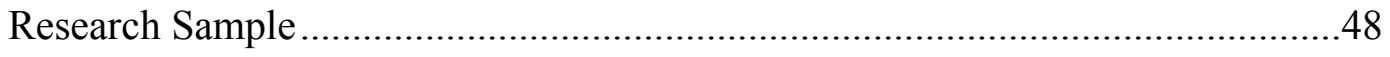

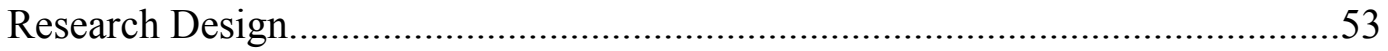

Research Instrumentation............................................................................57

Validity of Survey Questions ........................................................................58

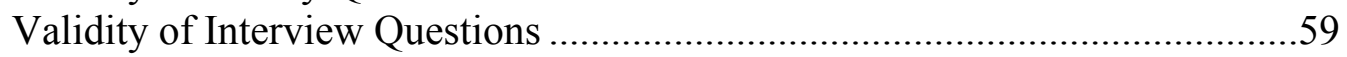

Qualitative Analysis Approach ............................................................................60

Analytical Tools Assessment …………………………...........................60

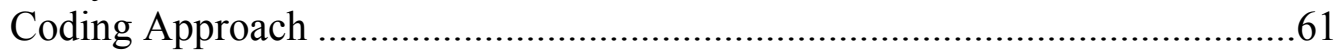

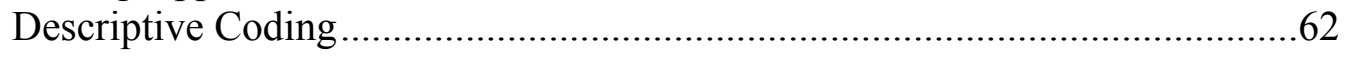

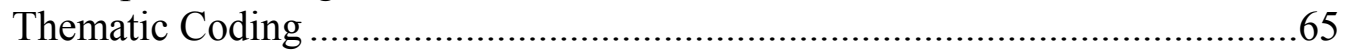

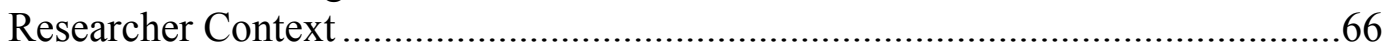

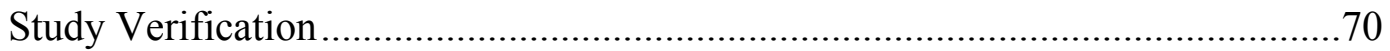

Study Delimitations and Limitations ................................................................

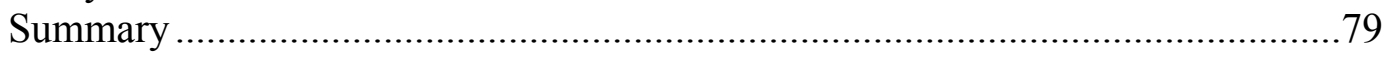

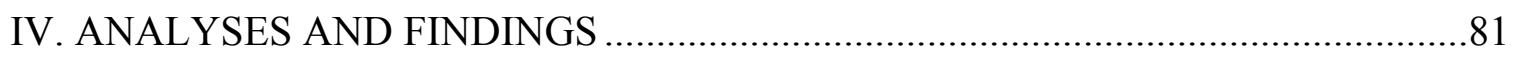

Frequency of Analysis and Cross Tabulation Results .......................................8

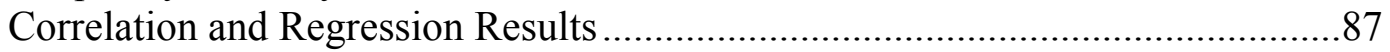

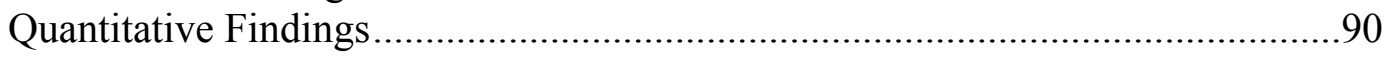

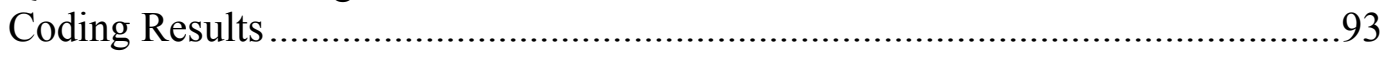

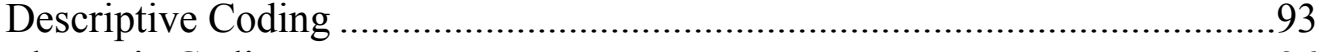

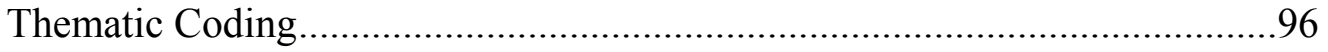




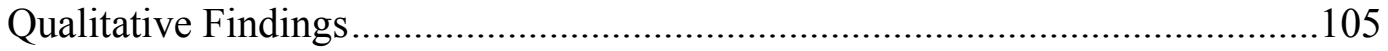

Describing and Defining Learning Preferences ............................................106

Diametric Learning Modalities ..................................................................107

Modality Dichotomies and Learning Design .................................................108

Modality Preferences and Content Suitability ...............................................110

Learning as Relationship........................................................................112

Learning as Real-Time Engagement............................................................114

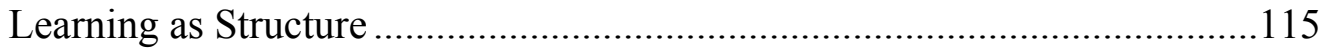

Learning as Discovery ……………......................................................116

Summary of Analytical Findings ....................................................................118

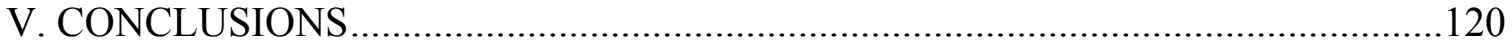

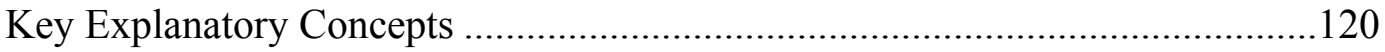

Learning Preference Premiums ...................................................................120

Ubiquitous Blend in Learning Design .........................................................124

Absolute Proximity in Learning Delivery..................................................127

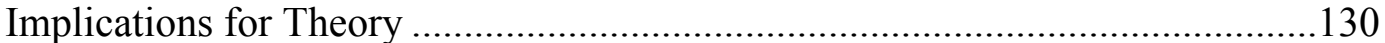

Implications for Further Research .................................................................133

Learning Function, Proximity, Transfer and Value .........................................133

Learner Personality and Learning Modality Value.........................................134

Learner Motivation and Learning Modality Value ........................................136

Learner Demographics and Learning Modality Value ....................................137

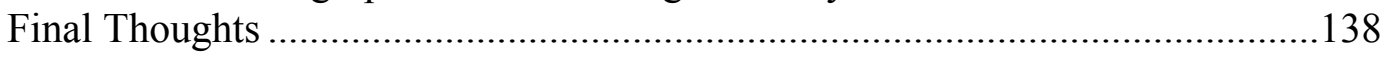

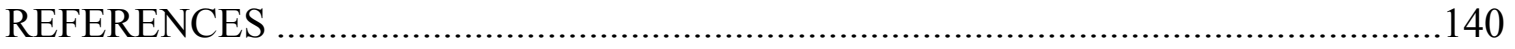

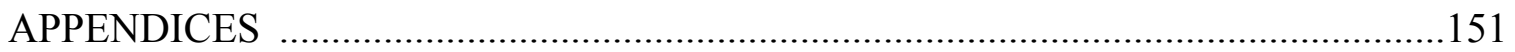

VITAE 


\section{LIST OF TABLES}

TABLE

PAGE

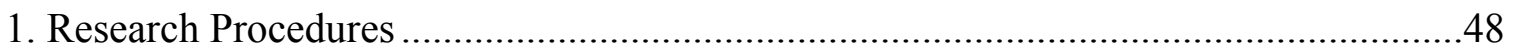

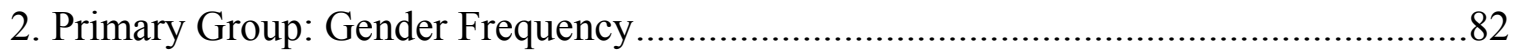

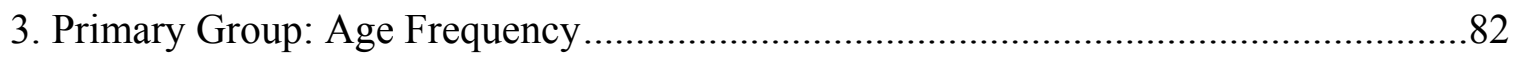

4. Primary Group: Online Learning Experience Frequency .............................................82

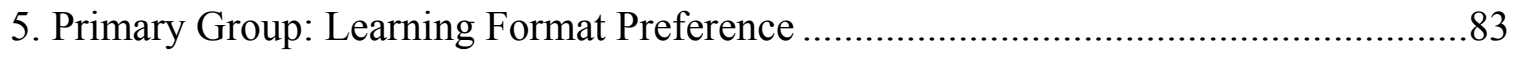

6. Primary Group: Learning Format Preference * Gender Cross-Tabulation.....................83

7. Primary Group: Learning Format Preference * Age Cross-Tabulation ...........................84

8. Primary Group: Learning Format Preference * Online Experience Cross-Tabulation..84

9. Secondary Group: Learning Format Preference * Gender Cross-Tabulation.................86

10. Secondary Group: Learning Format Preference * Age Cross-Tabulation.....................86

11. Secondary Group: Learning Format Preference * Online Experience Cross-

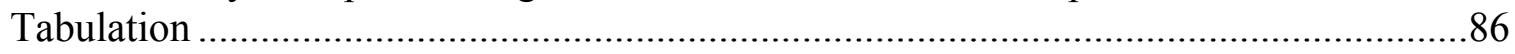

12. Primary Group: Learning Format Preference * Gender Chi-Square Correlation

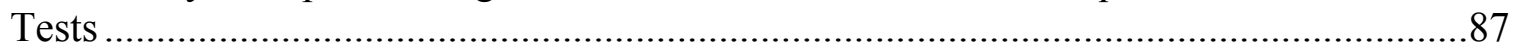

13. Primary Group: Learning Format Preference * Age Chi-Square Correlation Tests....87

14. Primary Group: Learning Format Preference * Online Learning Experience Chi-

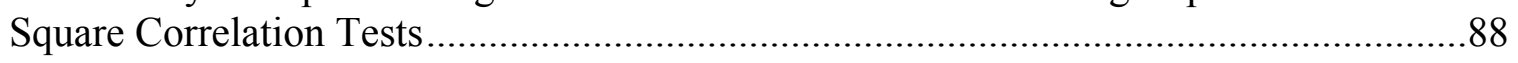

15. Secondary Group: Learning Format Preference * Gender Chi-Square Correlation

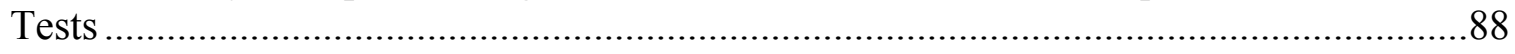

16. Secondary Group: Learning Format Preference * Age Chi-Square Correlation Tests .88

17. Secondary Group: Learning Format Preference * Online Learning Experience Correlation 


\section{LIST OF TABLES (CONT.)}

TABLE

PAGE

18. Secondary Group: ANOVA - Online Learning Experience and Learning Format

Preference

19. Secondary Group: Coefficients - Age and Learning Format Preference

20. Secondary Group: ANOVA - Age and Learning Format Preference

21. Secondary Group: Model Summary - Age and Learning Format Preference .90

22. Macro Categories and Descriptive Codes for Professional Learning.

23. Meaning-Driven Thematic Codes for Professional Learning .97

24. Research Questions and Findings 118 


\section{LIST OF FIGURES}

FIGURE

PAGE

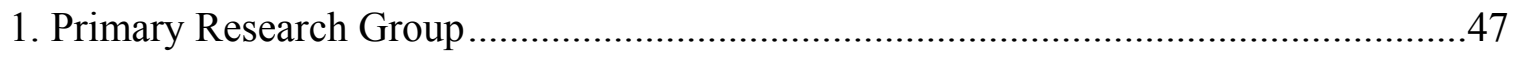

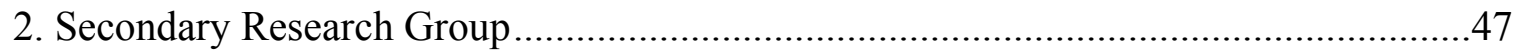

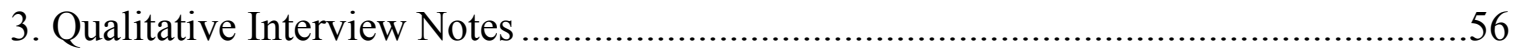

4. Demographic and Learning Preference Survey Sample Question ..............................57

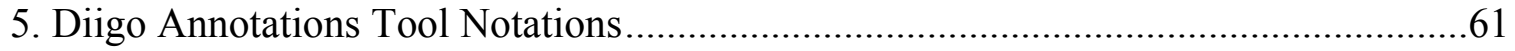

6. Participant Reponses: Professional Learning Definitions and Purpose ......................63

7. Learning Experience and Delivery Mode Preferences .............................................64

8. Insider Researcher Advantages and Disadvantages.............................................68 


\section{LIST OF APPENDICES}

APPENDIX

PAGE

Appendix A - Respondent Confidentiality Assurance.....

.151

Appendix B - Survey Instrument

Appendix C - Interview Questions.

Appendix D - Sanders Online Learning Reflections.............................................155

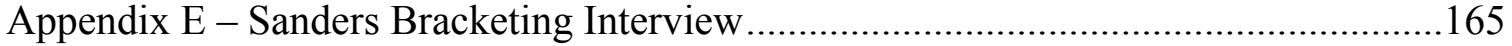

Appendix F - Relevant Technology Software and Services ......................................168

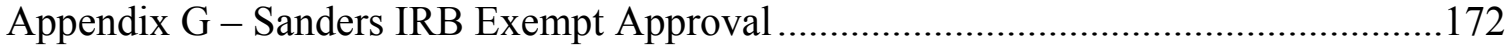




\section{CHAPTER I}

\section{INTRODUCTION TO THE STUDY}

\section{Background}

Technology-involved learning is not the future of education. It is, rather, the normalized now of education. Traditional public universities are heavily invested and offering fully online degrees (Haynie, 2014). Harvard University is priming undergraduate business minds via its online Credential of Readiness certificate (Byrne, 2014). A handful of states and several districts now require high school students take a class online before graduation (Sheehy, 2012). And K-12 teachers are adding "LMS" and "Apps" to their educator jargon vocabularies. With millions of learners of all ages experiencing courses or programs via technology, indeed there is no going back to a time when we did not learn in front of a personal screen.

In the context of nondegree professional learning, online delivery has long been utilized in support of primarily on-site professional learning. Secondary technologyinvolved activities have included online document delivery, business simulations, games, webcast lectures, virtual discussion boards, virtual office hours with learning providers, and mobile content delivery via phones and tablets. Some professional training programs at universities have even included immersive virtual realities where learning participants interact with space, objects and each other in realistic environments that bring learning into their working lives (Antonacci, 2009).

The dire economic times of 2008 and 2009 precipitated financially painful drop-offs in U.S. corporate spending on nondegree learning for professionals. In the recovery since, 
however, the potential of online delivery as a primary learning solution in the nondegree arena has expanded with notable industry disruption (Gutierrez, 2012; Stopper, 2013).

In 2012, online learning in the nondegree context began to gain momentum with the rise of high-profile technology-driven learning startups such as Udacity, Coursera and Udemy offering free or inexpensive massive open online courses (MOOCs) for nondegree learning from traditional institutions such as Wharton School of Business, Stanford University, Duke University and Harvard.

As quickly as MOOCs captured industry attention, the next evolution in nondegree technology-involved learning unfolded: the emergence of fully online learning options, facilitated by university executive education centers and education technology upstarts like ExecOnline. ${ }^{1}$ These online nondegree programs allow participants to maintain their work lives as they learn, instigating a fundamental shift from on-site learning immersion. The emergence of these technology-mediated programs in particular led to this dissertation's exploration of learner perspective about the learning value associated with varied learning modalities.

Before 2012, online delivery had hardly registered a notable measure of prevalence among professional learning's most prominent providers. A key example was university executive education centers, which dominate professional learning for middle managers, high-potential leaders, senior directors and executive leadership. In its 2012-2013 stateof-the-industry figures, the International University Consortium for Executive Education (UNICON) reported $50 \%$ of university-based executive education programs accounting for $90 \%$ of the nondegree professional learning industry's global revenue. Among university-based executive education centers in the United States, where globally 
prominent education brands such as Harvard predominate, nine out of 10 centers touted in-person learning as the primary delivery method.

On the client side, professional learning's corporate customers did not yet seem positively predisposed to technology-mediated learning. In a 2013-published big data study of 7,500 Internet-based conversations about online learning, corporate executives and employees registered the lowest recorded positive disposition toward online learning compared to university administrators and students. Chatter about online learning in the corporate realm was just as likely to be negative as positive (Maven Magnet).

Just two years later, that anti-online mindset had lessened, giving rise to education technology startups such as Coursera, Udacity and Udemy. Additionally, as the first technology startup solely dedicated to delivering wholly online professional learning for upper management, the aforementioned ExecOnline has become a bellwether company for the growth of nondegree professional learning online. Launched in 2012, the company's growth has shown itself to be both a driver and reflection of the growing prevalence and acceptance of online delivery in professional learning. The company had no corporate client commitments for online-only professional learning when it first opened partnership conversations with university executive education centers for online course design. By 2013, the startup had secured commitments from 10 corporate clients to send five to 20 participants each to online-only professional learning programs. During 2014, that number increased from 10 to 25 to 75 corporate clients who, attracted by prospects of efficiently achieving scale in their learning and development efforts, sent upwards of 700 high-potential leaders, senior directors and executives to online programs in innovation and strategic management (Sanders, 2014a). 


\section{Problem Statement}

The growing adoption of online delivery in nondegree professional learning has brought increasing relevance to the question of why choose online learning. If research and industry conversation are useful indicators, it seems questions of whether to opt for some amount of online delivery in both corporate learning and higher education are often driven by efficiency expectations more so than learning value or learning gains (Graham, 2013). When the focus is efficiency, what matters is how technology-mediated learning facilitates access while saving money and time for learners and companies. Such focus, however, does not address whether and to what extent technology-mediated learning generates value for participants or organizations where professionals spend their working lives. This focus on monetary and temporal efficiencies is problematic in that it provides insufficient evidence of technology's contribution to the value of learning and even less clarity about the value of online learning compared to in-person learning. Beyond common concerns of cost and time efficiencies, the research presented in this dissertation tackles the challenges of differentiating learning benefits for online and in-person delivery and discerning whether these benefits transform into distinct kinds of value.

Regardless of program delivery mode, the most prevalent and consistent drivers of cost are directly tied to program faculty, learning providers and subject matter experts (SMEs). When faculty or content experts in professional learning are paid rates for online delivery commensurate with rates paid for in-person delivery, the substance of learning costs as much online as it does in person. Even when online delivery lowers travel or other logistics costs associated with in-person learning, returns on learning investment remain ever-present industry concerns (Beecham, 2012; Burnett, 2011; Charlton \& 
Osterweil, 2005). Measuring professional learning's bottom-line contribution to a learner's professional life or organization is not necessarily resolved with logistics costsavings because each learning dollar spent implicitly requires an explanation of that learning's value.

With regard to saving time via online learning, research and reports from higher education suggest learning participants should expect otherwise. In formal surveys and informal conversations, students in online college graduate courses report spending as much or more time working through their online courses than time spent for their oncampus courses. In fact, more time spent in online courses combined with effective curriculum design and pedagogy has been noted in some studies to deliver stronger performance compared to more student time devoted to offline courses (Kuong, 2009; U.S. Department of Education, 2010).

Of course, graded degree programs and nongraded nondegree professional learning programs are not wholly analogous, especially because nondegree learning participants are neither incentivized nor penalized with grades for program completion or incompletion. Nonetheless, a self-set learning pace does hold true in both scenarios and may exert as much influence on time spent completing online professional learning courses or programs, as is the case with time spent in online college courses. Interestingly, a lengthier four- to six-week duration has emerged as a design option for online executive education courses, spreading the participant learning experience beyond one- to three-week norms for the most immersive in-person executive education programs. In this long-format design paradigm, participants will spend more weeks engaged in the learning process online than in person. 
Thus, with online learning's cost- and time-savings proving somewhat questionable, modality-driven learning value becomes even more important to investigate and clarify for professional learning design and delivery.

\section{Study Purpose}

Given the increasing pervasiveness of technology-mediated online delivery in nondegree professional learning at the individual and enterprise levels, the purpose of this dissertation is to undertake a learner-centered exploration of delivery mode relevance in professional learning. Hence, this study has a particular focus on learning value ascribed by learners to online and in-person delivery in relation to their professional development. And, this study's purpose is to develop explanatory concepts of how learners define value and how those definitions were influenced by delivery format.

\section{Study Significance}

This inquiry into the learning value associated with learning modality stems from years of practitioner experience in professional learning and first-hand experience with the increasing impact that the option of online delivery is having on learner decisionmaking about professional development. Having framed the problem and the purpose of this study as one of determining value in learning, the resulting significance of this dissertation is based on its ability to deliver informed vantage points for both professional learning providers currently exploring the business case for online delivery as well as for learning and development decision-makers considering technology-mediated professional learning as an option for addressing individual or organizational learning needs.

As a practitioner, I come to this research from where I stand as a professional whose livelihood revolves around design, delivery, facilitation and direction of professional 
learning for corporate clients in the U.S. and abroad. I have been in the field for more than 20 years and come to this research endeavour with professionals objectives and a backlog of questions that have built up over two decades of working with learners.

Efforts to manage simultaneous roles as researcher and practitioner are further addressed in the study's Methods discussion, but my researcher status also merits mention now, as it has affected (among several research facets) my perspective on this study's significance, which is steeped in practice and centered on the following propositions for why a study on learning value matters for learning providers:

1. A growing prevalence of online delivery in professional learning appears inevitable. Industry players and stakeholders should expect online learning to take on an increasingly significant role in the professional learning marketplace.

2. There is unrecognized and unexplored opportunity for professional learning providers to differentiate value propositions for online and in-person learning in ways that bridge each of these learning modalities for optimal ability to meet corporate client and participant learning needs.

3. There remains an undetermined, or at least underexplored, relationship between online delivery in professional learning, participant learning outcomes and transformative effects of learning for organizations, all of which carry potential implications for decision-making about professional learning and development.

From my practitioner's perspective, I am inclined to question whether saving money and time are the most relevant aspects of online delivery's significance as a learning modality. If the suggested significance of this study holds true, perhaps these efficiencies should be inextricably paired, if not altogether preceded, by questions of the distinct learning value provided by online delivery in comparison to in-person delivery.

\section{Research Questions}

This dissertation's research questions anchor this exploration of learning value in learner perspective by quantitatively establishing learner perspectives about online and 
in-person learning modalities, then qualitatively examining the learning value associated with modality by learning participants. The research questions include:

1. Are there differences in preferred learning format between men and women?

2. Are there differences in preferred learning format between professionals in varied age groups?

3. Are there differences in preferred learning format between professionals who have engaged in learning online and people who have not?

4. For participants who indicate learning format preferences, how do they define and describe their preferences and on what aspects of the learning experience do they base their preferences?

5. For participants who indicate learning format preferences, how are these participants describing and interpreting meaningful relevance for learning in their day-to-day professional lives?

\section{Definition of Terms}

For the purposes of this dissertation, working definitions used in the context of this research have been formulated based on a combination of guidance from published research, industry understandings and the researcher's expertise as a practitioner in learning and development for executive, managerial and Digital Age professionals.

Well-respected counsel has advised that all definitions be sourced from published references, but this is impractical in a practice-based context like online delivery in professional learning which also has not been as robustly researched or widely published as, say, online delivery in higher education.

Additionally, review of dissertations by education doctoral students writing about online delivery and/or professional learning from and beyond my home institution show little in the way of a standardized approach to operational definitions (Chejlyk, 2006; Goodwin-Lee, 2010; Lopez, 2001; Maxfield, 2008; Pettazzoni, 2008). Some definitions come from published sources, and some do not. Many definitions are put forth unjustified 
and unaccompanied by explanation of their origins. Inevitably, definitions for similar terms vary. For example, varied and wholly unsourced definitions were provided in education dissertations for "distance-learning" to include:

- Learning that occurs when instructor and student are separated by time and place (Chejlyk, 2006)

- Process of undertaking educational classes or programs remotely from the schools, campuses, or physical institution that provides the education for primarily nontraditional learners. It can be either synchronous or asynchronous and can include elearning, video or broadcast (Goodwin-Lee, 2010)

- Instruction that involves physical and/or temporal separation of student from instructor and/or other students enrolled in the course. Course delivery and activities are conducted via web-based technology (Pettazzoni, 2008)

Though similar, these definitions for distance learning bore the distinctive marks of their research context and their researchers' perspectives. With all due respect and a transparency that invites critique, distinction is made here between research-driven, industry-driven and originally established definitions. Defined terms are underlined and alphabetically ordered:

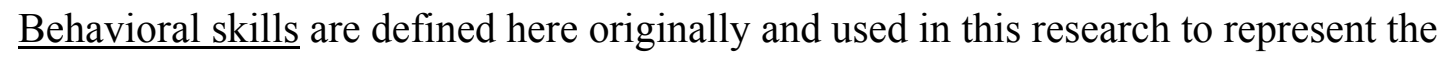
wide array of personal and interpersonal abilities typically referred to as soft skills. Such skills include ways of conceptualizing, perceiving, reflecting, relating and engaging oneself or others to affect performance or outcomes. 
Blended learning, synonymous with hybrid learning, occurs when a learning course or program includes partial engagement of learning participants in face-to-face nontechnology mediated interactions and partial engagement through technologyenhanced delivery with some element of student control over time, place, path and/or pace of learning. This definition is taken from Horn and Staker's (2011) "The Rise of K12 Blended Learning" policy document. For the purposes of this dissertation, when online learning occurs in conjunction with on-site learning (or vice versa), the term blended learning will be used. No distinctions will be made for learning that is primarily online or primarily on-site. If both delivery modes are simultaneously employed to any degree, the learning environment will be described as blended.

Corporate education and corporate learning are descriptives typically used in industry parlance as umbrella terms for all enterprise-related learning. The terms will be used thusly in this dissertation. Corporate training is a descriptive used in industry to generally reference enterprise-related learning but is also used to describe specific learning targeted to the development of specific functional skills. As corporate training receives the bulk of research focus in professional learning, much of the literature referenced for this dissertation on professional learning will involve studies on corporate training in its various forms.

Education technology, abbreviated here as edtech, is defined as tools, platforms and practices used to facilitate learning and improving performance via technological processes and resources. This definition is based in part on the 2008 definition put forth by the Association for Educational Communications and Technology (Richey, 2008). 
Keeping in mind AECT's 2008 definition was their fifth iteration of edtech's meaning since the 1990s, the definition used here recognizes evolution in the understanding and use of the term and has been specifically crafted by this dissertation's researcher for the purposes of this study. In this dissertation, technology is referred to in its broadest sense and includes but is not limited to: computer, mobile and tablet software, hardware and applications; web-based activities; Internet applications; learning management systems; customer relationship databases; audio and video hardware and software; Internet- and console-based gaming; virtual reality applications; and social media.

Executive education is an industry term referencing the multi-million dollar nondegree learning industry dominated in the United States by university providers and typically situated in business schools. There is a paltry lack of publicly available research on market specifics for the executive education industry. UNICON is currently one of the more recognized sources of industry information, publishing research from its own surveys alongside select research from other sources. But even a UNICON 2011 industry analysis, the University-Based Executive Education Markets and Trends report, includes as its sole figure on executive education market size an $\$ 800 \mathrm{M}$ estimation offered by BusinessWeek magazine in 2001 based on its research of what was then called executive training (Lloyd \& Newkirk, 2011). While fixed values, terminology and definitions of executive education remain elusive, there are some industry norms that help frame understanding of executive education and its relevance to professional learning.

Often included under the umbrella of business or corporate education, executive education programs typically differ from corporate training and skills development in distinct ways. Executive education's target learning audience is often and specifically 
comprised of senior managers, directors and leaders with significant and strategic levels of responsibility for projects, products, processes and people in an organization.

Task-specific functional skills and tactical competencies (e.g. understanding business financials) may be explored in specific executive education sessions, and some executive education programs do build middle-manager functional skills (e.g. product management). For the most part, however, executive education is usually undertaken to develop strategic knowledge, expertise, perspectives, approaches and insight applicable both within and beyond a chosen industry or field. ${ }^{2}$

Learning value is the term used in this research to indicate whether learning provides explicit utility, effectiveness, productive consequences or productive contribution to a learner's professional development beyond the original learning context. This is an original definition crafted by this dissertation's researcher for the purposes of this study and based on theoretical and empirical discussions in literature of learning's purpose.

In the introduction to Psychology of Learning for Instruction, instructional learning theories are described as sharing a basic definitional assumption of learning as:

... a persistent change in human performance or performance potential. This means that learners are capable of actions they could not perform before learning occurred and this is true whether or not they actually have an opportunity to exhibit the newly acquired performance. Typically, however, the only way a teacher, instructor, or researcher knows that learning has occurred is to ask the learners to demonstrate in some fashion what they have learned. Finding good indicators of learning is as important for designing instruction as it is for building theory. (Driscoll, 2005, p.9)

For its "good indicators of learning," the larger education industry - from K-12 through college - lives and dies by quantitative scores. How learners fare on quizzes, tests, exams and grades all provide tangible measures of learning performance. These 
performance measures subsequently provide the handiest way to assess and represent outcomes in a learning context. In essence, scores are how educators show whether the learning completed has amounted to something for the people who (supposedly) have been educated. A learner's perspective of the learning experience is irrelevant in scorebased assessment. Learner productivity matters most, and that productivity remains confined to quantitative measure in the original learning context.

Some investigations into student satisfaction and performance in online learning for corporate professionals go so far as to lay out implications for online delivery by extrapolating and generalizing from a degree-seeking business school student's context to the corporate learning context (Cater et al., 2012; Rafferty \& Anderson, 2013). Despite arguments in these papers to the contrary, the researcher disagrees such extrapolation is well-founded enough to overcome the substantial differences in learning needs, learning drivers and signifiers of learning success that exist between degree-seeking business learners in college and nondegree professional learners in practice.

Particularly in online learning research such as Cater et al.'s (2012), where discussion of adult online learning is about whether college students' exam scores and grades are comparable in online and in-person courses, the supposition is, if learners pass their tests, they have learned something of use. In nondegree and noncertification learning for professionals, however, score-based measures have little meaning in the absence of exams or grades.

The substantive measure that matters most is whether learning changes how the learner performs in their professional role. As training transfer researchers note, learning for professionals is intended to generate value for organizations, and that means learning 
must transfer to professional performance (Holton et al., 1997; Yamnill \& McLean, 2001). Hence, learning for professionals earns its value when it can help solve real-world problems, when it has effect outside the learning context, and when it transfers to and is put to work in real-life situations. Test scores, arguably, do not capture such value.

How, then, to measure the value of learning for professionals when their learning is online? Research presented here is a preliminary step toward explorations that may answer this question with quantitative and qualitative analysis of learners' perspectives on learning in person versus online. The ultimate goals are to reveal and reinforce those "good indicators of learning" for professionals who engage in learning to the benefit of their organizations and their professional lives.

Online learning, technology-involved learning and technology-mediated learning are used synonymously in this dissertation based on an amalgamation of understandings from a variety of academic and industry sources. The terms are used in the writing of this dissertation to describe learning experiences that involve any one of a range of technologies such as communication, education, electronic, information or mobile. The term represents technology-enhanced learning that occurs in or out of a class setting, is synchronous or asynchronous, and is self-directed or instructor-led. Perhaps unique to this study is the suggestion that in the current Digital Age and specifically in the context of learning for professionals, effective use of technology in learning that does not mix information retrieval with interaction and/or communication is exceptionally rare. Thus, there is little occasion (or necessity) to distinguish online, technology-involved and technology-mediated as different categories of learning. 
One could argue, for example, that using SMART Boards or PowerPoint (PPt) presentations in a class is technology-mediated - but not online - learning. However, the point made here is that the scenario in which a provider of learning to professionals would design a PPt with no links to online content or use a SMART board with no online interactivity represents such an underuse of the technology as to make such use a rarity in effective learning design.

In industry practice and academic research, there is arguably little commonality in the definitions of or the distinctions between online learning, e-learning and e-education, all of which are broadly synonymous with a range of similar terms focused on particular aspects and delivery methods (Lowenthal \& Wilson, 2010; Volery \& Lord, 2000). Additional terms include computer-assisted instruction, computer-based instruction, computer-based training, multimedia learning and technology-enhanced learning

As Moore et al. (2011) assert in their online learning definitional meta-analysis, this lack of definitional commonality causes research difficulty when attempting to make meaningful cross-study comparisons and build on previous studies. Terms are interchanged without meaningful definitions, resulting in plethora of conflicting findings about online learning efficacy. In response to this issue, definitional simplicity of online learning as formal and structured course delivery was imposed on the survey used in this dissertation's research to achieve at least a minimal degree of alignment with prior research. However, in follow-on interviews with respondents, it quickly became clear that a broader - if still simplified - definition of online learning was necessary to fully capture learners' experiential diversity. This discovery, discussed in the Limitations section of 
this research, prompted a widening of online learning's definitional bounds as a learning experience by inclusively allowing the experience to occur in a variety of contexts.

For the purposes of this dissertation, when online learning occurs in conjunction with on-site learning (or vice versa), the term blended learning is used. See this dissertation's definition of blended learning for further clarity.

$\underline{\text { On-site, }}$ in-person and face-to-face learning are terms used synonymously in this dissertation to describe learning experiences requiring participants to engage collectively at a common physical location in nontechnology-mediated environments. Relevant locational contexts include but are not limited to classrooms, conferences, organizational visits, roundtables or panel discussions. This is an original definition based on industry practice and adopted by this dissertation's researcher for the purposes of this study. In this dissertation, the terms on-site learning, in-person learning and face-to-face learning will be used synonymously. When on-site learning occurs with online learning, the term blended learning will be used. See this study's "blended learning” definition for clarity.

$\underline{\text { Professional learning is defined here as formal and informal nondegree learning }}$ undertaken by adults to strengthen or advance their knowledge or skills related to their vocations or primary sources of livelihood. This is an original definition based on industry practice and adopted by this dissertation's researcher for the purposes of this study. The definition is also informed by survey results collected for this study in which learning participants ascribed a related assortment of generalized characteristics to the “professional learning” descriptive.

From these survey results, "professional learning" emerged as an acceptable umbrella term for all nondegree learning, training or education designed and intended for 
professionals. Also referred to in this dissertation as nondegree learning for professionals, the term professional learning represents any vocation or job-related learning regardless of where it is undertaken, whether there is accredited or institutionally approved curriculum, whether the learning results in certification, and whether the subject matter or content relate to technical, functional or behavioral skills.

Professional learning programs confer no college degrees and typically offer no transferrable academic credits. Some programs, however, do contribute to professional certifications. A substantial amount of relevant research for this dissertation comes from explorations in corporate training specifically, and employee training generally. The definition of professional learning provided here has been made intentionally broad to reference and incorporate training-related research.

Proximity in this dissertation refers to spatial and temporal contiguity between work and learning contexts and comes from learners' ability to remain fully engaged professionally while also fully participating in professional learning. This is an original definition based on industry practice and adopted by this dissertation's researcher for the purposes of this study.

In online professional learning, arguably more so than in on-site professional learning, a learning participant has flexibility to organize learning around other life responsibilities, to include work. Proximity is called out in this dissertation because it is a distinct characteristic of the online format, yet this aspect of online delivery has received scant attention in research on professional learning. 


\section{Summary}

In sum, this study tackles the challenge of defining learning value from the learner perspective. Learning value is the term used in this study to indicate whether learning provides explicit utility, effectiveness, productive consequences or productive contribution to a learner's professional development beyond the original learning context. Learner perspective was gathered from a sample group of self-selecting research participants, with no incentives provided for participation and all data reported anonymously.

This study's research questions anchor exploration of learning value in learner perspective by quantitatively and qualitatively examining the learning value associated with modality by learning participants. The research questions posed for this dissertation focus on professional learning's relevance to daily work experience and aim to produce an operational definition for learning value based on learning's ability to help solve real-world problems via transfer into real-life work situations.

Having framed the problem and the purpose of study as one of determining value in learning, the resulting significance of this dissertation is based on its ability to deliver informed vantage points for professionals engaged in learning for their development and for professional learning providers looking to drive value in learning design and delivery. This study is of particular relevance to learning practitioners who face a growing prevalence of online delivery in learning for professionals. The insights provided here are intended to support differentiated value propositions for online and in-person learning in ways that address varied participant learning needs. 


\section{CHAPTER II}

\section{LITERATURE REVIEW}

Research questions posed for this dissertation focus on professional learning's relevance to daily work experience. The questions also aim to produce an operational definition for learning value based on learning's ability to help solve real-world problems via transfer into real-life work situations. To inform and craft exploration of these learning-related questions, literature examined for this dissertation includes research related to learning value and training transfer.

With an eye toward the relevant paradigmatic, epistemological, ontological and methodological underpinnings guiding the dissertation's inquiry process, literature on grounded theory, pragmatism and mixed methods is also reviewed. The aim of this portion of the literature review is conceptual integration of these research devices based on how they shape, inform and strengthen the sophistication, substance and rigor of this dissertation's research process.

\section{Learning Value}

An initial review of literature related to online delivery specifically for professional learning has revealed significantly little exploration of learner perspective on learning value among adult learners, and what exploration there is typically examined adults in the context of college-based degree programs. An article reviewing experiences and attitudes of novices to online learning, for example, analyzes "quality indicators" and the learning experience's "impact on trainees" in college-based computer courses by examining indicators such as whether learning participants found their online courses "stimulating" or "useful and effective" (Delfino et al., 2004, pp. 34-35). But these indicators of impact, 
measured quantitatively via surveys, do not clarify how the courses are useful to participants or address what learning value participants glean from online delivery beyond the flexibility of study "without moving to the university" and the indulgence of learner preference "for interacting at a distance" (p.33).

In research on motivation in online courses from the perspective of adult learners, Styer (2007) called out interactivity and personal control as impactful variables in learner motivation but did not specify or delineate between the kind/s of value these variables contributed to learning in the context of online delivery. Styer notes:

Some adult learners choose online delivery because they do not need (or) want to participate in social aspects of instruction, thus making socialization and collaboration activities demotivating factors for those learners. However, since some learners are motivated by online socialization and collaboration, making this type of interaction optional allows online adult learners control over their learning, which increases motivation. (pp. 113 \& 114)

Interactivity in this context reflects aspects of instruction, particularly social aspects of instruction. As such, interactivity as an aspect of instruction could be reasonably asserted as associated directly with the cognitive experience of learning. Personal control, on the other hand, characterizes a related modality aspect of online learning. While personal control may very well affect a learner's engagement in the learning process, it is arguably indirectly associated with the actual cognitive experience of learning in Styer's research, where control is a driver of learner motivation. Though Styer does not name them as such, interactivity and personal control both emerge as examples of learning value in the online modality - but only the former is called out as a contributor to 
learning value. A lack of learner voices hinders better understanding of how these variables add value to learning.

In contrast, Maxfield (2008) gave ample voice to learning participants' views about how learning online directly affected interaction, engagement, directional flow and content of their learning. The researcher's qualitative research explored emergency service workers' perceptions and attitudes about taking an online course as part of college degree requirements. In discussing the value of education generally, the researcher used participant interviews to highlight goal-achievement, improved career competitiveness and exemplary pursuit for children and other family members. Cognitively transformative aspects of participant learning online (namely self-directed study and reflectivity), however, were relegated to subthemes alongside self-discipline and assumptions of convenience under an overarching theme of flexibility.

To be fair, Maxfield (2008) throws the brightest spotlight found in this research's initial literature review on the adult experience of developing knowledge acquisition and making meaning out of learning in the online delivery context. He even heralds learning participants' reasons for pursuing online coursework as "not just to obtain a degree, but to actually gain an education; the degree was secondary to the actual learning" (p.116). Nonetheless, Maxfield's research falls short in not calling out self-direction and reflectivity in the online learning experience as indicative of online learning value with the same clarity that aspects of general learning experience are called out as indicative of education value.

The issue is not so much the researcher failing to recognize online learning experiences as important in the online learning process, but rather that these experiences 
never advance beyond the phenomenological realm to become explicit elucidations or representations of learning value - that is to say, creators or embodiments of learning value in the online delivery context. This analytical and interpretive choice leads to questions about whether the researcher simply conflates general education value and online learning value as synonymous, if not wholly interchangeable, concepts.

Maxfield's (2008) work mines learning theory to the exclusion of professional learning practice in an effort to explicitly define learning in terms of outcome. For example, Maxfield utilizes Driscoll's (2005) aforementioned description of learning as part of his exploration of online learning in an academic setting. As a researcher of emergency service workers who are college students, Maxfield's discussion occurs at the theoretical levels of "psychological epistemologies" and "principles of adult learning" (p.15). Researchers concerned with learning in professional contexts must, in contrast, occupy themselves with concretizing learning's purpose as much as theorizing its principles. With real-world learning concerns in mind, a notable portion of the literature utilized to inform this dissertation is an effort to bridge practical questions about the value of varied delivery modes in professional learning, of which little specific exploration has been made, with existing research into what approaches to professional learning lend themselves to transfer from learning contexts into professional practice.

Because direct links between the questions of learning value pondered here and answers provided in literature are few and tenuous, development of these links requires turning examinations from higher education and corporate training toward unintended but related contexts of professional learning. In that sense, this dissertation's literature review is itself a tempered and critical exercise in transfer from one context to another. 


\section{Training Transfer}

The search for literature related to learning value in online delivery and professional learning generally revealed a robust degree of attention paid to professional learning's transfer value in professional practice. Training transfer is generally understood in the literature as the application of knowledge, skills, concepts, insights and perspectives from a learning environment to a work environment. Researchers seeking Driscoll's "good indicators of learning” $(2005$, p.9) for professionals have most often and most extensively focused their attention and explorations on structured managerial and employee training, with the bulk of research attention devoted to whether skills training, performance feedback and performance management transferred from the context of learning to the context of performance. With training transfer research focused on the degree to which learners apply and derive utility from their learning, training transfer surfaced in the literature as a prominent proxy for learning value.

The transfer of training concept relates to transfer of learning theory, introduced by Woodworth and Thorndike (1901) and summarized as exploration of the interdependence of mental functions and the effects of learning, performance or previous experience across cognitive areas. Since its introduction, the transfer concept has suffered no shortage of theory attempting to explain the how and why of its occurrence.

Researchers from a variety of fields - behavioral psychology, cognitive psychology, adult learning - have explored how and why transfer occurs with varying degrees of contradiction, convergence and evolution. As the following literature review attempts to illustrate, availability of training transfer theory is in no short supply, and the concept demands examination in a dissertation attempting to define and explore learning value. 
Woodworth and Thorndike (1901) showed in their research that "improvement in any single mental function rarely brings about equal improvement in any other function" (p. 250), but also suggested the amount of transfer between a familiar situation and an unfamiliar one is determined by the number of identical elements the two situations have in common. This perspective came to be known as identical element theory. Contrary to Thorndike and Woodworth, psychologist Charles Judd (1908) deemed identical elements theory simplistic and insisted transfer related to instruction. If instructors taught for transfer and learners discerned transfer was meaningful, then transfer would occur.

Stokes and Baer (1977) put forth similar ideas with their exploration of 270 studies on generalization from the field of applied behavioral analysis. The two researchers describe generalization as therapeutic behavioral change over time, contexts, interpersonal interactions and related behaviors. Rather than seek behavioral change with a "train and hope" approach (p.350), Stokes and Baer suggested two approaches: programming generalization via more deliberate techniques such as teaching multiple examples of behavior change until generalization is achieved, and training specifically for generalization by positively reinforcing generalizing behavior. With their approaches, Stokes and Baer encouraged behaviorists to think of generalization not just as "an outcome of behavioral change" but also as a trainable behavior in and of itself (p.363).

In contrast to identical elements theory in training transfer but similar to generalization concepts in applied behavior analysis, near and far transfer theory as posited by Laker (1990) suggests training transfer can effectively occur in the application of learning to situations both similar and dissimilar to the original learning context. Near transfer is more likely when training reflects the workplace, while far transfer is more 
likely when learners understand the underlying principles, concepts and assumptions of skills or concepts they are learning. Whether near or far transfer occurs depends, according to Laker, on the transfer training theories used to design the training.

As both the concept of generalizability and Laker's definitions of near and far transfer suggest, learners can apply learning in situations that reflect the workplace or can leverage what they learn in contexts that are dissimilar to their workplace. In either case, the explicit foci in these conceptions of transfer are the degrees of difference between learning context and context of training application. The learning's purpose - that is, what learners expect to accomplish with the skills or concepts they attain - holds steady in these conceptions. It is the shift in context that defines transfer.

Training transfer researchers, however, have long insisted that transfer is much more difficult to come by in training. Baldwin and Ford (1988), for example, estimated $10 \%$ or less of training transfers to the workplace. Wexley and Latham (2002) from their research estimated $40 \%$ of content is transferred immediately following training, but the degree of learning transferred falls to $25 \%$ after six months and $15 \%$ one year after training. Cromwell and Kolb (2004) insisted trainees transfer 15\% of their learning to workplace, while London and Flannery (2004) report that in spite of heavy investment in training activities, trainees transfer less than $10 \%$ to $20 \%$ of their new skills and knowledge into the workplace. ${ }^{3}$ Because in-person delivery certainly predominated in professional learning during the majority of these seminal studies, it would seem the value of a supposedly tried-and-true delivery mode was no less insured than the value of newfangled modes such as online or blended learning. 
A mixed-methods study by Gunawardena et al. (2010) of learning participants in a corporate online education program offered a noteworthy exception to the trend in academic literature of studying college students for insight into adult or professional learning online. Gunawardena et al. undertook their study to explore predictive variables for online learners' satisfaction (self-efficacy) and transfer of training (collegial support), providing useful insight into transfer of online-based training into professional practice.

Their research drew from Baldwin and Ford's 1988 transfer of training model's three categories of factors affecting transfer of training: training inputs understood as training design and learner characteristics, training outputs understood as learning and training retention, and transfer conditions which include the generalizability of training and posttraining follow-up or maintenance. Their model holds learning and retention to be the two primary outputs of training.

Prior to Baldwin and Ford, principles theory as set forth by Goldstein (1986) was more circumscribed and nebulous in suggesting that training optimized for transfer should focus its design on general principles necessary to learn a skill or concept so learners could apply those skills to solve problems in the transfer context. The Baldwin and Ford model grew out of their comprehensive transfer of training literature review, which highlighted what the two researchers called the transfer problem for workplace training: notoriously limited degree to which learners transfer their training to work contexts. Baldwin and Ford's investigation led to their transfer of training model's inclusion of training design, trainee personal characteristics and work environment to craft a useful prototype for identifying, defining and exploring variables that instigate learning transfer in a professional setting. 
Following Baldwin and Ford, Holton's (1996) transfer of training model proposed three similar and different factors in training transfer-motivation to transfer, transfer climate and transfer design - with three primary training outcomes: learning, individual performance and organizational results. While Baldwin and Ford's model holds learning and retention to be primary training outputs, Holton's model takes into account improved performance as a significant purpose and relevant output of training and development. In Holton's transfer of training model, learning achievement and learning outcomes are reflected as change in individual performance, the result of learning applied to one's professional context with consequences for organizational performance.

Systems-based organization theory from Kozlowski and Salas (1997) bolsters Holton's transfer of training model by delineating theoretical concepts - levels, content and congruence - as tangible work environment characteristics that influence individual perception of and response to organizational environment. Put more plainly, training participants are more likely to accept training-induced change or express newly learned capabilities at work - and training is thus more likely affect change in an organization - if it is delivered at an appropriate level (individual, team or unit, organization) with meaningful content and aligned to existing contextual supports. Training delivery is a reflection of design, and training transfer is an outcome of whether training has thus been designed to produced transfer.

According to Yamnill and McLean (2001), what is missing from - and others based on it - are Holton's evaluation model offers no guidelines for what constitutes appropriate transfer design. Several theories, however, provide information about conditions needed for professional learning transfer that further develop Holton's three 
factors affecting the transfer of training. For a more comprehensive understanding of what motivates learners to apply knowledge, skills, and insight in their workplace, Yamnill and McLean reference:

- Expectancy theory as introduced by Vroom (1964), which defines employee motivation and job satisfaction as driven by beliefs about the likelihood that a particular act will precede a particular outcome.

- Equity theory from Adams (1963), which defines employee motivation and job satisfaction as a reflection of the extent to which rewards received match rewards expected to be received, in all fairness.

- Goal-setting theory, which links heightened learning transfer for groups with relevant performance goals by suggesting that once a task becomes an accepted objective, the logical pursuits are successful achievement or a decision to lower or abandon the goal (Locke, 1968). Hence, goals serve as motivation to transfer learning.

Relying on theories' explanatory power and conceptual frameworks should, Yamnill and McLean (2001) insist, aid researchers in understanding and predicting factors that contribute to transfer, support high-quality exploration of effective solutions to the transfer of training problem, and help organizations achieve a high level of transfer from learning designed with learner and enterprise expectations, goals and rewards in mind.

Along with transfer design, Yamnill and McLean (2001) align themselves with transfer climate, or how organizational environment fosters or hinders training transfer. Training participants' perceptions of the extent to which factors in the workplace support employee training are at the heart of an organization's transfer climate. Posited as a mediating variable between organizational context and individual performance, transfer climate's conceptual framing and theoretically based explanatory power has been explored with a variety of survey instruments from researchers, to include Holton. 
Initially, Rouiller and Goldstein (1993) deemed transfer climate critical to transfer of training from learning to work contexts. The researchers operationalized transfer climate with a conceptual framework describing two sets of necessary workplace cues: situation cues offering reminders to use what has been learned in training at work; and consequence cues providing feedback when knowledge or skills acquired in training are applied at work. The researchers put their survey instrument to work with learning participants in a fast-food chain's training program for assistant managers, identifying the existence and degree of an organization's transfer climate and finding that the better the transfer climate, the more that transfer occurred.

In conducting a follow-up validation study with 189 petrochemical plant technicians in a safety training program, Holton et al. (1997) put the Rouiller and Goldstein instrument to work and found nine factors affecting transfer climate that varied from those used by Rouiller and Goldstein. Among these factors were supervisor and peer support and the design of training to produce transfer.

In seeming response to or anticipation of critique levied against his evaluative transfer model, Holton subsequently developed the Learning Transfer Inventory System (LTSI) as a diagnostic device for assessing where transfer may break down (Holton, 2000). Intended for training participants at the conclusion of a program, the LTSI measures 16 factors related to transfer to include motivation, personal outcomes, peer and supervisor support, and expectations for training. Several of these 16 factors are referenced in prior models, theories, survey instruments and research not just by Holton but also by research predecessors and contemporaries. 
But even though Holton's LTSI has been positioned as the only research-based instrument for comprehensively assessing factors affecting learning transfer, and despite studies validating the LTSI, Velada et al. (2007) questioned whether a reliable empirical relationship had yet been firmly established between LTSI measures and training transfer. There is, in sum, no definitive agreement on measuring training transfer.

In a transfer of training literature review available solely as a working paper, Clardy (2006) catalogued more than 30 empirical and theoretical explorations of factors that affect, hinder and/or contribute to training transfer from a professional's learning context to their working context. Though a collection of learning transfer factors (e.g. design, motivation, support, organizational climate) seem to have gained widespread traction, no one model, theory or instrument emerges as the standard for defining, describing or determining the degree to which transfer occurs between learning and practice.

Work places are widely varied, and learning needs are widely varied. As a result, necessary training practices and outcomes are widely varied. In any case, notes Clardy, how and to what extent the breadth of research on training transfer even applies to online learning for professionals is also open to question. Because online learning can occur with a proximity to work that simply may not possible with in-person professional learning, one must wonder (as Clardy does), whether learning transfer is the most relevant measure of value in such learning contexts.

Virtual coaching provided to new teachers of students with significant disabilities offers up a powerful example of these new technology-enabled professional learning and development contexts. As described in Israel et al. (2012), virtual coaching for special education teachers involves using Internet-connected video, microphones and wireless 
earpieces to conduct remote observations, cue critical instructional moments and participate in real-time feedback and collaborative reflection (p.200). Typically undertaken to expand access and save on travel costs incurred with on-site coaching, virtual coaching has proven just as impactful for its ability to transform professional learning from a linear experience of distinct instructional, observational and feedback periods to a cyclical experience of simultaneous observation, instruction and feedback. Coaches can now observe, interject and engage teachers during their real-time workflow and provide professional development in its precise moment of relevance. Virtual coaching is learning nested within work. The technology-enabled proximity of jobembedded professional development is precisely the kind of learning that obliterates dividing lines between training and transfer, bringing to light a wholly different type of modality-dependent learning value.

Among the research recommendations in their transfer of training literature review, Burke and Hutchins (2007) encourage future researchers to take several steps in their research approach to insure research is borne out of and responsive to problems encountered in organizational and professional life:

- Apply methodological rigor and empirical tests to organizational practices

- Make findings easier for managers to understand

- Infuse academic journals with knowledge derived from practice

The combination of abysmally low training transfer rates observed in research plus industry concerns about professional learning's return on investment, plus the dearth of perspective on the learning value of online delivery specifically and professional learning generally all point to an unexplored wealth of potential insight. The research potential in 
exploring the value of online and in-person learning modalities in professional learning emerges as an area too obvious and too rich with possibility to ignore.

\section{Grounded Theory}

From the literature, it is apparent that training transfer remains a field of theory with no standard explanation for how/why professional learning transfers into professional performance and minimal information regarding the relevance of transfer issues in the Digital Age. Hence, this study also relies on grounded theory for developing insight into professional learning's value beyond the learning context and in varied delivery modes.

Grounded theory is a framework for generating or discovering explanations of processes or phenomena via emergent insight from data systematically obtained and reviewed during social research (Glaser \& Strauss, 1967). Grounded theory guides researchers in uncovering conceptual relationships, processes, patterns of actions and interactions, and conditions under which concepts are revealed or specified. The aims of grounded theory can be methodological and/or theoretical and can include efforts to verify research questions or hypotheses throughout the research process or development of explanatory theory via iterative processing of the research data.

Researchers who take a grounded theory approach seek to uncover in their research variable and conceptual relationships, processes, patterns of action, interactions, and conditions under which concepts are revealed or specified. Data sources are often predominantly but not solely qualitative (e.g. interviews, field observations, documents, video), and data analysis can combine both qualitative and quantitative methods. Voices and perspectives of participants must be included in data interpretations, and researchers 
must be immersively familiar with data to systematically insure development of concepts and relationships between variables.

Following development and debut of grounded theory by Anselm Strauss and Barney Glaser in the 1960s, Juliet Corbin's work with Strauss further developed grounded theory in a direction divergent from the Glaser/Strauss approach on several points to include literature review and coding (Corbin \& Strauss, 2008). In attempting to generate original explanations for learning value as a concept and construct in online and in-person delivery, this study takes its methodological cues from grounded theory but does not side exclusively with any one variant in the theory's major philosophical disputes. Indeed, the purpose of this study's exploration of grounded theory is not to explicate on the various strains of and arguments within the field, but rather to elucidate decisions here to leverage various aspects of grounded theory in the pursuit of more explanatory clarity for learning value.

Chief among grounded theory debates most relevant for this dissertation is discussion of whether a priori knowledge from literature reviews is detrimental to grounded theory analysis. The Glaserian variant of grounded theory urges against contaminating analysis with a priori knowledge (Åge, 2011). Meanwhile the Straussian variant supports literature review and a priori knowledge to be gained therein (Strübing, 2007). Though presentation of Glaser’s guidance in Åge simultaneously references “preexisting prejudices" and "pre-existing views" (p. 1606), these terms do not necessarily stand in for each other. Whether Glaser intended these terms to be used interchangeably remains arguable. 
For researchers informed, however, by early guidance on grounded theory from Glaser and Strauss together, this argument is mostly unnecessary. Writing together, grounded theory's originators insisted researchers "must have a perspective that will help (them) see relevant data and abstract significant categories from (their) scrutiny of the data" (Glaser \& Strauss, 1967, p.3). This dissertation includes a review of literature with perspective-gathering in mind.

Along with opting not to forgo pre-research literature review, this dissertation also sets aside grounded theory's caution to refrain from discussing potential theory as it emerges and before the research is written for fear of clouding researcher judgment. Providing clarity about how, why and under what conditions learning value has been understood, especially in the context of training transfer, is fundamental to the research task at hand of establishing and validating learning value in various modes of learning delivery. A doctoral dissertation from an early-career research can effectively and efficiently accomplish this task via collaborative conversations with research participants, advisors and colleagues.

In any case, whether perspectives (and preconceptions and prejudices) come from literature-driven a priori knowledge or seep into the inquiry process from a researcher's relevant a priori experiences and conversations, these intellectual influences should be transparently examined and explicated for their potential impact on research outcomes. Such is the case in the Context section of this dissertation's Methods discussion, where measures taken to mitigate risks of clouded judgment (e.g. journaling, capturing conversation notes) are further detailed. 
Another debate frequently mentioned in literature on grounded theory relates to whether the word-driven coding and memo-marking of qualitative data to unveil patterns and meaning should be driven by an abductive, systematic repeat process of data examination (in which codes might change with each examination) or by an inductively emergent set of repeatedly applied codes. Glaser promoted grounded theory as analysis guided by the inductive process of data examination. Strauss and Corbin promoted grounded theory as analysis guided by the abductive, systematic repeat process of data examination. This debate is succinctly summarized as Glaser's creative emergence of concepts versus Strauss and Corbin's systematic construction of concepts - though Glaser bitingly termed these polarities "emergence versus forcing” (Åge, p.1601).

Originally, both Glaser and Strauss promoted the research-permeating process of "open coding" or the constant comparison of gathered data / emerging concepts to continually gathered data / further emerging concepts (Åge, p.1600). Data are compared to data to generate conceptual properties, while concepts are compared to concepts to instigate and integrate theoretical explanations.

In this dissertation, regular observation of, immersion in and engagement with collected data - qualitative and quantitative - determined the examination approach at any given stage in the analysis. Where data are orderly and amenable to systematic analysis, the Straussian approach is employed. Where concepts emerge and lend themselves to repeat analysis, the Glaserian approach is utilized. In either case, the stage is set for emergence of constructs and explanatory insights that may not lend themselves to clear-cut association with previous conceptualization and theory. Such is the ultimate point of utilizing grounded theory in this dissertation. 
Kathy Charmaz's strain of constructivist grounded theory, which has further diversified perspectives in the field, encourages grounded theory researchers to consider their subjectivity and its role in theory-making (Charmaz, 2013). Though the strategies of grounded theory methodology are somewhat neutral, according to Charmaz, the epistemology on which the theory has been built, is not" (p.13).

Glaser took particularly active issue with Charmaz for having analyzed grounded theory's conceptual and philosophical foundations as objectivist "in the sense that representation is seen as ultimately unproblematic once a neutral point of reference can be insured for the researcher" (Bryant, 2003, p.3). With a respectful nod to Charmaz's (2013) perspective, however, the notion of dynamically constructed knowledge claims and theoretical explanation is further explored in this dissertation's upcoming discussion of the nexus between pragmatism as a research philosophy, grounded theory as a research framework and mixed methods as a research approach.

Suffice to say here that there can be no assumptions of either conceptual objectivity or conceptual consistency in relation to theories of learning value based on training transfer, which seemingly represents within the current research canon the whole of learning value in the professional context. Yet with all the research approaches, schools of thoughts and instruments deployed to measure learning value via employee training transfer, there remains a dearth of understanding about the relationship between varied modes of professional learning delivery and professional learning transfer.

This is not to suggest that the hefty body of research on training transfer has no application to this study. As the aforementioned study from Gunawardena et al. (2010) aptly demonstrates, traditional training transfer research and theory can be put to 
effective use for understanding transfer in online learning delivery. Yet, one must also wonder what outcomes might have emerged if, instead of utilizing Baldwin and Ford's three categories of factors, Gunawardena et al. had instead examined transfer via Holton's 16 factors or through the explanatory lens of either expectancy theory, equity theory or goal-setting theory. The point is not that there is no useful transfer research or theory from which to choose, but rather that there are so many factors and so much theory put forth to explain transfer, yet no definitive conclusions can be claimed. Instead, researchers continue to explore, discuss and debate which combination of factors are most relevant to transfer, and the same arguments prevail more so now that online delivery has gained relevance in professional learning and changed how learning occurs.

Putting grounded theory to work in an exploration of learning value in online and inperson learning delivery makes way for a productive shift in the research conversation by allowing potential relevant theory to arise from the data itself. Rather than peering at learner experience through an explanatory lens, this research is guided and informed by learner experience toward an explanation of what constitutes learning value and how that value is generated in various learning modalities.

Another reason for relying here on grounded theory has to do with the research approach taken in this study. This is addressed in greater detail in the Methods discussion, but in sum, this dissertation breaks from the norm found in the majority of studies that seek to comprehend professional learning transfer by examining one learning program at one company with one set of learners in the same organizational context. Researchers then typically attempt to generalize from that specific corporate learning context, as is the norm when relying on previously developed theory as a research foundation. The 
approach makes some sense, if researchers believe minimized variation in the learning context under study will fortify a particular training transfer theory's generalizability.

This study takes a different approach. If this study's purpose was to solve a particular organization's learning transfer challenge, then existing research and theory focused singularly on one organization at a time might be useful. But, as stated, the purpose of this research is to gain clarity from learners about the value they ascribe to online and inperson delivery for their professional and organizational development. Curiosity here is based on the question of whether there may be more insight to gain by drawing from the experience of learners with diverse professional backgrounds and professional learning circumstances, and seeking commonality amid variety. The more diverse a group offering perspective, the more compelling any emergent common findings of learning value will be, as they will cut across organizational and individual specifics, circumstances and peculiarities. The use of grounded theory in this study naturally aligns and supports a potentially novel exploratory approach to professional learning value with a pursuit of fresh, learner-centered explanatory perspective.

\section{Pragmatism}

Because of its oft-repeated connection to grounded theory, the particular strand of pragmatism relevant to this dissertation is found in the intellectual works of F.C.S.

Schiller, William James, Charles Sanders Peirce, George Herbert Mead and John Dewey - the latter being one of the more heralded American educationalists. These philosophers challenged "assumptions that knowledge and action are two separate spheres, and that there exists an absolute or transcendental truth above and beyond the sort of enquiry organisms use to cope with life" (Chiari \& Nuzzo, 2010, p.27). This strand of 
pragmatism, labeled "classical pragmatism" by Johnson, McGowan and Turner (and hereafter referenced as such), is concerned with both the nature of reality and the nature inquiry (2010, p.73). These preoccupations elevate pragmatism's relevance for researchers seeking not just an intellectual toolset but an organizing belief system.

In the context of inquiry, classical pragmatism takes an experienced-based stance on what is labeled "real" and "true" in human understanding. James' lectures in Pragmatism (1907) and their sequel The Meaning of Truth (1909) posit that "true ideas are those that we can assimilate, validate, corroborate, and verify" while "false ideas are those we cannot" (1907 \& 1909 Guttenberg ebook versions). Like a guardrail alongside a winding mountain road keeping motorists on track, this distinction serves the practical purpose along the path to inquiry of keeping researchers focused on the actionable criteria needed to discern when one is dealing with reality that can be characterized as truth.

James insists that "truth happens" to ideas, which are "made true by events" (emphasis James, 1909). The inquirer's duties are "to gain truth" and "to agree with reality" by finding those ideas that meet the aforementioned criteria of true (James, 1907). For it is these event-dependent ideas that are the sum total of truth in any given reality. Indeed, a core tenet of pragmatist philosophy is that truth is made, and the human mind is its chief creator.

James' metaphor was of a sculptor's mind working a block of stone from "a theatre of simultaneous possibilities" (James, 1890, p.288). His philosophical contemporary Schiller (1907) likened the crafting of reality to the crafting of a chair, which begins with existing materials. Reality, similarly, begins with existing events. What differentiates reality from imagination is the necessity of experience as material for construction. 
Contrary to imagination, which can be fabricated from nothingness, "truth is a transformation of our experience" (Chiari \& Nuzzo, 2010, p.27). In pragmatism, the inquirer divines ideas from experience, making practical use of experience as substance for truth. Which begs the question, what is practical use in a philosophical paradigm?

In pragmatism, practical use is more than a given functional approach to analyzing or solving problems. Beyond the "crude summary" of pragmatism as a question of "what works" (Morgan, 2014, p.1), pragmatism is simultaneously a question of "what is" and how one comes to know it. As Morgan states with reference to Dewey, pragmatism "points to the importance of joining beliefs and actions in a process of inquiry" and "concentrates on beliefs that are more directly connected to actions" (p.7).

Along with this high-utility connection between what is and what works, pragmatism's practicality also stems from its ability as a paradigm to "stand outside previous assumptions" (p.7) and respond to the circumstances of inquiry driving a particular knowledge quest. Assumptions are inherent to beliefs and actions in any given set of circumstances. When circumstances change, as they inevitably do, so will actions. When actions change, so too must assumptions. For knowledge-creating researchers, pragmatism is a means of finding and framing beliefs in the context of action. It is a philosophy of action - an applied (i.e., practical) use of experience and truth.

A Dewey-influenced perspective points researchers toward an understanding of truth (and knowledge) as "contextual, temporal, and related to action" (Greene, 2007, p.84). The meaning of human experience, according to Dewey, is to be found not in objective reality or the internal mind of the knower but rather in their interaction/transaction, which changes what can be known from transaction to transaction over time, (Dewey, 1930). 
Particularly for education researchers working in the realm of social inquiry, to research pragmatically is to uncover what is and what is not via subjective experience of objective reality. The coming together in pragmatism of experience/action and belief/meaning in the construction of knowledge/truth provides researchers with a coherent philosophy of inquiry that allows not only for flexibility but also inclusivity in explanatory approach and methodological agenda. This inclusivity and flexibility is the heart of pragmatist philosophy.

\section{Pragmatism and Grounded Theory}

In an exposition on what grounded theory is not, Suddaby (2006) notes that "like most difficult subjects, grounded theory is best understood historically" (p.633). Motivated against grand theory's focus on ready-made reality and the "extreme positivism that had permeated most social research" (p.633), Glaser and Strauss looked to pragmatism for a practical method of conducting social science research and building relevant theory.

Classical pragmatism is associated with Glaser and Strauss' conceptualizations of grounded theory because - in classic pragmatist form - Glaser and Strauss' grounded theory joins actions and beliefs in a process of inquiry, relying on the transformation of experience as the substance of meaning and truth. Because social science research examines how human invention continually generates new ways of interaction and organization, Glaser and Strauss devised a practically interpretative theoretical approach "that does not bind one too closely to long-standing assumptions" (Suddaby, p.641) but instead is responsive to outcomes from an ongoing iterative exchange between data collection and theoretical explanation. 
Influenced by Peirce's abductive and integrative thinking, the "pragmatic middle road of grounded theory" (Suddaby, p.639) eschews deduction's fundamentalist tendency toward testable consequences and induction's fundamentalist tendency toward predictive forecasting. As Peirce emphasized, abduction is a "process for forming explanatory hypotheses" which can be subjected to subsequent assessment in the discovery phase of inquiry (Collected Papers V.5, p.172). Grounded theory's encouragement of ongoing data collection amidst continuous data interpretation, concept emergence and theory construction embodies a cyclical process of creative reasoning that binds initial discovery and explanation with further discovery and explanation until the researcher determines the data are sufficiently saturated in meaning. This cyclical process in grounded theory hones a researcher's "rational instinct" via pragmatically flexible and inclusive response to circumstances of inquiry (Ayim, 1974). Instead of pursuing confirmation of assumptions that are non-native to the substantive areas of investigation, researchers embark on a search for new ideas and assumptions embedded in the circumstances of inquiry.

\section{Pragmatism, Grounded Theory and Mixed Methods}

Because some of grounded theory's key methodological elements include purposive sampling of participants "chosen for their ability to confirm or challenge an emerging theory" as well as an iterative study design with "cycles of simultaneous data collection and analysis" (Lingard, et al., 2008, p. 459), grounded theory is most often associated with qualitative research methods. The full title of Glaser and Strauss' seminal work The Discovery of Grounded Theory: Strategies for Qualitative Research (1967) also initiated the link between classic grounded theory and qualitative research methods. 
Nonetheless, Glaser and Strauss's (1967) writings in Discovery purposefully, pragmatically and repeatedly insisted on grounded theory's compatibility with all manner of data collection and analysis methods. They not only called out both qualitative and quantitative data as "useful for both verification and generation of theory" but also went so far as to suggest "in many instances, both forms of data are necessary" (pp. 17-18). Even after the Glaser/Strauss parting of ways generated a new grounded theory variant, its progenitors Strauss and Corbin (2000) maintained that "grounded theorists can utilize quantitative data or combine qualitative and quantitative techniques of analysis" (p. 274).

As Creswell (2003) notes, pragmatist research "applies all approaches" to understanding research problems (p.11). Ideally, research methods follow research questions, and Dewey agreed inquiry methods must fit the questions posed, "but more profoundly, he averred that methods also determine question(s) just as question(s) define methods, that methods and questions are mutually constitutive" (Greene, 2007, p. 84).

Dewey "spent his career applying pragmatic principles ... in the practice of educating children" (Johnson \& Onwuegbuzie, 2004, p.17) and emphasized in his epistemology the dynamic nature of knowledge claims and theoretical explanations. This dynamism is generated in active coming-to-know processes between inquirer and information. The "logical status of interrogations" writes Dewey (1938), "is that they are only tentative" (p.169). If one subscribes to this idea of knowledge creation as a dynamically tentative process, then research methods as knowledge-building tools are by extension as embedded in that process as researchers and thereby imbued with researchers' philosophical inclinations and intent. 
While it may be difficult to definitively argue in favor of any one philosophical paradigm having exclusive claim to a research methodology, it can be reasonably asserted that pragmatism exhibits a particular affinity for mixed-methods research. It is a paradigm which explicitly encourages malleable methodological approaches to support research questions that flexibly define data collection and analysis while allowing data collection and analysis to adaptively generate and guide research questions.

As pragmatism hones a researcher's focus on practical consequences, mixedmethods research provides a pluralistic toolset to match pragmatism's high-utility mindset. In these complementary philosophical and methodological paradigms, the usefulness of mixed methods research is most appealing. More than simply a varied toolset, mixed-methods research is a philosophically flexible approach.

Hence, the intentional association here of pragmatism, grounded theory and mixed methods is not merely a matter of methods preference but also a practice of philosophy. The research methods chosen and the explanatory theory pursued are both outcomes and drivers of research questions. While quantitative results can point the way toward compelling investigations, the qualitative exploration of quantitative findings can provide meaningful clarity on which to substantiate new knowledge. When a researcher is compelled to simultaneously inquire what is happening, why it is happening and what does it mean, this mode of inquiry reflects a philosophical decision to pragmatically join objective and subjective exploration in the inquiry process.

The coming together in pragmatism of experience/action and belief/meaning in the construction of reality and truth provides researchers with coherently useful inquiry. Grounded theory's iterative relationships between data gathering, data analysis, concept 
emergence and theory construction actively test and verify objective reality via subjective interpretation. Such continuous iteration also relies on interactions between experience and beliefs to explicate reality and discern its meaning. Mixed methods contributes the necessary flexibility and inclusivity in investigative approach to effectively execute a pragmatic, consequence-focused methodological agenda. This particular conceptualization of collaborative connectivity between pragmatism, grounded theory and mixed methods brings paradigm, theory and methodology together in a cohesive philosophy of action.

\section{Summary}

In sum, an initial review of literature related to online delivery specifically for professional learning revealed significantly little exploration of learner perspective on learning value among adult learners. Literature-driven review of learning value generally required the exploration of training transfer, an oft-used proxy of learning value in research on learning for professionals. Thus, it is worth noting that use of the term "learning value" in this study not only reference literature but also reflects research-driven efforts to craft an original definition based on theoretical and empirical discussions in literature of learning's purpose.

This study's literature review also explored the conceptual integration of grounded theory, pragmatism and mixed methods as a means of crafting a cohesive philosophy of practitioner-focused research action. As the literature showed, the relationships between grounded theory, pragmatism and mixed methods support a dynamic, flexible and indispensable coming-to-know process for a study intended to chart a previously unexplored path of understanding for learning value among adult professionals. 


\section{CHAPTER III}

\section{METHODS}

Two groups of prospective research participants contributed several samples and a total of 347 participants to this study. Multiple samples helped to validate the study's survey instrument, iterate on initial analysis and corroborate unexpected research findings.

Though qualitative data were expected to predominate in relevance, this study evolved into a fully mixed-methods endeavor when quantitative analysis of demographics and learning preference wholly contradicted preconceived notions about age groups and preferred modes of learning. Quantitative analysis of this demographic data resulted in the unexpected finding that younger professionals preferred learning in person, while older professionals expressed more openness toward technology-mediated learning. These findings and their accompanying preconceptions are discussed further in Chapter 4.

Qualitative research consisted primarily of 1:1 interviews with 19 participants. Because learners did not prefer learning as expected, qualitative exploration served a critical purpose in exploring the value learners attributed to learning in varied modalities that would lead to preferencing one modality over another. Ultimately, the mixedmethods research design of this study put quantitative data analysis first, followed by qualitative analysis, but with concurrent interpretation of all data informing investigative questions and research findings. Given the involved nature of mixed-methods and grounded theory investigations included in this study, several introductory figures and tables are provided at the start of this chapter to clarify research samples and designs discussed later in this chapter. As mentioned, several participant groups were utilized for survey validation and theory iteration, as illustrated in Figures 1 and 2: 


\section{Figure 1}

Primary Research Group

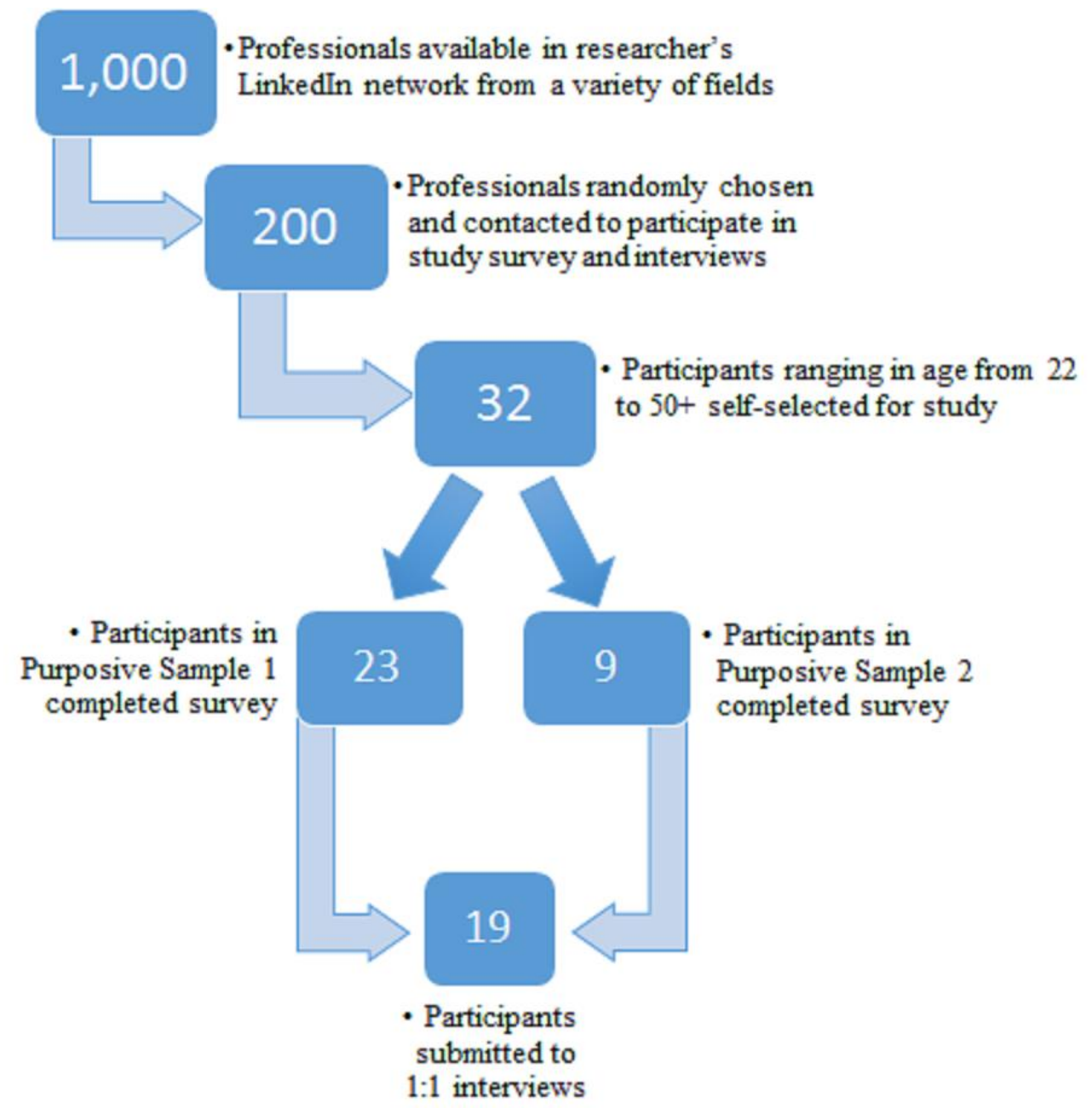

\section{Figure 2}

Secondary Research Group

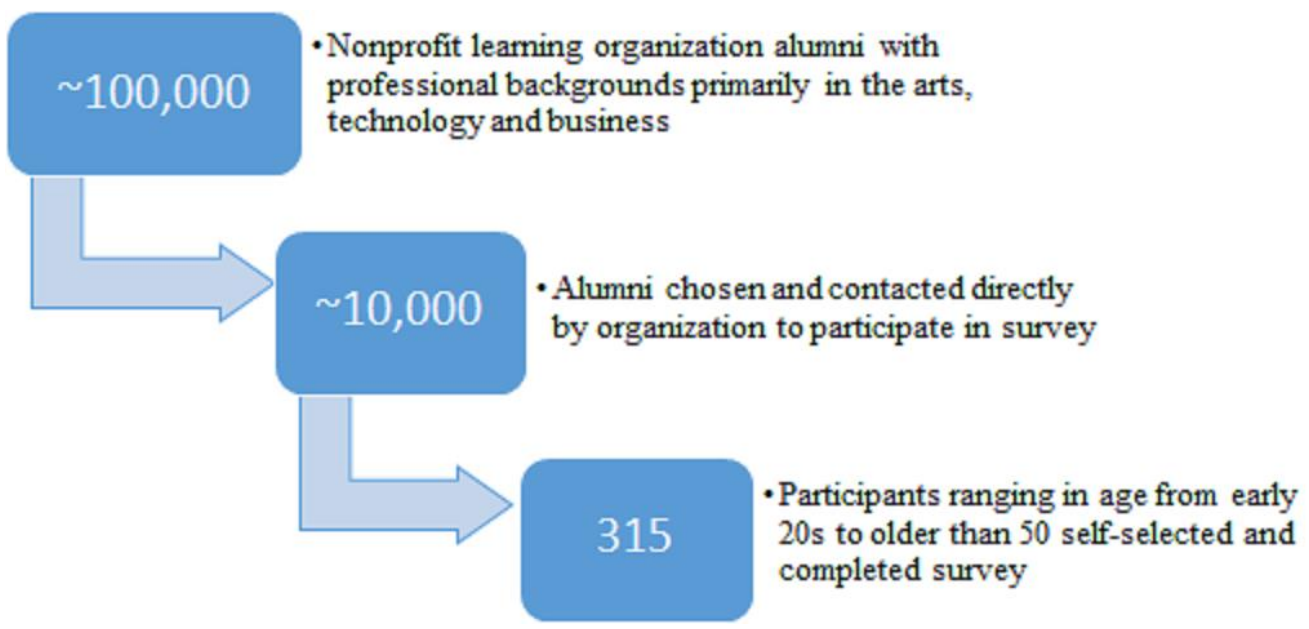


For clarity and organization, Table 1 summarizes the research procedures utilized in this study to collect quantitative and qualitative data via these participant groups:

Table 1

Research Procedures

\begin{tabular}{|c|c|c|c|c|}
\hline & \multicolumn{2}{|c|}{ Quantitative Exploration } & \multicolumn{2}{|c|}{ Qualitative Exploration } \\
\hline & $\begin{array}{c}\text { Demographic } \\
\text { Survey } \\
\text { Questions }\end{array}$ & $\begin{array}{c}\text { Learning } \\
\text { Preference } \\
\text { Survey } \\
\text { Questions } \\
\end{array}$ & $\begin{array}{c}\text { Open-Ended } \\
\text { Professional } \\
\text { Experience } \\
\text { Survey Questions }\end{array}$ & $\begin{array}{c}\text { Learning } \\
\text { Experience } \\
\text { Interviews }\end{array}$ \\
\hline $\begin{array}{r}\text { Primary } \\
\text { Research } \\
\text { Group } \\
\text { Purposive } \\
\text { Sample 1 } \\
\end{array}$ & $\begin{array}{l}\text { Completed } \\
\text { by all } 23 \\
\text { participants }\end{array}$ & $\begin{array}{l}\text { Completed } \\
\text { by all } 23 \\
\text { participants }\end{array}$ & $\begin{array}{l}\text { Completed } \\
\text { by all } 23 \\
\text { participants }\end{array}$ & $\begin{array}{l}\text { Completed } \\
\text { by } 14 \text { of } 23 \\
\text { participants }\end{array}$ \\
\hline $\begin{array}{r}\text { Primary } \\
\text { Research } \\
\text { Group } \\
\text { Purposive } \\
\text { Sample 2 } \\
\end{array}$ & $\begin{array}{l}\text { Completed } \\
\text { by all } 9 \\
\text { participants }\end{array}$ & $\begin{array}{l}\text { Completed } \\
\text { by all } 9 \\
\text { participants }\end{array}$ & $\begin{array}{l}\text { Completed } \\
\text { by all } 9 \\
\text { participants }\end{array}$ & $\begin{array}{l}\text { Completed } \\
\text { by } 5 \text { of } 9 \\
\text { participants }\end{array}$ \\
\hline $\begin{array}{r}\text { Secondary } \\
\text { Research } \\
\text { Group }\end{array}$ & $\begin{array}{l}\text { Completed } \\
\text { by all } 315 \\
\text { participants }\end{array}$ & $\begin{array}{l}\text { Completed } \\
\text { by all } 315 \\
\text { participants }\end{array}$ & $\begin{array}{l}\text { Completed } \\
\text { by all } 315 \\
\text { participants }\end{array}$ & $\begin{array}{l}\text { N/A for } \\
\text { secondary } \\
\text { research } \\
\text { group }\end{array}$ \\
\hline
\end{tabular}

\section{Research Sample}

Because of the iterative nature of grounded theory investigation, this research relied on multiple samples drawn from a primary research group of 32 professionals. Extensive and detailed qualitative data from 1:1 interviews were drawn from this primary research group, which was intended to provide demographic and other categorical quantitative data along with qualitative data via interviews. The primary research group was so named as the only group where qualitative data - this study's primary source of learning value insight - was collected. 
A secondary research group of 315 participants was also leveraged to test the survey instrument but ultimately provided a wealth of additional categorical quantitative data as the study evolved. Though larger in number, the secondary group was named as such because the data collected from these respondents was limited solely to the survey instrument and was added as a secondary measure to validate the relevance of unexpected outcomes from the primary research group.

This larger secondary research group came from the alumni of a nonprofit learning organization who partnered in this research study to offer a large sample group in exchange for resulting insights on learning value for professionals. The parameters and benefits of this partnership were clear: the researcher expected to receive and benefit from large sample group to test this study's survey instrument, and the organization expected to receive and benefit from insights this study might provide on how professionals define and seek value from learning providers.

As mentioned, the secondary research group was solely intended to insure the validity and reliability of a demographically- and learning preference-focused survey instrument of multiple-choice and open-ended questions. Hence, these participants are also referred to as the survey test group in this study. Given the limited scope of the survey instrument, the survey test group was expected to have little impact on research outcomes beyond confirming the survey instrument was logical, valid and reliable.

Participants in both the smaller primary research group and larger survey test group were self-selecting. No incentives were provided for study participation by either the researcher or nonprofit learning organization who partnered in this study. All respondent data were reported anonymously, adhering to assurances provided in the confidentiality 
assurance sent to potential participants and in the survey instrument (Appendices A and B respectively).

From a pool of 1,000 potential research subjects, $20 \%$ were contacted randomly to participate in this study. Of the 200 contacted, $16 \%(N=32)$ agreed to take a survey and submit to in-depth interviews about their learning experiences and preferences. This primary group of 32 participants was a mix of professionals who self-selected for this research by responding to requests sent to 200 professionals in the researcher's LinkedIn network. These 200 professionals were selected using random number assignment and selection from 1,000 professionals in the researcher's network, as a means to mitigate possible researcher influence on participant selection and allow for a diverse array of people who might choose to participate in this research (Dillman et al., 2009).

Though contacted via an online network, none of the prospective participants was screened or selected with presumed experienced in online learning. This approach was purposeful to minimize selection bias from tainting the study with data from respondents who were more adept, comfortable or amenable to learning online. As a result, some respondents participated in this study with no online learning experience. This lack of learning experience, however, did not keep several participants from expressing perspective and opinion about online learning delivery, as the Analysis chapter shows.

Though choosing respondents from my professional network potentially introduced influence bias, a key driver for having done so is explained by findings in Anseel et al. (2010) indicating the relevance of personal connection and communication in increased survey response rates. With a meta-analytical focus on survey response rates of executives, managers and other professionals typically included in organizational science 
research, Anseel et al. found "a complicated picture of response rate trends" (p. 346) that not only called into question notions of average expected response rates but also showed varied response rates depending on respondent type. According to this meta-analysis, "the higher respondents are situated in the organizational hierarchy, the harder it may be to persuade them to respond to surveys" (p. 346).

With Anseel et al.'s (2010) meta-analysis in mind, no response rate expectations were set forth in this research. Rather, the research approach here focused on response enhancing techniques taken from Dillman et. al's (2009) “Tailored Design Method" (p. 336) and presented in research for engaging of professionals at varied levels within organizations and in their careers. Those techniques included: delivering surveys via the Internet; ensuring survey topic relevance to the population surveyed; and personally addressing potential survey respondents, noted as particularly effective with higher-level professionals.

This outreach led to an initial purposive sample of respondents who were an eclectic tech-savvy collection of 23 people with a 60-40 female-to-male split, sitting on 4 continents and in all 4 U.S. time zones and ranging in age from 22 to 50+. Their professional development ranged from newly graduated at the bachelor's and master's level to near retirement. They represented a wide array of professional pursuits - health care, videogaming, finance, real estate, retail, management, entrepreneurship, education, social justice, social media and marketing.

In keeping with grounded theory's methodological practice, this study also included a second round of purposive sampling, which led to nine additional participants also of mixed professional, learning and technology backgrounds whose responses bolstered data 
and strengthened the study's analytical insights. Data from these respondents were utilized to confirm and challenge concepts and theoretical explanations emerging from data gathered via the first set of research participants.

The primary aim of purposive sampling in this study, as mentioned in the Grounded Theory section of this research's Literature chapter, was to insure a diverse pool of learners with a range of professionals, learning and technology experiences. Group diversity was expected to make common findings on learning value that emerged from the participants all the more compelling, as these findings would cut across organizational and individual specifics, circumstances and peculiarities. Each purposive sample was intentionally limited in size $\left(1^{\text {st }}\right.$ group $<25 ; 2^{\text {nd }}$ group $\left.<10\right)$ to support deeply descriptive data gathering in follow-on interviews that could aptly capture participant experience.

The survey test group of 315 learning organization alumni self-selected for survey participation following email outreach to $10,000+$ members of the organization's alumni association by members of the alumni office. Like the primary research group, participants in the survey test group ranged in age from early 20 s to older than 50 , skewed more female than male, included a range of professional level from early careerstarters to retirees, and spanned geographic locations. Unlike the primary research, career pursuits for the survey test group were more concentrated in arts, technology and business.

Though contacted via email, none of the potential participants in the survey test group were screened or selected with presumed experienced in online learning. This approach was purposeful to minimize selection bias from tainting the study with data from respondents who were more adept, comfortable or amenable to learning online. As a result, some respondents participated in this study with no online learning experience. 
This lack of learning experience, however, did not keep participants from expressing perspective and opinion about online learning delivery, as the Analysis chapter shows.

By design, only the learning organization's alumni office had access to the population from which the survey test group was drawn. Thus, this survey test group remained wholly anonymous and inaccessible to the researcher, avoiding bias that might have resulted from further insight into the group but nonetheless delivering a survey response rate of more than $30 \%$. What is known and most relevant about this survey test group are their experiences and perspectives about learning preferences, which appear in results presented in this dissertation's Chapter IV Analysis.

\section{Research Design}

This study was originally planned as a qualitative investigation of professionals' experience with and perceptions of learning and development in their professional lives. The most relevant data collection was expected to consist primarily of open-ended questions and focused interviews, with the most impactful data expected to come from 1:1 interviews with a $<50$-respondent sample. Qualitative interviews were employed in this study expressly for the purpose of gathering direct perspective from learners about how they ascribe value to learning and why they deemed certain aspects of learning valuable. Interviews were undertaken only with participants from the 32-respondent primary research group and only when respondents provided their names at the end of their demographic surveys as an indication of their willingness to be contacted. All survey-takers were provided with confidentiality assurances at the start and end of their surveys pledging that no information would be shared from their survey responses in ways that would personally identify respondents (see Appendix A). 
Demographic inquiries and learning experience questions were presented using the aforementioned survey that asked participants for their age bracket, gender, online learning experience and learning preferences (in-person, online, mix, no preference). These demographic questions were asked and analyzed originally to confirm that a balanced representation of men, women, age groups and learning experiences were represented in this research. The survey of demographic data and learning preference questions was expected simply to contextualize learners' experiences and provide a jumping off point for interview questions. An additional expectation of both learning organization and researcher was confirmation via demographic information and categorical questions that learning designed for young Digital Age professionals would need to involve technology based on their learning preferences.

Though qualitative data were expected to predominate in relevance, this research endeavor evolved into a "fully mixed sequential equal status" mixed-methods study (Leech \& Onwuegbuzie, 2006, p. 271) when quantitative analysis of demographics and learning preference wholly contradicted preconceived notions about age groups and preferred modes of learning.

One of eight mixed-methods designs delineated by Leech and Onwuegbuzie, a fully mixed sequential equal status study features one type of data analysis method following another, but mixed data interpretation occurring throughout the study. In the case of this study, all 32 primary research participants responded to categorical survey questions on age, gender, online learning experience and learning format preference. These questions generated data for cross tabulations and correlations, subsequently leading to further 
quantitative data-gathering from a larger sample size and compelling quantitative analysis that ultimately informed qualitative data collection.

Quantitative data did not speak directly to the question of how professionals valued learning. But, given the presumed importance of technology in learning for younger professionals, quantitative analysis did indeed sound a compelling alert that perceptions about learning needed further exploration in a particular direction.

Because learners did not prefer learning as expected, it became all the more important to explore how learners did indeed determine their learning preferences, that is, what value they did assign to learning in varied modalities that would lead to preferencing one modality over another. Qualitative exploration took on that explanatory task. The mixed-methods research design that resulted put quantitative data analysis first, followed by qualitative analysis, but with concurrent interpretation of all data informing investigative questions and research findings.

Following the surveys, in-depth focused interviews took place with 19 participants who made themselves available for conversations of varied lengths. Because research participants were located all over the world, these conversations took place via phone, email, Skype and text-messaging. The busy nature of working professionals required constant flexibility in conducting and condensing interviews to fit into compressed timeframes provided by research respondents for qualitative exploration.

Of the 19 interviews conducted: 14 interviews were conducted via telephone conversations ranging in duration from 15 to 45 minutes; three interviews were conducted via one-time email with no follow-up; two interviews were conducted via 
Skype video calls of 20 and 30 minutes; and one interview was conducted over a series of 10 text message exchanges in the midst of the research participant's work day.

No interviews were recorded to preserve and insure the confidentiality promise that no personally identifying information would be linked to research participants. The lack of recording thus meant a heavy reliance on copious field notes during and immediately post-interviews. Answers to interview questions in the form of direct quotes, alongside researcher notes about the interviews, were captured in an online form completed by the researcher as conversations with participants progressed (see Figure 3).

\section{Figure 3}

\section{Qualitative Interview Notes}

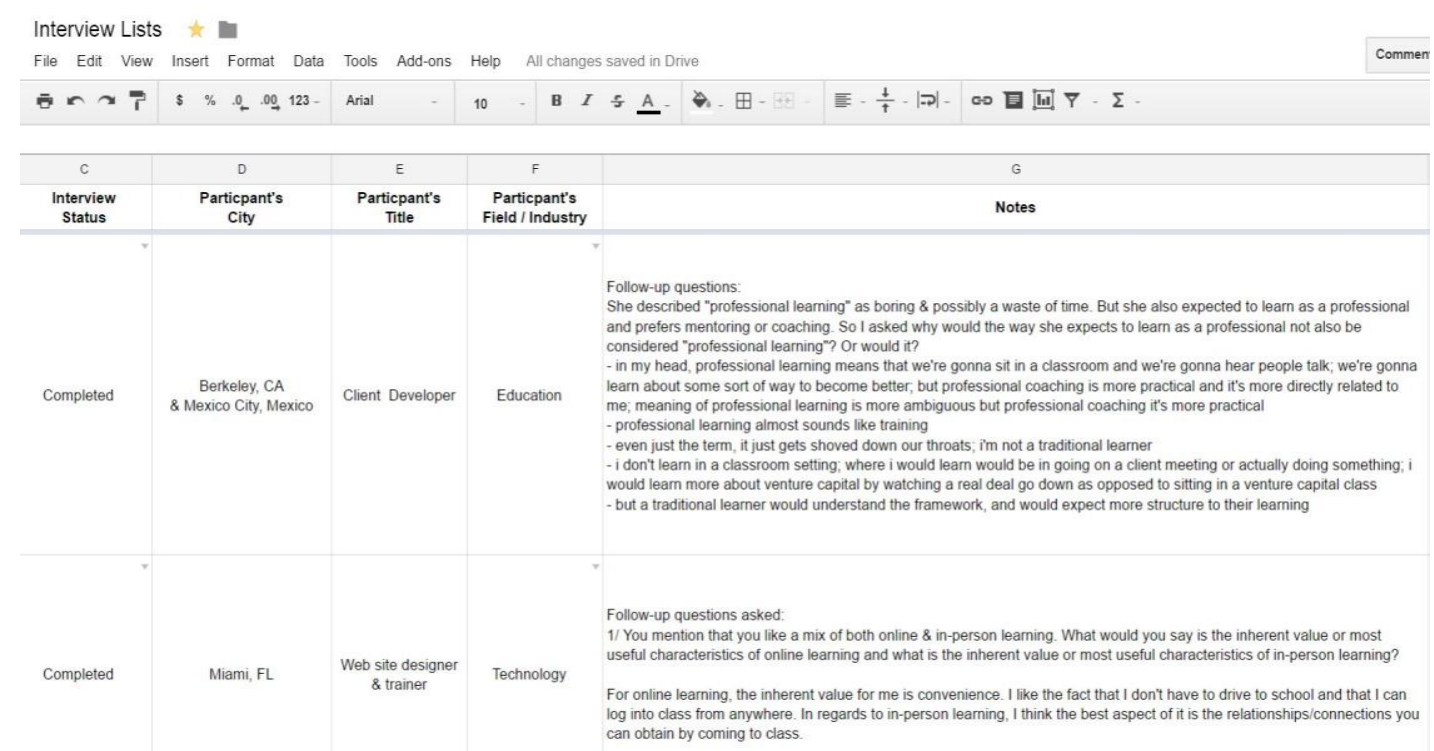

This capture format allowed for answers to be preserved in a secure cloud-based account that would be safe from hardware failures, theft or other potential causes of computer-based data loss.

Prior analysis of demographic and other survey data influenced the direction of these interviews, opening new areas of investigation related to participants' learning experience 
and learning delivery preferences based on interpretations from quantitative data.

Subsequently, interpretations from qualitative investigation substantiated the relevance of learning delivery preference for establishing the value of learning for professionals. This quantitative/qualitative interpretative interaction throughout the study proved crucial to the direction of research and insights gleaned in analysis.

\section{Research Instrumentation}

The survey instrument, attached to this dissertation as Appendix B, was kept straightforward with sections on demographics, professional experience and professional learning experience. The instrument's development was driven in large part by this study's research questions on learning delivery mode preference in relation to age, gender and online learning experience. The intended purpose of the survey instrument was to gather basic information on who research participants for the purpose of contextualizing their answers with regard to age, gender and learning experience.

To insure substantial completion rates, it was imperative professionals be able to navigate the survey as a simple form that could be understood without explanation and completed in fewer than 15 minutes (see Figure 4).

\section{Figure 4}

Demographic \& Learning Preference Survey Sample Question

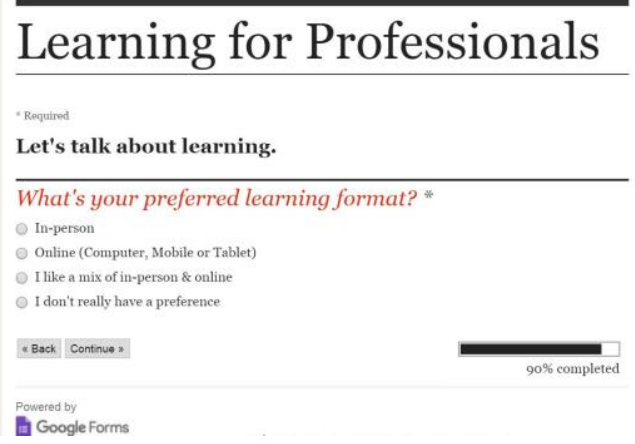




\section{Validity of Survey Questions}

The survey was thus piloted for ease-of-navigation, completion time, reliability and face validity during a pilot run with 315 former learners from the professional learning organization that participated in this study. Following guidelines provided by Dillman et al. (2009), survey questions were asked one at a time, were written to minimize the need to reread for comprehension, and were grouped by overarching topics for clarity. Face validity and reliability were designed into the survey with direct questions about simple concepts with single and/or highly recognizable measures. These measures were typically offered as detailed sets of pre-defined answer options with no overlapping ranges or ambiguous language. Along with a pilot run of the survey, validity and reliability were also confirmed by this dissertation's committee of four seasoned education researchers whose expertise included quantitative measurements and online learning-related research.

With full survey completion by 315 respondents, pilot data showed an average completion time of $<10$ minutes. The survey produced data that was deemed viable based on the variety of participants across age, gender, professional levels and learning experiences, as well as consistent answers across all questions. Where the survey test data also proved surprisingly and analytically valuable was in highlighting and solidifying unexpected correlations between learner age and learning preference. These early analytical indications drove the grounded theory approach of this study to better understand quantitatively and qualitatively how learners ascribe value to learning and what delivery mode has to do with that value. This analysis is discussed in Chapter IV. 


\section{Validity of Interview Questions}

Two aims drove this study's focused interview questions, a sample of which are outlined in Appendix C. Interview questions were firstly driven by expressed research intent to explore how adult professionals describe and ascribe meaning and value to their learning experiences. Interview questions were also driven by concepts that surfaced in literature as relevant to understanding the effectiveness of adult professional learning.

Regarding the second aim, examination of training transfer in this dissertation's Literature Review chapter was necessitated by the prevalent tendency in research to explain professional learning's value by way of training's transfer. This study, however, did not aim to study training transfer in particular but rather sought to better understand learning value. To that end, this study's interview questions about professional learning's primary purpose and usefulness were intentionally broad attempts to capture relevant insights without leading participants toward specific interpretations of transfer.

These indirect questions may have weakened face validity to some degree with their implicit approach to understanding transfer. But the space given in analysis for training transfer to organically emerge from learners' perspectives as a relevant concept was an arguably worthwhile advantage gained from not asking more direct questions about whether and how adult professionals transfer their learning to their work contexts.

To bolster their face validity, this study's interview questions were reviewed by two professional learning experts and former colleagues who had used similar questions in post-delivery surveys to determine whether and how learning programs prove useful to learning participants. These experts confirmed the potential of these broad questions about learning usefulness to unearth insightful feedback about transfer and value. 
Literature also provided informative guidance on conducting investigative conversations (Bogdan \& Biklen, 2007; Rubin \& Rubin, 2012), leading to the investigative choice to pursue reliability via a sole interviewer who could ask questions in a singular manner and keep interviews aligned in pursuit of participant insight into learning value. Further steps to insure the reliability of this study's qualitative investigation are explored in this chapter's sections on Research Context and Study Verification.

\section{Qualitative Analysis Approach}

\section{Analytical Tools Assessment}

When interviews were conducted with professionals based on survey answers about their learning experiences and preferences, these interviews were captured in an online form completed by the researcher as conversations with participants progressed. The online form utilized to capture interview responses was similar to the online form used to capture survey responses about learning experiences and learning preferences, allowing perspective-driven data from participants to be stored together and analyzed in parallel.

Ahead of coding in earnest, several qualitative and mixed-method data analysis (QDA) tools - Atlas.ti, Ethnographer, Nvivo and DeDoose - were tested with a limited set of responses to determine effectiveness for coding qualitative data from this study. Perhaps if research presented here had involved a larger volume of data, such as what might be expected with a longitudinal qualitative study, the challenging interfaces and interpretative complexity presented in these tools would have been worth the multilayered code books and hierarchical code trees available to facilitate analysis. In the case of this study, however, these tools proved to be more complicated than was needed and became more of an analytical hindrance than a help. 
Another barrier to use for most of these tools was the confinement of data to the computer used for analysis, as opposed to secure cloud-based data accessible to the researcher via the web. While cloud-based DeDoose was an exception to this barrier, its complexity and limited customer support (emails and calls for assistance went several days without useful reply) significantly curtailed the tool's utility.

In the face of complex QDA tools, and given this study's manageable data set available online in a secure cloud-based account, the analytical approach taken here was an intentionally simple one leveraging the cloud-based annotations application Diigo to highlight and notate interviews as a means of coding (see Figure 5).

\section{Figure 5}

Diigo Annotations Tool Notations

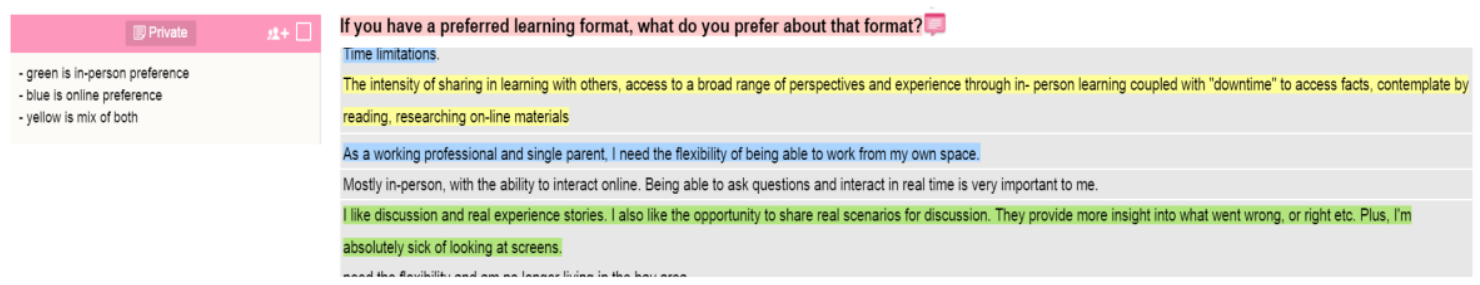

Participant responses were sorted via color-coding, and the electronic equivalent of sticky notes were used for memoing to keep track of categories, codes and connections within and between responses. Color-coding plus annotations allowed for focused and efficient review of responses when comparing, revising and expanding codes.

\section{Coding Approach}

Guided by grounded theory's emergent approach, this study's qualitative discovery process began with insights gleaned from interviews with an initial purposive sample of 23 interview participants. Verification and continual discovery came from a follow-on purposive sample of 9 participants, whose perspectives stress-tested initial insights 
against additional data. As discussed in the Literature chapter of this dissertation, a pragmatic philosophical approach to coding allowed the researcher to leverage both the Glaserian method of repeatedly applying orderly coded concepts in data examination and the Straussian method of mining for meaning via repeated examination of orderly data for potentially emergent codes. The Glaserian method was used to descriptively organize data, and the Straussian method was subsequently utilized to explore data thematically for meaning.

\section{Descriptive Coding}

Strauss and Corbin's (1998) method of combing through data descriptively gave rise in this study to categories and codes that became data organizers which were then repeatedly applied to the data to find relevant points of focus in participant responses. Data from research participants was reviewed line by line with descriptive intent in mind to generate codes that summarized primary topics in the data. The resulting descriptive categories and codes were then used to organize and describe data.

An example is the data category related to learning definitions, which included several topics ranging from continuous learning to skills improvement, career change and learning approach - all of which proved useful as data codes. To further clarify the distinction made here between data categories and data codes: categories served as macro organizers, while codes specified detailed areas of analytical focus.

Given the research focus on participant learning in relation to their roles as professionals, it was especially necessary as an insider researcher (discussed in this chapter's Research Context section) to give participants a voice in delineating the definition and purpose of professional learning. In addition to mindfully mitigating 
researcher biases, questions about professional learning's particulars provided a natural starting point for data organization, since nearly half the interview time with participants was typically spent discussing what professional learning meant to them (see Figure 6).

\section{Figure 6}

Participant Reponses: Professional Learning Definitions and Purpose

\begin{tabular}{|c|c|c|}
\hline DPivate & $2+\square$ & What comes to mind when you hear the term "professional learning"? \\
\hline \multirow{7}{*}{\multicolumn{2}{|c|}{$\begin{array}{l}\text { - professional learning objectives } \\
\text { - pink is general continuous learning } \\
\text { - green is improved job skills } \\
\text { - blue is career change or advancement } \\
\text { - yellow is differentiated learning approach }\end{array}$}} & I think of a whole range of different dimensions when hearing the term "professional learning". I think of learning on the job or through collaboration, I think of leaming in order to improve the \\
\hline & & way I'm doing my job or to change my job, I also think of different approaches to and different format of learning - whether that be one-to-one, classroom, action-based learning, etc. \\
\hline & & Improvement of self \\
\hline & & I's a positive term that reflects the concept of continual learning over the entire spectrum of your career (in a host of topics, venues, media, etc.) No one likes to be "trained". Everyone likes \\
\hline & & to "learn". Learning - to me - equates to periods of time or venues to gather more insights, information, practice what you've gained, etc. \\
\hline & & Boring. Obligatory. Talking heads. \\
\hline & & Learning that broadens the students view of life and changes the way they look a their life, others, and their work. \\
\hline
\end{tabular}

With a good deal of interview data focused on participant notions about learning as professionals, learning definitions naturally presented itself as a macro-level category of data organization, with several code-worthy areas of focus.

Survey and interview questions that probed for details about learning format preferences also provided useful starting points for illuminating and organizing aspects of the learning experience, leading to the categories in-person learning, online learning and blended learning as naturally emergent foundations for data organization.

Alongside illuminating details of what respondents preferred for learning delivery, descriptive analysis also helped to broadly categorize why respondents expressed preferences for a given mode of learning delivery. For example, respondents who had not taken an online course still revealed motivations that provided descriptively clarifying links between learning experience and delivery mode preferences (see Figure 7). 


\section{Figure 7}

Learning Experience and Delivery Mode Preferences
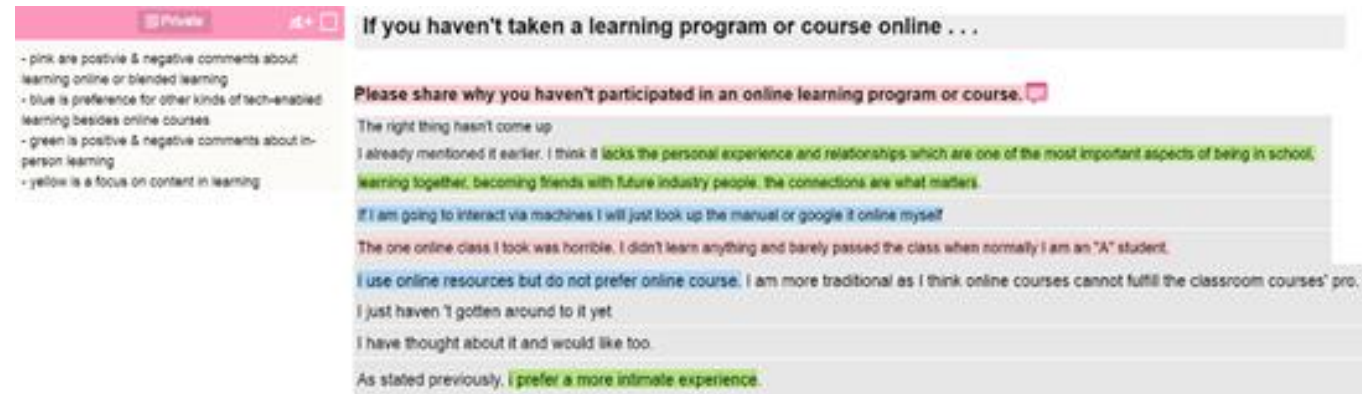

Keeping in mind this study's quest to define, describe and interpret relevance for learning format preferences, data that spoke to learning format preferences unsurprisingly provided relevant descriptively-focused codes: positive learning experience; negative learning experience; non-course tech-enabled learning; and learning content focus.

While the overall goal of descriptive coding was to capture and categorize the breadth of perspectives found in the data, this initial sorting activity inevitably shaped subsequent searches for patterns by including and excluding data from further analysis. A key example of data exclusion can be seen in the coding of answers to why respondents had not yet engaged in online learning (Figure 8). When respondent answers either explicitly ("I just haven't gotten around to it yet") or implicitly ("I have thought about it and would like to") lacked concrete perspective or opinion about delivery mode preferences, these answers were not descriptively coded.

If coding is indeed "the transitional process between data collection and more extensive data analysis" (Saldana, 1998, p.4), to leave participant responses uncoded is to leave data in limbo between collection and analysis. The decision to leave data uncategorized and undescribed was thoughtful, intentional and ultimately based on 
responses that read as being void of concrete perspective and thereby irrelevant to research questions seeking clarity and meaning about experiences and preferences.

\section{Thematic Coding}

Once descriptive codes were matched against research questions to organize data and check it for relevance, theoretically-driven codes were utilized to illuminate patterns and draw themes from respondents' experience and perspectives. This thematic coding was most informed by the grounded theory-supported practice of In Vivo coding, which keeps data analysis rooted in participants' own language (Saldana, 1998, p.6). The process of Straussian coding - repeatedly examining orderly data for coding direction - resulted in a more refined understanding of persistent themes reflected in participant experience.

The richness (and challenge) of analyzing interview data were the many avenues of meaning any one bit of data revealed and the resulting interpretive decisions that needed to be made about whether and how participants' perspectives fit together to tell a research story. At times, characteristics that led to codes were exclusive to or heavily favored one mode of learning delivery over another. For example, participants repeatedly ascribed social characteristics to learning in person. But oftentimes, similar characteristics were ascribed by various learners to multiple modes of learning delivery and described in contradictory terms. These characteristics were notable and codeworthy for their persistent presence in the data and the consistency with which participants expressed a wide variety of opinions about them.

Following guidance from Saldana (1998) to look for commonality in differences and to think of patterns "not just as stable regularities but as varying forms" (p.6), these 
thematically contentious and data-persistent characteristics became top level codes, while their details were teased out for sub-level codes.

\section{Researcher Context}

As mentioned in the Significance section of this dissertation's Introduction, I am researching from the context of a professional learning industry insider, having dedicated the last decade of my career to designing, directing and facilitating learning programs for professionals. My experience and expertise include: delivery of experiential and technology-mediated learning for clients; negotiating strategic partnerships with learning technology providers referenced in this dissertation; and brokering the sale of a boutique learning-focused consulting firm working in corporate education.

Given my professional background, it is not an overstatement to describe myself as deeply embedded in my research context of learning for professionals. As such, I embody the complete membership role noted by Adler and Adler (1987) as a standing for researchers by which "they and their subjects relate as status equals" (p. 67). The complete member researcher does not necessarily share the same role as their research participants but is nonetheless fully immersed in the research context and, as such, encounters related advantages and disadvantages. This native or native-type researcher experiences rapid acceptance and openness by participants but is also challenged to:

.. . create space and character for the research role to emerge. They must look at a setting with a fresh perspective, . . change the nature of their preexisting relationships (and) become involved with the setting more broadly. This can be difficult, awkward, and heighten the sense of unnaturalness that invariably surrounds the research process. Augmenting the membership role with the research enterprise can also become confusing and overwhelming (Adler \& Adler, 1987, pp. 69-70). 
The noteworthy contradiction here is how having or approximating native advantage in a research context opens access to the researcher on the one hand, but raises barriers to the research process on the other. Researchers cannot take for granted that contextbelonging will smooth the research engagement. Indeed, it is likely to add layers of issues and compound challenges that would not exist for outsiders.

Adler and Adler's (1987) delineation of the "complete member researcher" has given way over the years to the descriptive insider researcher, understood as the researcher who hails from the research domain under study. Bonner \& Tollhurst (2002), for example, referred to Adler \& Adler when defining the insider-researcher as simply a researcher who is already a native or insider to the research context before the study commences. Insider researcher advantages include greater cultural understanding, natural social interaction and established relational intimacy (Bonner \& Tollhurst, 2002, pp. 8-9).

These advantages ease the flow of truthful and verifiable information but encourage equally impactful disadvantages such as: erroneous assumptions based on prior knowledge; illusions of sameness prompted by personal familiarity; and unique methodological issues such as balancing insider and researcher roles (Breen, 2007). As Dwyer and Buckle (2009) aptly observe, insider status does not make for better or worse researchers. It simply makes for researchers with particular benefits and difficulties to mind (p. 56).

A plethora of social science researchers from various fields have undertaken reflexive examinations by learning from their insider research context and/or by investigating the process and quality (e.g. validity and credibility) of research conducted by insiders (Coghlan, 2003; Dwyer \& Buckle, 2009; Herrmann, 1989; Kerstetter, 2012; 
Mercer, 2007; Myerhoff, 1978; Rooney, 2005; Tedlock, 2000). As Creswell notes, one key characteristic of qualitative research in social sciences is "the researcher as the primary instrument of data collection and data analysis" (2007, p. 5). When people are both research instrument and subject, research interests naturally lead to contexts researchers know best - their own. These insider research benefits and challenges experienced as part of this study were pronounced but not unique and are summarized here as a model of insider researcher advantages and disadvantages that a mindful insider researcher can anticipate and mitigate in the research process (see Figure 8).

\section{Figure 8}

Insider Research Advantages and Disadvantages

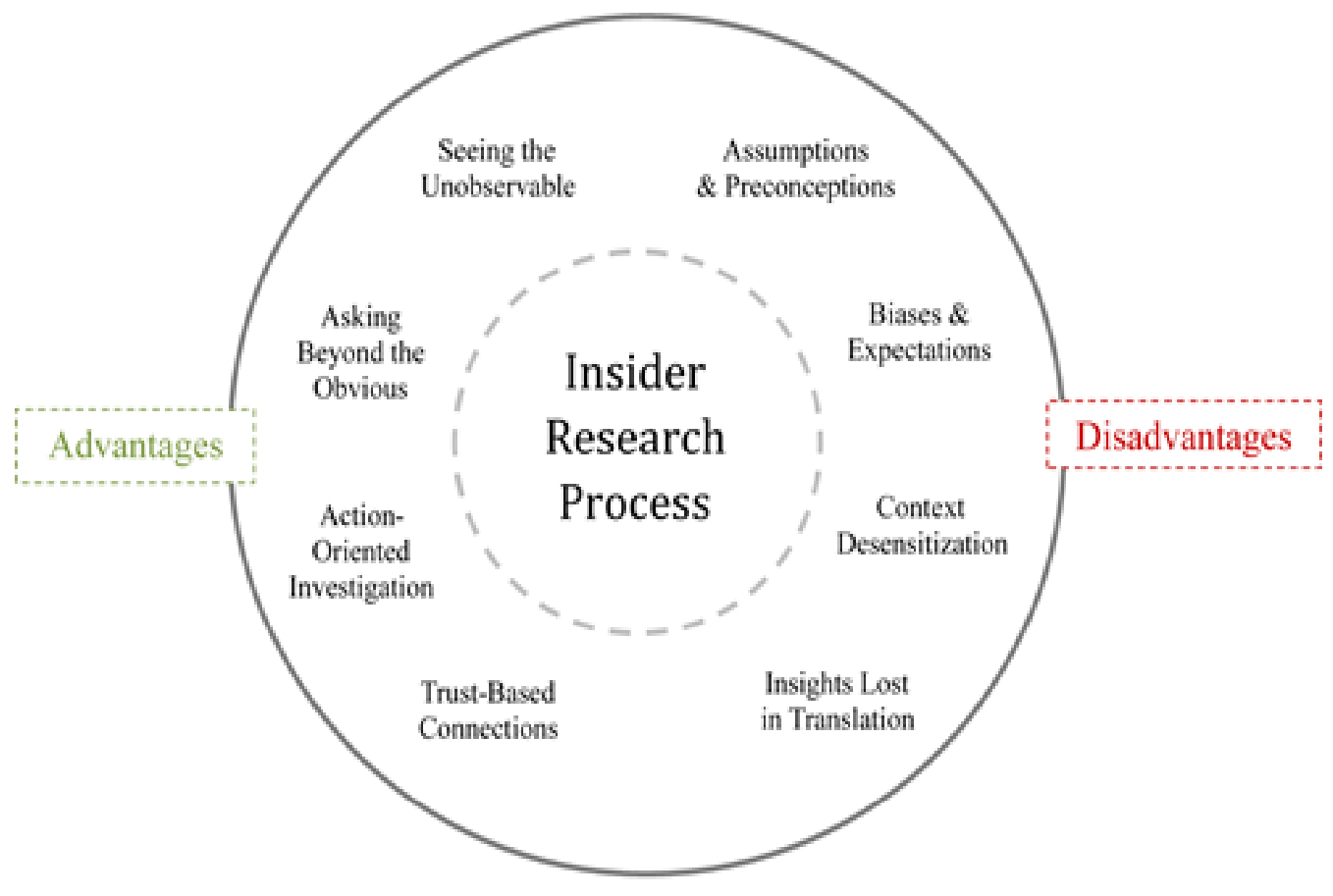

As in previously referenced experiences of insider researchers who have come before me, my research experience has been no less influenced by similar methodological issues inherent in the constellation of advantages and disadvantages concurrently surrounding my research process. With information from years of shared encounters in my research 
context, I can see unobservable areas of investigation such as the absence of learning value focus in industry conversations about online learning's efficiencies. In the quest for meaningful data, I can dig deeper than what appears to be happening and get beyond what participants initially say and do not say.

Having operated in this context for years, however, has also desensitized me to some of its particulars and exacerbated my expectations and biases about the meaning behind the words and actions of participants. A key example was my presumption that a penchant for cell-phone use during class time was yet another indicator of favorable Millennial disposition toward technology-mediated learning (Sanders, 2014b).

Trust-based relationships with colleagues from my professional network facilitated access to many respondents who signed on as my research participants alongside my access to the research context. My extensive familiarity with both participants and context, however, also generated preconceptions about what does and does not need questioning or further illumination as well as the assumption that I intrinsically understood a general experience when perhaps I may have only intrinsically understood my own experience.

The constellation model presented here of insider research advantages and disadvantages cannot and does not intend to capture the complexities of all insider researcher situations. Reflective of experience in this research process and informed by reported experiences of other insider researchers, this model is rather a cautionary collection of insider researcher process pros and cons. As such, it may heighten awareness and thus offer transferrable utility for researchers taking on the distinctive task of exploring personal or professional domains where they are most immersed. 


\section{Study Verification}

In any knowledge-generating enterprise, trustworthiness is a foremost concern. This research is, of course, no exception. As mentioned in the Instrumentation section of the Methods discussion, trustworthiness of this dissertation's quantitative data and analysis was addressed by ensuring face validity and reliability of the main survey instrument responsible for generating categorical variables that served as quantitative data.

For qualitative data and analysis, verifying trustworthiness requires attention to a different set of considerations. Guba's (1981) criteria for evaluating trustworthiness of qualitative research include: credibility, understood as confidence in the truth of findings; confirmability, understood as neutrality in findings shaped by respondents as opposed to researcher preconceptions, bias, motivation or interest; and transferability, understood as findings that are potentially applicable in other contexts.

In Guba (1981), transferability is "analogous to generalizability or external validity" and is thus dependent upon the degree of "fittingness" between two contexts (p.81). Since this dissertation aims to be both descriptive and prescriptive with a model that could be used to better understand learning value, Guba's conceptualization of transferability as an effort to form commutable insights or "working hypotheses that may be transferred from one context" is most relevant (p.81).

Keeping Guba's (1981) trustworthiness criteria in mind, this research includes extensive quotes from participants, my online learning reflections (Appendix D) and a bracketing interview (Appendix E) to demonstrate that a true picture of the phenomenon has been presented (credibility) and to lay bare my biases, critiques and preconceptions on the way to ensuring research insights were rooted in data rather than my dispositions 
(confirmability). The Context section of this Methods discussion describes my insider researcher position, clarifies the prevailing research environment and contextualizes this particular study on learning for professionals for potential transferability of insights.

The bracketing interview was most informative as a structured approach to deliberate self-examination prior to research. Citing Creswell's (1998) definition of bracketing as a phenomenological approach to identifying and suspending judgment and bias, Maxfield (2008) utilized this reflective tool in notable form. He submitted to an open-ended interview about his online learning experiences as a nontraditional adult student as part of his inquiry into online education for students like himself. Maxfield's bracketing interview is transcribed and included as part of his research data, with his biases clearly called out.

Lopez (2001) also made effective use of bracketing by answering the interview questions she had planned for her participants and acknowledging from the process an overly positive disposition toward her research domain, a teacher-initiated learning community of which she was an active member. Though Lopez neither explains bracketing nor attributes use of the term in her research, the term's meaning is clarified by repeated use and aligns with Maxfield's (2008) use of the term.

Following these two research examples, I submitted to an email-based bracketing interview facilitated by a former colleague from the University of California, Berkeley's Center for Executive Education who is a longtime learning professional. Questions for the bracketing interview mirrored survey and interview prompts planned for research participants. Once I sent my completed survey and answered interview questions, my 
former colleague reviewed my responses, offering follow-up questions and pertinent observations based on personal knowledge of my professional and academic interests. My responses to survey and interview questions (see Appendix E) brought to light my strong bias for the merits of nondegree learning over learning in formal degree programs. I have a pronounced disinterest in test-based assessment of learning performance and an unwavering belief in literature-supported notions that learning is of little value to professionals unless it transfers in some way to performance. Hence, deference given to such characterization of learning in the Definitions section this dissertation's Introduction. This bias has also likely narrowed my research focus on learning value solely to nondegree learning, given my suspicion of how learning performance - and by extension, learning value - is assessed in formal degree learning.

As illustrated, bracketing does not eradicate bias but rather raises researchers' awareness of their personal perspectives. When these perspectives inform research, they can do so transparently via bracketing, which can also help a researcher choose which perspectives to utilize and which to suspend entirely when they threaten to dominate or derail data gathering or analysis.

As Tracy (2010) notes, credibility also entails transparency about a researcher's role/s, which is all the more relevant when a researcher is both observer and member of a complex context like an education setting "involving a great number of players, each of whom brings to the research process a wide range of perspectives, including the researcher's own" (Unluer, 2012, p. 1).

In addition to the research literature and four seasoned educational researchers to draw upon, as guided by Dillman et al. (2009), I queried learning professional peers and 
colleagues for informal discussions to probe how my role as an insider researcher affected how I perceived, analyzed and conveyed my research situation. In soliciting informal conversations with peers and colleagues, I took them as an opportunity to invite into my research process outsiders who could hear with fresh ears and see with clear eyes, observing what might otherwise go unnoticed in my insider process. The checkand-balance nature of these conversational critiques served to monitor and mitigate my insider researcher disadvantages. These sessions were not recorded, but useful feedback from them was incorporated into my research journal. Their relevance to the research process is referenced in the context of data collection, analysis and interpretation.

Morse et al. (2002) argue Guba's (1981) verification criteria attends only to the tangible outcomes of research findings but that verification strategies in qualitative studies should also relate to the conduct of inquiry during the research process. The approach advocated by Morse et al. defines verification as both "the process of checking, confirming, making sure, and being certain" and "the mechanisms used during the process of research to incrementally contribute to ensuring ... the rigor of a study" (p.10).

Their recommended verification strategies include: methodological coherence to insure rational consistency between research questions, data-gathering methods and analytical procedures; sampling sufficiency to insure samples consist of participants who best represent or have knowledge of the research topic; and investigator responsiveness, understood as a researcher's iterative engagement with sampling, data collection and analysis to continually assess and bridge the gap "between what is known and what one 
needs to know" (p.12). These verification strategies "help the researcher identify when to continue, stop or modify the research process" (p.10) on the road to ensuring rigor.

Examining the conceptual integration of grounded theory, pragmatism and mixed methods in this dissertation's Literature discussion addresses the call for methodological coherence with attention to the rational consistency of this study's primary research devices. Sampling sufficiency and investigator responsiveness are addressed in this research as part of grounded theory's requirements for data saturation and iterative analysis to discover emergent concepts and explanations.

In an effort to provide practical guidance for estimating purposive sample sizes, Guest et al. (2006) operationalized data saturation as the point in data collection and analysis when new data produces little to no change in thematic coding of interviews. Their definition is at odds with grounded theory's typical characterization of theoretical data saturation occurring "when all of the main variations of the phenomenon have been identified and incorporated into the emerging theory" and concepts are researched "to exhaustion" (Guest et al.,p. 67). A lack of sample size guidelines related to theoretical saturation in grounded theory, however, makes operationalizing data saturation a necessary task.

Guest et al. defined their saturation point retrospectively after examining data collected in a study of a relatively homogenous participant group. Having operationalized data saturation in relation to thematic coding, Guest et al. uncovered consistently present metathemes at 6 interviews and data saturation by 12 interviews. Following Guest et al.'s lead, this study lays claim to saturation territory with four consistent themes uncovered in 19 interviews with a heterogeneous participant group. 
Though the Guest et al. frequency recommendation of six to 12 interviews is an assuring concrete guideline for data collection decisions, as Adler and Adler (1987) remind early-career researchers, an "epistemology of numbers" cannot resolve trustworthiness questions in qualitative inquiry with neat precision (Baker \& Edwards, 2012, p. 8). The reality of qualitative data collection is that even one respondent can produce a useful case.

The point of data saturation reveals itself in both the repetitive presence of perspectives, codes and concepts gleaned from engagement with participants and in the transparency by which the researcher accounts for and measures this repetition. The investigator's primary analytical task is to continually stress-test research conclusions against newly available data and provide clarity by which decisions were made based on data comparisons. The degrees to which this study achieved sampling sufficiency expressed as valid data saturation as well as investigator responsive via analytical iteration are further assessed in this dissertation's Analysis.

\section{Study Delimitations and Limitations}

As mentioned in the Sample section of this dissertation's Methods discussion, the 32 participants who participated in this research came from an original pool of roughly 1,000 potential participants, none of whom who were randomly selected from the larger professional population. The nonprobabilistic purposive samples that resulted are a hallmark of grounded theory, as noted in this study's Literature Review, but can be considered a shortcoming from a quantitative analysis standpoint. While nonprobabilistic sampling does not prevent generalization, it must be acknowledged that a limited number 
of nonrandomly selected participants limits the confidence with which quantitative analysis can be generalized beyond the original nonprobabilistic samples.

Another shortcoming relates to how potential research participants were contacted for study participation. Nearly all participants self-selected after outreach either via email or via private message in an online professional network. Connecting with participants solely through technology-mediated communication could have introduced bias in favor of technology-mediated experiences among participants who are clearly comfortable communicating and engaging online.

Along the line of technology-mediated communication, it is also possible that conducting interviews via email and text message - while highly convenient for participants - may also have circumscribed responses. For participants who experience greater ease with vocal conversation, the effort of typing written responses may have hindered the breadth and depth of exchange during interviews. Conversely, participants who might have benefitted from the time and space afforded in written communication to think and re-think responses to questions may have provided more thoughtfully constructed answers with interviews conducted in written formats. Since participants were given the option to interview in whatever manner they preferred, convenience may have taken precedence over optimally efficient and effective communication style.

Survey questions related to online learning experience resulted in yet another limitation for this study. Experience learning online was specified in the research survey as whether participants have taken an online course of any kind. The survey allowed participants to reference online courses of any duration, taken formally or informally, in any format (web, mobile, tablet), from degree-granting or nondegree granting 
organizations. As previously explained in this dissertation's Definitions section, this definitional decision for online learning was imposed in the survey to achieve at least a minimal degree of alignment with prior research. Despite its inclusivity, a shortcoming in the survey resulted from this question. In asking participants whether they had taken an online course, the survey narrowed online learning experience to structured learning designed for participants. This narrowing excluded free-form self-driven exploration of Wikipedia, online news and articles, videos, podcasts, blogs, infographics and myriad other nonstructured ways participants use technology beyond instructors and courses to advance their learning.

Not until follow-up interviews with the primary research group was this shortcoming discovered, as those conversations delved deeper into how respondents' perceived and described their online learning. For respondents, what qualified as online learning diverged enough from how online learning is represented in research to warrant further consideration in the context of this study. While this broader diversity in online learning definitions was captured in interviews, this lacking datapoint from survey responses became a missed opportunity to cross tabulate participants' learning preferences with structured and nonstructured technology-mediated learning experiences for more nuanced understanding about how participants find value in learning online.

Scholarly examiners of this research make take issue with the inclusion here of online learning in degree-seeking contexts, given that this study is primary oriented toward nondegree professional learning. Indeed, this study's discussion of learning value in the Definitions section takes to task the practice of extrapolating and generalizing research findings from degree-learning contexts to corporate and other nondegree 
learning contexts. Including professionals with online learning experience in degree contexts as part of this study arguably transgresses into similar territory and may limit this study's credibility. Two points of clarity are offered here to mitigate this issue.

First, as discussed in the Introduction, technology-mediated learning is still gaining traction in professional learning, and participants did not always have nondegree online learning experience to contribute. Instead, for some participants, their online learning experience was gained in degree-oriented environs. In recognition of this reality and to with respect for this constraint, this dissertation was specifically crafted not as a study of online nondegree learning but rather as a study of learning from the perspective of professionals, some of whom have experience learning online in degree-seeking contexts, and some of whom garnered their online learning experience in nondegree-settings.

Additionally, focused interviews provided a key opportunity to mitigate this transgression with direct insight from research participants about the relevance - or lack thereof - that learning online in a degree program has had for their perceptions about value in their professional learning. Put simply, this study did not presume value from one learning context to the other, but rather relied on focused conversation with participants to speak to the relevance of online learning undertaken in any context from the learning participant's point-of-view.

This issue of porting online learning from one context into another might have been altogether avoided had the survey used in this study included a broader range of options for online learning experience. As mentioned previously here in Limitations, a lack of attention to unstructured online learning experiences narrowed the scope and definition of online learning and, unfortunately, narrowed this study's analysis. 
To its credit, however, this study's reach has been strictly defined as learning undertaken by professionals. And, transparency has replaced presumption in the assessment of learning relevance, regardless of context. Hopefully these combined steps mitigate the legitimate issues that come with mixing data from distinctly varied modes of learning in a uniformly presented analysis of learning value.

Along with narrowing the scope of technology-mediate learning to structured courses, the survey did not ask whether those participants with online learning experience completed the courses they took. Nor did the survey ask whether the courses were required or voluntary. These lacking distinctions are all relevant datapoints that could have affected whether research participants carry positive or negative perceptions of online learning delivery and thus would have made a useful variable for crosstabulation and correlation.

\section{Summary}

Demographic and learning preference survey data were collected from a total of 347 participants divided into two research samples: a primary research group that contributed qualitative and quantitative data, and a secondary research group that contributed quantitative data only and was originally approached solely as a test group to pilot and validate the study's survey instrument. This study morphed into a fully mixed-methods endeavor when quantitative analysis of demographics and learning preference from one group wholly contradicted expectations about age groups and preferred modes of learning, with younger professionals expressing stronger preference for in-person learning, and older respondents expressing more openness toward technology-mediated learning delivery. Having two sample groups helped corroborate unexpected research findings. 
Qualitative research consisted primarily of 1:1 interviews with 19 research participants from the primary research group. Because learners did not prefer learning as expected, it became all the more important to explore the value learners attributed to learning in varied modalities that would lead to preferencing one modality over another. Qualitative exploration took on that exploratory task. The mixed-methods research design that resulted put quantitative data analysis first, followed by qualitative analysis, but with concurrent interpretation of all data informing investigative questions and research findings.

Several mitigating steps were taken to reduce the bias of researcher influence on participants and to lay bare researcher preconceptions on the way to ensuring research insights were rooted in data rather than researcher dispositions. These mitigating steps included separating the researcher from sample selection for the secondary research group, a researcher bracketing interview, research journaling, and extensive quoting of research participants to present a true picture of the phenomenon explored in this study.

Despite to mitigating efforts, this study nonetheless has its limitations and deliminations, to include nonprobablistic samples that call into question attempts to generalize quantitative findings. Another recognized shortcoming of this study includes online-only participant recruitment methods, a communication approach that could have introduced bias in favor of technology-mediated experiences among participants. 


\section{CHAPTER IV}

\section{ANALYSES AND FINDINGS}

The collated, orderly and comprehensible manner in which research analysis is presented in this chapter belies the messy, iterative and interdependent approach to analysis that was part and parcel of this dissertation's application of grounded theory and mixed methodology. The analytical work began on a presumed straight path from demographic survey and quantitative analysis to focused interviews and qualitative analysis. Research reality was much more of a winding road.

The journey began with demographic surveys and quantitative analysis leading to provocative but contradictory outcomes from a small sample. This contradiction added a twist to the start of qualitative interviews while prompting a return visit to data from a larger survey sample with further clarifying quantitative analysis. All of this was followed by even more focused interviews and qualitative analysis. At some point in this study, crosstabulations, correlations and coding were taking place concurrently with results simultaneously driving, informing and evolving follow-on investigations and analyses. What follows here is the straightening out of this winding analytical process, with results presented as an orderly research story of initial discovery, deeper exploration and descriptions of learning delivery modes as key components of learning value.

\section{Frequency Analysis \& Cross-Tabulation Results}

In the primary research group of study for this dissertation, the learning preferences of a tech-savvy collection of 32 professionals ranging in age from 22 to $50+$ raised provocative questions about relationships between gender, age, online learning experience and preference for learning online, in person or via a mix of modalities. 
Frequency analyses from descriptive statistics clarified the following characteristics of the research participant group, represented by the following distribution tables and figures. Women comprised 63\% $(n=20)$ of the participant group (Table 2). Participants in their 30s made up the largest proportion of the participant group at 34\% $(n=11)$, while participants in their 20s were the smallest proportion at $16 \%(n=5)$. The proportion of participants in their 40 s was $28 \%(n=9)$, and $22 \%(n=7)$ of participants were 50 or older (Table 3). A 69\% $(n=22)$ majority of participants reported experience with online learning via an online course (Table 4).

\section{Table 2}

Primary Group: Gender Frequency

\begin{tabular}{|c|c|c|c|c|c|}
\hline & & Frequency & Percent & Valid Percent & Cumulative Percent \\
\hline \multirow[t]{3}{*}{ Valid } & Women & 20 & 62.5 & 62.5 & 62.5 \\
\hline & Men & 12 & 37.5 & 37.5 & 100.0 \\
\hline & Total & 32 & 100.0 & 100.0 & \\
\hline
\end{tabular}

\section{Table 3}

Primary Group: Age Frequency

\begin{tabular}{llllll}
\hline & & Frequency & Percent & Valid Percent & Cumulative Percent \\
\hline Valid & $20-29$ & 5 & 15.6 & 15.6 & 15.6 \\
& $30-39$ & 11 & 34.4 & 34.4 & 50.0 \\
& $40-49$ & 9 & 28.1 & 28.1 & 78.1 \\
$50+$ & 7 & 21.9 & 21.9 & 100.0 \\
& Total & 32 & 100.0 & 100.0 & \\
\hline
\end{tabular}

\section{Table 4}

Primary Group: Online Learning Experience Frequency

\begin{tabular}{llllll}
\hline & & Frequency & Percent & Valid Percent & Cumulative Percent \\
\hline Valid & Yes & 22 & 68.8 & 68.8 & 68.8 \\
& No & 10 & 31.3 & 31.3 & 100.0 \\
& Total & 32 & 100.0 & 100.0 & \\
\hline
\end{tabular}

Frequency analyses also revealed as many participants preferred learning in person as those who preferred all other learning format options combined (Table 5). In-person 
learning comprised $50 \%(n=16)$ of participant preference, while some $38 \%(n=12)$ of participants preferred a mix of in-person and online learning. Online learning on its own was the least-preferred format, selected by only one person in the research group.

Representing 3\% of all preference answers, learning solely online was preferred even less than having no preference at all, which was chosen by $9 \%(n=3)$ of participants.

\section{Table 5}

Primary Group: Learning Format Preference

\begin{tabular}{llllll}
\hline & & Frequency & Percent & Valid Percent & Cumulative Percent \\
\hline Valid & No Pref. & 3 & 9.4 & 9.4 & 9.4 \\
& Online & 1 & 3.1 & 3.1 & 12.5 \\
& Mix & 12 & 37.5 & 37.5 & 50.0 \\
In-Person & 16 & 50.0 & 50.0 & 100.0 \\
& Total & 32 & 100.0 & 100.0 & \\
\hline
\end{tabular}

Crosstabulation of gender and learning format preference indicated that learning in person was preferred by an equal proportion of both women $(50 \%, n=10)$ and men $(50 \%, n=6)$. The proportion of men who preferred a mix of online and in-person learning was slightly higher $(42 \%, n=5)$ than the proportion of women who expressed similar preference $(35 \%, n=7)$. Among men in the research participant group, none indicated a preference for learning solely online (Table 6).

Table 6

Primary Group: Learning Format Preference * Gender Crosstabulation

\begin{tabular}{lccc}
\hline & \multicolumn{3}{c}{ Gender } \\
\cline { 2 - 3 } Learning Format Preference & Female & Male & Total \\
\hline None & 2 & 1 & 3 \\
Online & 1 & 0 & 1 \\
Mix & 7 & 5 & 12 \\
In-Person & 10 & 6 & 16 \\
Total & 20 & 12 & 32 \\
\hline
\end{tabular}

In crosstabulation of age and learning format preference, the single participant to indicate a preference for learning online came from the 30-39 age group. (Table 7). The 
majority of participants in their 20s, 30s and 40s most preferred learning in person. The majority of participants 50 or older preferred a mix of in-person and online learning, which was least selected as a learning format preference by participants in their $20 \mathrm{~s}$.

Table 7

Primary Group: Learning Format Preference * Age Crosstabulation

\begin{tabular}{llllll}
\hline & \multicolumn{5}{c}{ Age } \\
\cline { 2 - 5 } Learning Format Preference & $20-29$ & $30-39$ & $40-49$ & 50 \& Older & Total \\
\hline None & 1 & 1 & 0 & 1 & 3 \\
Online & 0 & 1 & 0 & 0 & 1 \\
Mix & 1 & 3 & 4 & 4 & 12 \\
In-Person & 3 & 6 & 5 & 2 & 16 \\
Total & 5 & 11 & 9 & 7 & 32 \\
\hline
\end{tabular}

Crosstabulation of experience with online learning and learning format preference indicated that of the participants who had taken an online course, the majority preferred a mix of online and in-person learning $(55 \%, n=12)($ Table 8$)$. Though an equal number of participants preferred in-person learning regardless of whether they had experienced an online course $(n=8)$, no participant who had not experienced an online course selected a learning format preference that involved learning online.

\section{Table 8}

Primary Group: Learning Format Preference * Online Learning Experience Crosstabulation

\begin{tabular}{lccc}
\hline & \multicolumn{2}{c}{ Online Learning Experience } & \\
\cline { 2 - 3 } Learning Format Preference & Yes & No & Total \\
\hline None & 1 & 2 & 3 \\
Online & 1 & 0 & 1 \\
Mix & 12 & 0 & 12 \\
In-Person & 8 & 8 & 16 \\
Total & 22 & 10 & 32 \\
\hline
\end{tabular}

These crosstabulations ran counter to anecdotal and cultural narratives about the digital advantages of the youngest generation represented in this survey (Palfrey \& Gasser, 2008). Instead of reflecting natural inclinations toward living online, these 
crosstabulations suggested advantages in technology experience and the accompanying comfort level attributed to digitally native 20 -somethings may not translate into preferences for learning online. Given the unexpected outcome and the primary research group's relatively small sample size, crosstabulations were also conducted using data from a 315-participant survey test group to investigate whether similar outcomes would result from a larger sample size that was significantly different population than that of the primary research group.

This survey test group was comprised of alumni from a learning organization who partnered in this research by offering a survey test group in exchange for insights from this study on learning value for professionals. There was no population overlap between the survey test group and the primary research group. Originally intended to test a routine demographics-focused survey instrument for ease-of-navigation, completion time, reliability and face validity, the larger survey pilot revealed no significant changes needed to the survey instrument but did show results similar to those of the primary research group.

As with the primary research group, survey test group participation featured more results from women (69\%), fewer results from participants in their $20 \mathrm{~s}(12 \%)$, and a majority of participants (57\%) reporting online learning experience. And, despite vastly different populations for the two survey runs, cross-tab outcomes were relatively similar.

As with the primary research group, the survey test group crosstabs showed men and women similarly preferred learning in person (Table 9). Crosstabulation of age and learning format preference showed no participants in the 20-29 age group indicating a 
preference for learning solely online (Table 10). And, a majority of all participants

preferred learning in person irrespective of online course experience (Table 11).

Table 9

Secondary Group: Learning Format Preference * Gender Crosstabulation

\begin{tabular}{lccc}
\hline & \multicolumn{2}{c}{ Gender } & \\
\cline { 2 - 3 } Learning Format Preference & Female & Male & Total \\
\hline None & 26 & 9 & 35 \\
Online & 8 & 3 & 11 \\
Mix & 64 & 32 & 96 \\
In-Person & 120 & 53 & 173 \\
Total & 218 & 97 & 315 \\
\hline
\end{tabular}

Table 10

Secondary Group: Learning Format Preference * Age Crosstabulation

\begin{tabular}{lccccc}
\hline & \multicolumn{5}{c}{ Age } \\
\cline { 2 - 5 } Learning Format Preference & $20-29$ & $30-39$ & $40-49$ & $50 \&$ Older & Total \\
\hline None & 2 & 6 & 6 & 21 & 35 \\
Online & 0 & 3 & 2 & 6 & 11 \\
Mix & 4 & 26 & 21 & 45 & 96 \\
In-Person & 32 & 40 & 38 & 63 & 173 \\
Total & 38 & 75 & 67 & 135 & 315 \\
\hline
\end{tabular}

\section{Table 11}

Secondary Group: Learning Format Preference * Online Learning Experience Crosstabulation

\begin{tabular}{llll}
\hline & \multicolumn{2}{l}{ Online Learning Experience } & \\
\cline { 2 - 3 } Learning Format Preference & Yes & No & Total \\
\hline None & 15 & 20 & 35 \\
Online & 9 & 2 & 11 \\
Mix & 72 & 24 & 96 \\
In-Person & 84 & 89 & 173 \\
Total & 180 & 135 & 315 \\
\hline
\end{tabular}

Crosstab results across the two populations show consistent results: Younger learners did not prefer learning that is primarily online. And, even more provocatively, Millennial Generation learners preferred learning in person, while older learners prefer technology-mediated learning delivery. From these crosstabulations, further analyses 
were conducted to examine whether associations between age and learning preference remained consistent.

\section{Correlation Results}

Given examination of predominantly categorical variables, a Chi-square test was used to determine correlation between variables examined for the 32-participant primary research group. However, because several variables included fewer than five frequency observations, Fisher's exact test was used for more accurate correlational measure.

Correlation results between learning format preference and online learning experience showed significance $p=.005$ (Table 14), supporting a relationship between online learning experience and preferred mode of learning delivery in the primary research group. Correlation results showed no statistically significant relationship, however, between learning format preference and gender or age (Tables 12 and 13).

\section{Table 12}

Primary Group: Learning Format Preference * Gender Chi-Square Correlation Tests

\begin{tabular}{lllll}
\hline & Value & $d f$ & Asymp. Sig. (2-sided) & Exact Sig. (2-sided) \\
\cline { 2 - 5 } Pearson Chi-Square & $.711^{\mathrm{a}}$ & 3 & .871 & 1.000 \\
Fisher's Exact Test & .896 & & & 1.000 \\
N of Valid Cases & 32 & & & \\
\hline a. 5 cells $(62.5 \%)$ have expected count less than 5. The minimum expected count is .38.
\end{tabular}

a. 5 cells $(62.5 \%)$ have expected count less than 5 . The minimum expected count is .38 .

\section{Table 13}

Primary Group: Learning Format Preference * Age Chi-Square Correlation Tests

\begin{tabular}{lllll} 
& Value & $d f$ & Asymp. Sig. (2-sided) & Exact Sig. (2-sided) \\
\cline { 2 - 5 } Pearson Chi-Square & $5.931^{\mathrm{a}}$ & 9 & .747 & .859 \\
Fisher's Exact Test & 6.905 & & & .775 \\
N of Valid Cases & 32 & & & \\
\hline
\end{tabular}

a. 15 cells $(93.8 \%)$ have expected count less than 5 . The minimum expected count is .16. 
Table 14

Primary Group: Learning Format Preference * Online Learning Experience ChiSquare Correlation Tests

\begin{tabular}{lllll}
\hline & Value & $d f$ & Asymp. Sig. (2-sided) & Exact Sig. (2-sided) \\
\cline { 2 - 5 } Pearson Chi-Square & $10.279^{\mathrm{a}}$ & 3 & .016 & .015 \\
Fisher's Exact Test & 11.052 & & & .005 \\
N of Valid Cases & 32 & & & \\
\hline a. 5 cells $(62.5 \%)$ have expected count less than 5. The minimum expected count is 31.
\end{tabular}

a. 5 cells $(62.5 \%)$ have expected count less than 5 . The minimum expected count is .31 .

Crosstabs and correlations based on data from the primary research group generated conflicting messages about relationships between age and learning preference, raising questions that could only be resolved by further testing with a larger sample. Thus, correlation tests were also run on data from the 315-participant survey test group. Correlations between learning format preference and both age $p=.020$ and online learning experience $p=.000$ showed significance (Tables 16 and 17 respectively), supporting relationships between age and preferred mode of learning delivery as well as online learning experience and preferred mode of learning delivery. Meanwhile, even the larger survey test group resulted in no statistically significant correlation between learning format preference and gender (Table 15).

Table 15

Secondary Group: Learning Format Preference * Gender Chi-Square Correlation Tests

\begin{tabular}{llll}
\hline & Value & $d f$ & Asymp. Sig. (2-sided) \\
\cline { 2 - 4 } Pearson Chi-Square & .780 & 3 & .854 \\
N of Valid Cases & 315 & & \\
\hline
\end{tabular}

Table 16

Secondary Group: Learning Format Preference * Age Chi-Square Correlation Tests

\begin{tabular}{llll}
\hline & Value & $d f$ & Asymp. Sig. (2-sided) \\
\cline { 2 - 4 } Pearson Chi-Square & 19.743 & 9 & .020 \\
N of Valid Cases & 315 & & \\
\hline
\end{tabular}


Table 17

Secondary Group: Learning Format Preference * Online Learning Experience Correlation

\begin{tabular}{llll}
\hline & Value & $d f$ & Asymp. Sig. (2-sided) \\
\cline { 2 - 4 } Pearson Chi-Square & 23.362 & 3 & .000 \\
N of Valid Cases & 315 & &
\end{tabular}

Based on correlation results, regression analysis was used to test whether age and/or online learning experience predicted learning format preferences. Results indicated online learning experience did not significantly predict format preference, $p>.05$ (Table 18).

\section{Table 18}

Secondary Group: ANOVA - Online Learning Experience and Learning Format Preference $^{a}$

\begin{tabular}{llllll}
\hline Model & Sum of Squares & $d f$ & Mean Square & $F$ & Sig. \\
\hline Regression & .076 & 1 & .076 & .032 & $.858^{\mathrm{b}}$ \\
Residual & 742.387 & 313 & 2.372 & & \\
Total & 742.463 & 314 & & & \\
\hline
\end{tabular}

a. Dependent Variable: Learning Format

b. Predictors: (Constant), Online Learning Experience

Age, however, did show itself to be a significant predictor of learning mode preference, $b=-.168, t(313)=-3.011, p<.05($ Table 19) .

\section{Table 19}

Secondary Group: Coefficients - Age and Learning Format Preference ${ }^{a}$

\begin{tabular}{|c|c|c|c|c|c|}
\hline \multirow{4}{*}{$\begin{array}{l}\text { Model } \\
\text { (Constant) Age }\end{array}$} & \multicolumn{2}{|c|}{$\begin{array}{l}\text { Unstandardized } \\
\text { Coefficients }\end{array}$} & \multicolumn{2}{|c|}{$\begin{array}{l}\text { Standardized } \\
\text { Coefficients }\end{array}$} & \multirow[b]{2}{*}{ Sig. } \\
\hline & $B$ & Std. Error & Beta & $t$ & \\
\hline & 5.020 & .327 & & 15.356 & .000 \\
\hline & -.024 & .008 & -.168 & -3.011 & .003 \\
\hline
\end{tabular}

a. Dependent Variable: Learning Format

The significant negative weight of age in relation to learning preference suggested younger participants would show greater preference for learning in person (Table 20).

\section{Table 20}

Secondary Group: ANOVA - Age and Learning Format Preference ${ }^{a}$

\begin{tabular}{llllll}
\hline Model & Sum of Squares & $d f$ & Mean Square & $F$ & Sig. \\
\hline Regression & 20.899 & 1 & 20.899 & 9.066 & $.003^{\mathrm{b}}$ \\
Residual & 721.564 & 313 & 2.305 & & \\
\hline
\end{tabular}


Total

742.463

a. Dependent Variable: Learning Format

b. Predictors: (Constant), Age

Despite significance, however, results showed age explained just $2.8 \%$ of the

variance in learning mode preference, $R 2=.028, F(1,313)=9.066, p<.05$ (Tables 21$)$.

\section{Table 21}

Secondary Group: Model Summary - Age and Learning Format Preference

\begin{tabular}{lllll}
\hline Model & $R$ & $R$ Square & Adjusted $R$ Square & Std. Error of the Estimate
\end{tabular}

\begin{tabular}{lllll}
\hline 1 & $.168 \mathrm{a}$ & .028 & .025 & 1.51833
\end{tabular}

a. Predictors: (Constant), Age

\section{Quantitative Findings}

Researchers have explored and uncovered gender differences in online learning from the angles of: general learning styles (Garland and Martin, 2005); virtual learning styles (Goulão, 2013); achievement and motivational beliefs (Yukselturk and Bulut, 2009); and emotional responses (Zembylas, 2008). In these studies, men and women have been found to communicate, behave and perform differently in online learning environments.

Men and women have not, however, been questioned in previous studies about their preferences for learning delivery. Crosstabulation and correlation results from this study's primary group of 32 participants and the 315-participant survey test group suggest markedly different gender-related preferences for learning delivery are not likely to be found even if the question is asked. That the results of both small and large samples from wholly separate populations yielded similar outcomes serves as a confirmatory signal that there is indeed little relationship to be found between gender and learning delivery preference.

In the primary study of 32 participants, crosstabulation of age and learning format preferences revealed participants in their 20s least preferred learning that involved online 
delivery, but found no significant correlation between age and learning mode preference. Results from the larger 315-participant survey test group addressed the primary study's conflicting messages more definitively with both crosstabulations and correlations indicating a distinct lack of preference among learners in their 20s for technologymediated learning delivery. This outcome flies in the face of generally accepted cultural tropes about Millennials as bonafide digital natives. These narrative are reflected in descriptors assigned to Millennials such as those from a 2010 Pew Research Center report calling this young generation "confident, connected and open to change" (Taylor \& Keeter, 2010).

Crosstabulations in the two examined data sets and correlations in the larger data set, however, suggest the generational advantage in technology experience and comfort level that 20 -somethings own as their birthright apparently may not translate into a preference for learning online. As noted, participants in their 20s expressed no preference for learning solely online and preferred a mix of online and in-person less than all other age groups. Meanwhile, participants older than 50 expressed the greatest preference proportionally for mixing online and in-person delivery. From these results emerge counterintuitive provocations about preferences young people are expected have for how they learn. Indeed, it seems for Millennials, a highly connected generation, being online is not the same as learning online.

As noted in results reporting for both research groups, analyses to determine relationships between learning format preference and online learning experience showed a statistically significant correlation between these two variables with both small and larger sample sizes. These results resemble findings from other researchers' explorations 
of online learning experience and learners' satisfaction with online delivery. Gunawardena et al. (2010), for example, found indications of a positive relationship between ability to learn from online course discussions and willingness to participate in more online courses.

Research has also shown that motivation to learn online is also bolstered when learners feel well-suited for online learning environs and savvy enough for the online learning experience (Kim \& Frick, 2011). With previous research findings in mind, positive correlation here between online learning experience and a preference for learning that involves online delivery confirms literature-based expectations.

Despite the soundness with which online learning experience correlated with learning mode preference, there was no predictive relationship between the variables. Regardless of whether participants have experience with online learning, there was no discernible pattern to how this experience affects their learning mode preference - not surprising given the wide variety of positive and negative experiences any one learner can with learning online.

While age and learning mode preference showed a significant relationship, there was not by extension a strong predictive relationship between the two variables either. The degree to which age can predict learning mode preference was such a small percentage that even in significance, it was not a relevant predictive factor in determining how learners prefer to learn. Though not predictive, the combined crosstabulated and correlational results were nonetheless provocative and drove further questions: What is it about learning online that is lacking for 20-somethings, and what is worthwhile about learning online for older learners? 
Such questions shaped this study's qualitative investigation of learning value based on the notion that learners prefer learning modalities because of the ways they experience or perceive those modalities as driving learning value. With this notion in mind, qualitative inquiry began from the perspective that aspects of learning modality preference could serve as proxies and parameters of learning modality value.

\section{Coding Results}

Exploratory paths through this dissertation's data moved with mixed methods' investigative flexibility between demographic survey data and quantitative analysis to respondent interviews, researcher notes and qualitative analysis. Though correlations in quantitative data pointed toward paths of investigation, it was coding of qualitative data that described investigative paths through data and illuminated meaning along the way.

\section{Descriptive Coding}

As mentioned in the Methods chapter, the high-level categories and descriptive codes summarized here were most informed by the research questions in this study specifically aimed at describing and defining learning experience. The category and code hierarchy summarized in Table 22 pared down and organized data for further analysis:

\section{Table 22}

Macro Categories and Descriptive Codes for Professional Learning

\begin{tabular}{|l|l|}
\hline Category: Learning definitions \& applicability & $\begin{array}{l}\text { Category: Online learning } \\
\text { Code: Continuous learning }\end{array}$ \\
Code: Job skills improvement & Code: Negative experience \\
Code: Career change or advancement & Code: Non-course tech-enabled learning \\
Code: Differentiated learning approach & Code: Learning content focus \\
\hline Category: In-person learning & Category: Blended learning \\
Code: Positive experience & Code: Positive experience \\
Code: Negative experience & Code: Negative experience \\
Code: Learning content focus & Code: Learning content focus \\
\hline
\end{tabular}


Because participants defined professional learning by outcomes along with learning design and content, examination of their professional learning definitions led to insightful perspectives related to training transfer - even though transfer was not explicitly investigated in this study.

As discussed in this dissertation's Literature Review, training transfer has been linked to learning retention, improved performance and generalizability by researchers exploring the subject from various dimensions. Of these three conceptual areas of research focus, the perspectives of this study's participants aligned most readily with improved performance. Given an option to name the primary and secondary purposes of professional learning, for example, the majority of this study's participants mentioned broadening or otherwise improving job skills. This expectation that professional learning should change professional abilities resonates with Holton's (1996) training transfer model of learning outcomes driving notable change in individual performance.

However, when asked to define and describe what professional learning meant to them and how they found it useful, this study's participants spoke of not only of improved skills but also of continuous learning, career change and the relevance of experiencing different options for learning and growing professionally and personally. Said one participant about what the term "professional learning" brought to mind:

I think of learning on the job or through collaboration. I think of learning to improve the way I'm doing my job or to change my job. I also think of different approaches and formats of learning - whether that be one-to-one, classroom, action-based learning. And, I think of improvement of self.

Said another participant about the meaning of professional learning:

Professional learning to me equates to periods of time or venues to gather more insights, information, and practice what you've gained. 
A common thread in these collections of insights around continuous learning, career development and skills improvement is the notion of applicability - participants expected their learning to apply to various aspects of their lives in clear and direct ways. As described by this study's participants, learning applicability diverges somewhat from current research conceptions of training transfer.

This study's participants, for example, did not necessarily link professional learning's applicability to outcomes and consequences for organizational performance, as is the case in Holton's conception of training transfer. Indeed, not a single participant connected the context of their learning to the context of their professional organization. In their words, whether professional learning has consequences for one's organization is neither here nor there when determining learning's applicability to professional and personal development.

Participant assessment of learning's applicability was also somewhat differentiated from the concept of training generalizability as put forth by researchers including Stokes and Baer (1977) as well as concepts of near and far transfer as put forth by Laker (1990). Professional learning, as described by this study's participants, is inherently defined by whether it can be leveraged for a variety of uses beyond the original learning context and purpose. As one participant summarized professional learning:

(It) implies taking away something that you can use, something you haven't known before that is applicable to what you're doing as a professional. It's practical, real-world skill development. School is great for the theoretical and creative development, but a lot of my professional learning is filling in the gaps of practical knowledge I need and learning how to transition into advanced roles in my career. 
The notion of "taking away something you can use" resonates with generalizability in both near and far training transfer, given the focus on leveraging learning beyond its original context. Where applicability in this study diverged from generalizability and near and far transfer was at the point of purpose.

As discussed in the Literature Review on training transfer, generalizability and near/far transfer explicitly focus on the degrees of difference between the learning context and the context of training application, in other words, the learning environment and the work environment. Learning's purpose - that is, what learners expect to accomplish with the skills or concepts they attain - holds steady in these conceptions of training transfer. Instead, it is the shift in context that defines training transfer.

In contrast, applicability in this study is the relevance of learning to and beyond its intended purpose. Participants spoke of leveraging professional learning to fill "gaps in practical knowledge" and to learn how "to transition into advanced roles" in one's career. In these experiences, the primary point of transfer was the purpose of the learning. Participants expected learning to service a variety of needs simultaneously and tied the very meaning of professional learning to this conception of applicability.

\section{Thematic Coding}

As mentioned in the Methods chapter, this study's coding process was driven by systematically repeated data examination that sought to refine and sharpen codes such that patterns in the data would be clearly marked. Seeking to draw themes from respondents' experience and perspectives, additional coding was utilized to illuminate patterns and establish hierarchical meaning-filled data interpretations (see Table 23): 


\section{Table 23}

Meaning-Driven Thematic Codes for Professional Learning

\begin{tabular}{|c|c|}
\hline $\begin{array}{l}\text { Code L1: Learning as Relationship } \\
\text { Code L2: "Social environments" } \\
\text { Code L3: "Peer-to-peer" } \\
\text { Code L3: Groups } \\
\text { Code L2: Connection } \\
\text { Code L3: "Networking" } \\
\text { Code L3: "Intimacy" }\end{array}$ & $\begin{array}{l}\text { Code L1: Learning as Real-Time Engagement } \\
\text { Code L2: Interaction } \\
\text { Code L3: Verbal/nonverbal communication } \\
\text { Code L4: Conversations/discussions } \\
\text { Code L4: "Body language" } \\
\text { Code L3: Collaboration } \\
\text { Code L2: Direction } \\
\text { Code L3: Questions/answers } \\
\text { Code L3: Feedback }\end{array}$ \\
\hline $\begin{array}{l}\text { Code L1: Learning as Structure } \\
\text { Code L2: Content } \\
\text { Code L2: "Control" } \\
\text { Code L2: "Commitment" } \\
\text { Code L2: "Self-discipline" }\end{array}$ & $\begin{array}{l}\text { Code L1: Learning as Discovery } \\
\text { Code L2: Serendipity } \\
\text { Code L2: Spontaneity }\end{array}$ \\
\hline
\end{tabular}

Multi-layered perspectives from several participants typically resulted in multiple code possibilities presenting themselves in any given snippet of data. Take for example this response from a participant reflecting on their experience of answering questions about their learning preferences and participating in the research:

I got the sense that this (study) largely implies that learning happens in groups/social environments. Not sure how the rest of respondents feel but I wish the (study) would turn the dial a bit more towards busy professionals who prefer to learn on their own when their crazy schedule permits.

Along with providing an insightful view into how the participant interpreted the study's learning preference questions, this response also incorporated several themes social learning, learning commitment, control over learning - that emerged as patterns across data from other participants. Following this first example is another multi-layered response from a different participant speaking to their learning delivery mode preferences, which echoed the social theme from other respondents and introduced an additional theme to consider: 
I just prefer the in-person interaction. It could have something to do with the social nature of the interaction causing activation of different elements of your brain and it's a more immersive experience.

A first analytical pass of this response focused on the notion of interaction's social nature and led to coding that bound the concepts of social and interaction together as one theme. But as more data were sifted and studied, what emerged was a stronger sense of learning's social elements speaking to relationship-building among learners, while the importance of interaction in learning was its contribution to iterative and substantive thinking process that occurs in real-time engagement. Two additional response examples help illustrate this distinction. The first is a nuanced view from a participant whose response pulls apart in-person learning's interactive benefits from the delivery format's social benefits:

There is a level of collaboration and conversation that happens in-person that is never quite the same online, no matter how great the forum/discussion experience is. There is also a level of networking that is stronger in-person.

And from another respondent on the various elements of in-person learning's relationship value versus learning online:

Learning on the Internet lacks personal experience and relationships, which are one of the most important aspects of being in a learning environment. Learning together, becoming friends with future industry people - these connections are what matters.

This concept of networking was present in other participant responses and helped bring a finer point to the social value of learning in the realm of relationship. This was also the case with responses that spoke to the relevance of peer-to-peer engagement for learning success along with the intimacy and connection that can develop between 
learners who are working and growing together. Many of these topics were originally coded as stand-alone themes, along with social interaction.

But further examination of respondent experience unearthed several data gems highlighting uniquely specific aspects of interaction. One such gem came from a participant in their $20 \mathrm{~s}$ with ardent attachment to the value of learning in person: I go online for many things, almost anything, but when it comes to being a better person, bettering myself or my knowledge, to me nothing compares with face-to-face interaction. To be with people, to learn from others, to see body language and non-verbal cues, just to have a conversation. I would take "real life" any day. As much as I love doing things online, I would DIE without personal interaction.

This participant's advocacy for interaction was much less about building connection and more so about absorbing knowledge and information in real time through verbal and nonverbal communication.

All interaction is social, in that it naturally involves people engaging to some degree with one another. But what respondents often spoke to when they specifically discussed the social aspect of learning was more communal in nature, encompassing shared experience. Repeated examination of participant data ultimately pointed to social settings as key to learning's relationship-building aspect, while interaction more so reflected the relevance of real-time engagement in learning.

In contrast to relationship and real-time engagement as themes heavily favored in one mode of learning delivery over another, structure was repeatedly referenced by participants as relevant to their learning but was also shaded in both positive and negative lights in a variety of delivery modes. Take, for example, one participant who experienced structure as a problematic aspect of learning in person: 
I don't learn in a classroom setting. Where I would learn would be in going on a client meeting or actually doing something. I would learn more about venture capital by watching a real deal go down as opposed to sitting in a venture capital class - but a traditional learner would understand the framework, the context, and would expect more structure to their learning.

For this participant, in-person professional learning that took place in a classroom such as classes in a university executive education program represented structured learning, which she found inhibiting to her learning process. Structure is represented in this perspective as a rigid content-focused, in-person learning phenomenon that incorporates pre-set learning frameworks and excludes experiential activity. Another participant levied similar rigidity complaints against online courses, albeit with noticeably different focus:

At GE for example, they had really good financial management modules that had lots of content. However, what was frustrating is that . . every slide had to be clicked through and you had to play all the silly games to go along with the theme. I think that's what it comes down to, how much control you have over your own learning and development. I want to pick and choose what I learn and focus more time on. I don't want to have to go through every slide and play out the silly games because that's how the module was designed.

In this participant's perspective, structure is represented as a rigid control-focused online learning phenomenon that inhibits learners from engaging content in ways that work best for them. Having access to "really good" content is not so much the problem for this participant as is losing the ability to decide how and to what degree to engage the content.

Whether critical about not having enough control or in favor of how much control one can experience in online learning, several participants expressed similar expectations of control over engagement as fundamental to online learning's structure. 
One respondent praised online learning precisely because of how much learning control is available:

I've got control over when and how long I spend on activity and materials. And, the learning style of online provides a different structure and mode from in-person in that it is typically more sequential and individually focused.

This learner expressed unreserved appreciation for both the empowerment online delivery provided over when and how to engage learning as well as the structure of online learning environments which remains unaffected by the needs of others in a learning group.

Further driving home the importance of both content and control in relation to learning structure, a both-and perspective was introduced by a participant who spoke in somewhat more positive terms about the relevance of structure to professional learning's definition, regardless of whether learning is delivered in person or online:

When I really think about professional learning, I think about structured programs and specific associated topics. I'm looking at this from the business perspective and the topic that would further my business or my organization. I'm looking more at labels that tell me the content.

This participant's perspective on structure in professional learning speaks to this theme on two levels: topic-defined programs that guide learner decisions about whether learning will be useful to business; and organizational goals reached via learning. Indeed, this characterization of structure substantively solidified the relevance of content and control in how learners see structure's value for learning delivered in person and online.

Two other themes in the context of structure - commitment and self-discipline-were also presented by participants as both inhibitors and facilitators of value in various modes of learning delivery. Said one participant about a reluctance to learn in person: 
For me personally, that approach would constitute too much commitment in terms of having to be some place when the course dictates.

But about learning online, another participant noted:

I tried an online Coursera type class through Center for Creative

Leadership, but didn't have the time or energy to figure it all out.

And about learning in person learning versus learning online, one participant observed:

I'm a people person, it's my learning style. Online learning works for convenience but requires self-discipline.

Though sometimes referenced together, commitment and self-discipline were not synonymous. Commitment was typically framed in reference to external requirements, while self-discipline was framed as an internal driver of action. Having to be in a location to work on one's education was at once a constraining and valuable discipline-imposing commitment for some respondents. For others, latitude to learn when and how one chooses was a valuable opportunity but also a discipline-demanding motivational challenge.

Throughout the data, commitment and self-discipline were presented as contradictory elements of structure's learning value. The aforementioned snippets represent persistent sentiment in the data that some elements of structure can simultaneously support and inhibit the learning experience. Unsurprisingly, structure's value elements are ones that learners appreciate but nonetheless do not always buy into.

As much as research participants expressed persistent, if contradictory, notions about structure, so too did they express a variety of views about the relevance of discovery to learning. The emergence of discovery as a key characterization of learning ultimately 
begged several questions about the substance of discovery in learning and what particulars about discovery mattered most for learners. When explicitly mentioned in association with learning, discovery was frequently and almost exclusively referenced solely by research respondents who associated the concept with learning in face-to-face settings. Said one respondent about what they valued most about learning in person: I like face-to-face interaction. Brings you to a much greater understanding and discoveries than being isolated, just you in front of a screen.

Most research participants did not necessarily use the term "discovery" to describe their learning or its value but did describe characteristics that represented inexplicable naturalness and fortuitous extemporaneity in their learning. For example, in describing a preference for in-person learning, one research participant noted:

If I have spontaneous questions, it's a lot easier to ask them in person. You can have a back-\&-forth exchange, whereas communicating by email doesn't have that same dynamic.

Not knowing where learning is headed until after questions are asked emerged as a marker of discovery with noteworthy value especially for in-person learning. For respondents, questions and unexpected exchanges and unscripted conversations all served to immediately kick-start thinking through topics and developing new ways of processing, comprehending and internalizing ideas. In the context of spontaneity, question-driven exchange can be interpreted from the data as an ability to customize learning on-the-fly by bringing other people's perspectives and experiences into one's learning mix.

While spontaneity was called out as a key theme of discovery for in-person learning, it took more careful and deliberate culling of the data to find whether a similar discovery- 
oriented theme existed for learning delivered online. Indeed, the notion of value-laden learning customization via discovery existed for online learning, but respondent experiences indicated this learning end is achieved by different means - unplanned and unpremeditated journeys through content connections.

One example comes from a respondent, a student in an online course, who described how an online reading assignment led to fruitful exploration of creativity:

I'm taking this class on creativity and we had this reading assignment that mentioned this creativity method called synectics, which I'd never heard of. So I searched for it online, and ended up on a web site by George Prince, one of the founders. There's some pretty interesting articles and videos, and one of the videos had - in the comments section-something about this Kickstarter campaign for creativity card games. So I clicked to that, and it sounded like a cool way to work on creativity with a group, so I donated to the campaign, and now I'm pretty excited to try these cards. I don't know, I feel like you can't really do that kind of freeform exploring with a lot of other people - you have to be on your own and have room to do that.

This story's details, its run-on cadence and its grammatical structure collectively reflect the continual stream of connections that pulled this learner along an unexpected path toward discovery of a creativity-practice tool. The conjunction "and" is used 5 times as a link between steps along this path, while the transitional adverb "so" is used 3 times to indicate revelatory turns taken along the way. What resulted was discovery of a fundraising campaign several degrees away from the learner's online class but nonetheless providing a highly individualized and rewarding outcome for a learning expedition that began with the simple task of reading an article assigned for an online class.

This kind of fortuitous connectivity is the very embodiment of serendipity, commonly understood as a fortune-bearing combination of curiosity, sagacity and happenstance. Few participants in this research talked directly of discovery in online 
learning. But when they did, the common thread in their perspectives was the importance of the unpredictable connections one can make through online content. These unexpected connections helped customize their respondent learning on-the-fly by bringing a greater expanse of topics and material into their learning experience. One could viably call into question the validity of coding serendipity as a theme for discovery in online learning, given the infrequency of data points to support a prevalent pattern.

Nonetheless, the argument for including serendipity as a discovery-relevant theme for online learning follows Saldana's reminder that "idiosyncrasy" is also a pattern (2008, p.5). That learners explicitly talk of spontaneity in their learning but do not think to reference serendipity, even as they describe it in their connection-laden learning activity, speaks to detection of an aspect of discovery in learning that demands further inquiry. Serendipity makes space for open-ended exploration by encouraging learners to bring the wider online world into their specific learning context. Coding this theme helps direct research attention to opportunity for examination and interpretation.

\section{Qualitative Findings}

As Saldana notes in his coding manual for qualitative researchers: "Qualitative inquiry demands meticulous attention to language and deep reflection on the emergent patterns and meanings of human experience" (1998, p.10). Via similar attention and reflection, the previous Coding Results section showed how data were deciphered (decoded) and labeled (encoded) for categorical organization and thematic meaning. This section now aims to tell the research story to be found in this study's decoded and encoded data. 
As several qualitative researchers have noted, the research story told here is undoubtedly influenced by interview questions asked and not asked, along with how the answers provided were documented, perceived, coded and interpreted (Saldana, 1998; Adler \& Adler, 1987; Rubin \& Rubin, 2012). While subjectivity is arguably inherent in all research efforts, there can be no pretense of objectivity in qualitative undertakings. The qualitative findings presented here cannot presume to tell the only story available from the data. That being said, these findings do illuminate at least one of the research stories available in the data. Hence, we commence with its telling.

\section{Describing and Defining Learning Preferences}

Returning to questions proposed in this research, there are several key findings related to how learners defined and described their learning preferences as well as the aspects of learning experience on which they base their preferences. The first qualitative finding was that learners for the most part tended to associate in-person delivery with productive learning experiences and inconvenience, while online delivery was typically associated with suboptimal learning experiences but with a great deal more convenience and flexibility. The association of online learning with convenience is not unexpected, given reference in this dissertation's Introduction to the prevalent learning industry focus on time- and cost-savings as key advantages of online learning.

Additionally, there was no mention of impersonal in-person learning experienced by respondents. Keeping in mind the range of learning respondents referenced - from continuing education credits to corporate training seminars - it challenges expectations that no respondent had experienced something akin to lecture-style professional courses 
with little to no interaction designed or encouraged between participants. Nonetheless, not a single respondent levied such critique against in-person learning.

Though this absence could have been explored in interviews, it purposely was not in order to leave unaltered the perceptions of learning that respondents had naturally developed over time. Those perceptions were typically skewed with consistent expectations about learning in person and online. One such viewpoint provides a succinct summation of the traits learners frequently attributed as fundamental to each of the delivery modes:

For online learning, the inherent value for me is convenience. I like the fact that I don't have to drive to school and that I can log into class from anywhere. In regards to in-person learning, I think the best aspect of it is the relationships and connections you can obtain by coming to class.

Similar perspective from respondents echoed across the data:

There is a lot of learning that happens in a live, in-person group that cannot be replicated with just online learning. Online learning is great in terms of being able to not have to commute physically and work around a job - but it's not the best way to be saturated in a subject when you are looking to gain from your co-eds.

The requirement to engage in learning at a specific time, in a specific place with a specific group was identified as the primary drawback to learning in person. Otherwise, in-person learning dominated in the realm of fostering connective learning experiences.

\section{Diametric Learning Modalities}

Even respondents who had not engaged in online learning expressed preferences based on expectations about face-to-face learning's ability to provide a more intimate and personally resonate learning experience than what they might - but had not yet experienced online. Said one respondent pointedly: 
If I am going to interact with machines, I will just look up info myself.

Inherent in respondents' perceptions of the two learning delivery modes are two presumptions and a second finding from across the data.

The first presumption is that learning is fundamentally intended, or should at least be expected, to bring people together because in that collective experience is where learning's ability to stimulate new ideas and useful connections is best realized. A second presumption is that technology-mediated learning fundamentally disconnects and isolates a learner from what matters in learning experience, namely direct access to the minds of others.

Taken together, these two presumptions lead to a particular dichotomy of in-person learning's collective assembly as cognitively stimulating versus online learning's technology mediation as cognitively inhibiting. Hence, the second finding that learning in-person and learning online are not only differentiated, they are often dichotomously opposed in learners' perceptions.

\section{Modality Dichotomies and Learning Design}

While the positive-negative dichotomy between in-person and online learning was a prevalent experience, it was not unanimous. Some respondents spoke positively from both a content and connection perspective about online learning, having experienced technology-mediated settings that encouraged conversation, collaboration and exploration. One respondent described such an online experience:

This type of web-based learning that allows peer-to-peer collaboration or teleconference type is interesting. I've undertaken simulation-based work globally with team members based in Singapore, Hong Kong - so you had to do exactly that, teleconference and share resources and it was more of a 
competition scenario. Other than time-zone differences and cultural risk appetites, this worked pretty well because we felt in control.

As this perspective illustrates, online learning can be compelling in similar fashion to learning in person when the learning experience pushes participants beyond the bounds of a confined online space, brings learners together and empowers their discovery process. Unfortunately, as some respondents who happened to be education professionals noted, the overwhelming experience of online delivery is one of constrained approaches to learning design and a pointed lack of participant engagement:

Content modules are the only form of online learning. It's boring and doesn't bring you in contact with peers, and there's no exponential social effects with online learning. It is just a waste of everyone's time and money. I'm under pressure to create online courses at my institution and I won't participate.

And as a respondent on the learner side of this experience discerned:

I use online resources but do not prefer online courses.

Prompted by contradictions between some respondents' positive experiences with non-course online learning and other respondents' persistent association of online delivery with content-constrained online courses, a third finding materialized from the data. The characterizations in this dichotomy that portray online learning as the lesser delivery mode are not a function of an inherent flaw in the delivery mode. Rather, this dichotomy is the outcome of learning designs participants have experienced in these delivery modes - online learning itself is not suboptimal, but learning design for online delivery often seems to be. 
Where participants had experienced technology-mediated learning that was broadreaching and connective, negative characterizations of online learning were not as prevalent. A respondent speaking to blended learning's benefits confirms as much:

The intensity of sharing in learning with others, access to a broad range of perspectives and experience through in-person learning coupled with downtime to access facts, contemplate by reading, researching on-line materials - this is what works for me with having both options together.

This respondent's perspective along with others in the data provide models for how learning design could shift learner experience beyond the dichotomy of in-person learning having a social advantage and online learning having a convenience advantage. Learning perspective and experience indicate all delivery modes can be infused with similar connection-oriented positive aspects assigned to face-to-face delivery. This shift is a matter not of delivery platform but rather of design.

\section{Modality Preferences and Content Suitability}

Furthering dichotomous characterizations between in-person learning and online learning is a fourth finding in the qualitative data about the relevance of content to learning experience and delivery preferences. Based on what respondents believed was the purpose of professional learning, they often characterized topics as either more suitable for in-person delivery or for online learning but rarely suitable for both, regardless of whether any given topic had successful examples in either delivery mode.

Thus, the data's fourth finding is that while topics generally do not show themselves to be better suited for one delivery mode or another, respondents nonetheless perceive them as such, based on their learning experiences and expectations. For example, an 
architect expounding on the effectiveness of in-person learning versus learning online expressed definitive views on the subject of suitable topics for learning online:

It really depends on the format of the information you are trying to communicate. I have recently taken Real Estate classes online through the community college system, which is appropriate. Architecture in this format would not have been appropriate.

Interestingly, when asked what learning mattered most for execution of day-to-day professional responsibilities, the respondent mentioned keeping up-to-date on relevant software tools (e.g. AutoCAD, Chief Architect, ConceptDraw Pro), which a cursory Google search reveals are all widely taught online. Though technology skills necessary to architecture could potentially be taught online with success, the subject of architecture was deemed unsuitable for a technology-mediated learning experience. While there were conflicting perspectives about whether some topics and skills should or could be taught in any one delivery mode or another, there seemed to be no equal-opportunity topics or skills that respondents expected to learn just as well in either delivery mode. Said one respondent about learning software skills in face-to-face settings:

For tech-related classes, online usually works for me because I'm a quick learner, and in-person classes seem slow.

Based on their experiences, respondents generally spoke definitively and in absolute terms about whether any given topic would work online or in person - regardless of whether they were discussing project management, leadership development, credentialing courses or technical learning. One respondent adamantly insisted that "design classes do not work online" despite discussion during the research interview of the existence of multiple online design courses and degrees from myriad skill accelerators as well as reputable institutions such as Parsons School of Design and the Savannah College of Art 
and Design. As with positive and negative characterizations of in-person learning versus online learning, respondent perspectives around what suitable and unsuitable content in various delivery modes were based as much - if not more so - on what respondents expected to be suitable as opposed to what content inherently does or does not work in any given delivery mode.

Speaking to the final research question to be addressed, the next set of four findings from qualitative data focus on how participants who expressed learning delivery preferences subsequently assigned meaningful relevance for learning to their day-to-day professional lives. Presented as findings are four primary conceptualizations of professional learning to emerge from the data-Learning as Relationship, Learning as Real-Time Engagement, Learning as Structure and Learning as Discovery. These conceptualizations are supported by several sub-themes captured in coding as representative of how learners characterized and experienced the value of learning.

\section{Learning as Relationship}

As previously mentioned, respondents' generally believed that learning inherently requires collective experience for cognitively stimulating connections. Hence, it is not surprising that respondents placed significant importance on social environments, groups, peers and connectivity as elements of relationships in learning. An oft-expressed sentiment was the assertion that learning does not happen as well on one's own:

\section{I like face-to-face interaction. Brings you to much greater understanding} and discoveries than being isolated - you in front of a screen.

As referenced earlier in the Coding Results section, however, this sentiment was by no means unanimous, especially for respondents who insisted the commitment of in- 
person learning was too demanding for their lives or taxing for their individualistic learning style. But given the prevalence of this perspective across respondents and in relation to both in-person and online learning, learning as relationship is clearly a resonant reality for many learners who expect social environments to foster cognitive connections.

An additionally relevant aspect of learning as relationship was the opportunity afforded in social environments to connect with others not just for ideas, but also to experience relational intimacy and thereby more effectively expand professional networks.

Respondents spoke favorably of how in-person learning especially could make space for useful connections:

In my mind, professional learning encompasses networking, which isn't about broadening one's skillset but about creating connections to use your skills.

One respondent insisted that even nonlearning environs should be leveraged to foster greater personal connectivity, which would further learning:

An event at a bar with a little food and drinks could help us network more than a stuffy lecture. Learning does not always have to be so rigid and conformed.

In an articulation of learning as relationship-making between people as well as concepts, one can indeed argue favorably for a notion of learning value that manifests amidst the casual conviviality of refreshments and conversation. Respondents clearly find meaningful relevance for learning in their day-to-day professional lives when their learning is socially infused with peer connections, relational intimacy and networking that advances not just what they learn but also prospects for leveraging their learning. 


\section{Learning as Real-Time Engagement}

In close association with learning as relationship, respondents also found meaningful relevance from real-time engagement with others during learning. Respondents described a relevant sense of enrichment coming from interaction with others:

I like the experience of being there, being able to converse with the instructor in person, meeting peers, developing relationships. I would never take a class that I care about online, just because it's lacking in the personal experience.

Alongside its status as an essential element of relationship-building, interpersonal interaction mattered for many respondents because, in their experience, the combination of verbal and nonverbal communication along with conversation's immediate feedback loops helped to better inform and guide their learning. The dynamism of interaction enlivened the learning experience for respondents in a way many - but not all - insisted could not happen in a technology-mediated learning environment.

Respondents felt similarly about receiving direction during learning and the necessity of real-time engagement for that direction to satisfy immediate learning needs:

With online classes, a person could think of a question at work while their brain is being stimulated and not be able to ask it and possibly forget by the time they get to a communication device.

Regardless of what delivery mode respondents believed was optimal for interaction or direction, the key notion here is that participating in learning experiences without dynamic interaction and/or prompt direction lessens the learning experience overall for learners who rely on fully informed communication and conversation to better comprehend and process the information and ideas they are encountering. 


\section{Learning as Structure}

For learning as structure, two aspects of the data are worth noting: firstly, that respondents clearly experienced a sense structure in both delivery modes; but secondly, there was no clear consensus to be drawn from respondent experiences about whether any one mode offers more learning structure than the other or whether thematic elements of structure experienced in either mode were consistently more or less productive to learning.

For example, respondents called out content and control as pertinent elements of learning structure because content sets the bounds for learning, while control allows learners to override those bounds and exert influence over their own learning. The degree, however, to which content or control was perceived as a more rigid determinant of learning's structure in either delivery mode led to contradictive insight from respondents. Some insisted "collaboration and discussion" in face-to-face learning offered more opportunities for "meandering, versus the structured environment of online."

Other respondents insisted in-person learning provided "a more definite structure" than learning online because learners in face-to-face classes are unable to deviate in realtime from curricula or lectures to take self-determined "shortcuts based on relevance or interest." If these contradictory experience-based perspectives are taken as equally valid, then content and control can be seen as equally elemental in either delivery mode.

Regarding commitment, most respondents characterized in-person learning as commitment-intense because of innate expectations of interpersonal exchange as well as temporal and geographic requirements. But for some respondents, online learning was 
considered more commitment-intense based on their discomfort with the highly organized curriculum that can accompany online courses and the self-discipline needed to meet inflexible time-bound delivery expectations. Once again, while respondents found learning relevance from similar aspect across delivery modes, several points of divergence existed in the data between respondent experiences and evaluations of learning value in any given delivery mode. Indeed, it seems the only definitive statement that can be commonly said about all thematic elements of learning structure discussed here is that they fundamentally seem to matter, regardless of how or where learners are learning.

\section{Learning as Discovery}

In contrast to multiple and divergent areas of relevance for several aspects of learning structure across delivery modes, the two thematic elements most associated with learning discovery - spontaneity and serendipity - each emerged as meaningful in either

one learning delivery mode or the other. Across the varied experiences, when respondents prioritized interpersonal exchange as a path to learning, real-time interpersonal engagement mattered most. But when respondents prioritized content engagement as their imperative, online delivery seemed to speak more to their learning needs.

Based on the respondent experiences and perspectives previously discussed in Thematic Coding, spontaneity has been interpreted from the data as unpredictable moments of discovery resulting from interpersonal interactions. Spontaneity in learning is driven by questions, answers and conversations that come about unpredictably. Particularly for in-person delivery, where questions, answers and conversation can flow 
quickly, easily and freely, this thematic element of learning discovery facilitates iterative drill-down into topics and allows learners to take related tangents where needed.

Serendipity, meanwhile, is best described from respondent experience as trails of discovery resulting from actively exploring topics online. Serendipity happens when learners have been actively working toward making connections. To this end, serendipity is naturally unpredictable but is not accidental. It is the outcome of connective effort in learning. Online learning provides freedom, time and an infinite amount of content for self-determined wandering from idea to idea, theme to theme, and connection to connection. It is this continual connection-making that leads learners to unexpected discoveries with value specific to their unique learning aims and efforts.

As mentioned in the coding discussion, learners seem to easily recognize the presence and value of spontaneity when learning in person, given the explicit importance some respondents placed on this phenomenon for their learning. But even those respondents who called out the importance of self-driven exploration in online learning may not recognize serendipity as part and parcel of their learning experience likely because that aspect of learning is indistinguishable from similar online exploratory activities aimed at mental escapism or entertainment such as following blog post links or reading YouTube video commentary. Nonetheless, as thematic elements of learning discovery, spontaneity and serendipity generate similar value for learners: an ability to stimulate unexpected ideas and insights which in turn drive and expand knowledge and skill acquisition. 


\section{Summary of Analytical Findings}

Driven by this study's research questions, a total of 15 findings materialized from quantitative and qualitative investigations, all of which are summarized in Table 24:

\section{Table 24}

Research Questions and Findings

\begin{tabular}{|l|l|}
\hline Research Question & Finding \\
\hline $\begin{array}{l}\text { 1. Are there differences in } \\
\text { mreferred learning format between } ~\end{array}$ & $\begin{array}{l}\text { Finding 1: Learners show no markedly different } \\
\text { gender-related preferences for online or in- } \\
\text { person learning delivery. }\end{array}$ \\
\hline $\begin{array}{l}\text { 2. Are there differences in } \\
\text { preferred learning format between } \\
\text { professionals in varied age groups? }\end{array}$ & $\begin{array}{l}\text { Finding 2: Younger professionals prefer } \\
\text { learning in-person more so than learning online, } \\
\text { while older professionals are more open to } \\
\text { mixing online learning with in-person delivery. } \\
\text { Finding 3: While age and learning mode } \\
\text { preference show a significant relationship, there } \\
\text { is not by extension a strong predictive } \\
\text { relationship between the variables. }\end{array}$ \\
\hline $\begin{array}{l}\text { 3. Are there differences in } \\
\text { preferred learning format between } \\
\text { professionals who have engaged in } \\
\text { learning online and people who } \\
\text { have not? }\end{array}$ & $\begin{array}{l}\text { Finding 4: Learners who have experienced } \\
\text { online delivery are more open to technology- } \\
\text { mediated learning as a delivery option. }\end{array}$ \\
\hline $\begin{array}{l}\text { 4. For participants who indicate } \\
\text { learning format preferences, how } \\
\text { do they define and describe their } \\
\text { preferences and on what aspects of } \\
\text { the learning experience do they } \\
\text { base their preferences? }\end{array}$ & $\begin{array}{l}\text { Finding 5: Learners for the most part tend to } \\
\text { associate in-person delivery with productive } \\
\text { learning experiences and inconvenience, while } \\
\text { online delivery is typically associated with } \\
\text { suboptimal learning experiences but with a great } \\
\text { deal more convenience and flexibility. } \\
\text { Finding 6: Learning in-person and learning } \\
\text { online are not only differentiated, they are often } \\
\text { dichotomously opposed in learners' perceptions. } \\
\text { Finding 7: This dichotomy is the outcome of } \\
\text { learning designs that participants have } \\
\text { experienced in these delivery modes - online } \\
\text { learning itself is not suboptimal, but learning } \\
\text { design for online delivery often seems to be. } \\
\text { Finding 8: While topics generally do not show } \\
\text { themselves to be better suited for one delivery } \\
\text { mode or another, respondents nonetheless }\end{array}$ \\
\hline
\end{tabular}




\begin{tabular}{|c|c|}
\hline & $\begin{array}{l}\text { perceive them as such, based on their learning } \\
\text { experiences and expectations. }\end{array}$ \\
\hline $\begin{array}{l}\text { 5. For participants who indicate } \\
\text { learning format preferences, how } \\
\text { are these participants describing } \\
\text { and interpreting meaningful } \\
\text { relevance for learning in their day- } \\
\text { to-day professional lives? }\end{array}$ & $\begin{array}{l}\text { Finding 9: Participants who expressed learning } \\
\text { delivery preferences subsequently assigned } \\
\text { meaningful relevance for learning to their day- } \\
\text { to-day professional lives based on four primary } \\
\text { conceptualizations of professional learning: } \\
\text { Learning as Relationship, Learning as Real- } \\
\text { Time Engagement, Learning as Structure and } \\
\text { Learning as Discovery. } \\
\text { Finding 10: Learners place importance on social } \\
\text { environments, groups, and peers along with the } \\
\text { networking and intimacy of connectivity as key } \\
\text { elements of relationships in learning. } \\
\text { Finding 11: Learners place importance on } \\
\text { verbal and nonverbal communication, } \\
\text { collaboration and feedback as key elements of } \\
\text { immediacy experienced in the interaction and } \\
\text { direction of real-time engagement. } \\
\text { Finding 12: Learners place importance on } \\
\text { content, control, commitment and self-discipline } \\
\text { as key elements of structure in learning. } \\
\text { Finding 13: There is no clear consensus from } \\
\text { learners about whether any one learning delivery } \\
\text { mode offers more learning structure than the } \\
\text { other or whether elements of structure } \\
\text { experienced in either mode are consistently more } \\
\text { or less productive to learning. } \\
\text { Finding 14: Learners place importance on } \\
\text { spontaneity (interpersonal moments) and } \\
\text { serendipity (content-driven connections) as } \\
\text { elements of discovery in learning. } \\
\text { Finding 15: Learners find spontaneity to be of } \\
\text { particular relevance in face-to-face learning, } \\
\text { while serendipity is most resonant when learning } \\
\text { is delivered online. }\end{array}$ \\
\hline
\end{tabular}




\section{CHAPTER V}

\section{CONCLUSIONS}

\section{Key Explanatory Concepts}

Grounded theory mandates that explanations of these elements as research phenomena be steeped in and emergent from this specific research endeavour. In keeping with this framework, the emergent insight generated from systematic examination of this study's data suggest several key conclusions and explanations for why learning is valuable in different modalities. Described here as learning preference premiums, ubiquitous blend and absolute proximity, the explanatory concepts emerging from this study's findings offer several relevant implications for learning design and delivery.

\section{Learning Preference Premiums}

As previously noted, one of the more striking findings in this study was the strong preference among respondents in their 20s for in-person learning delivery in such sharp and unexpected contrast with respondents in their 30s and older who preferred a mix of delivery modes and were more amenable to learning online. These lopsided agedelineated preferences meant that online learning's value-drivers (e.g. control over one's learning experience) were most appreciated by respondents who were older and preferred to "pick and choose" their areas of learning focus. Relational and engagement-focused benefits of learning in person, meanwhile, were most preferred and appreciated by younger respondents who "like the experience of being there, being able to converse with the instructor in person, meeting peers, developing relationships."

In-person learning preferences existed for learners who put a premium on relationships, face-to-face interactions and real-time feedback. And, this premium was 
particularly high among younger professionals. The value of these learning aspects is their effect not just how leaners learn but also the content and substance of learning. Older learners showed more task-orientation in their learning preferences, with a premium placed on learning modalities and configurations that allowed learners to do work when they wanted, manage their learning process and own more accountability for the act of learning. These preferences were also noted by respondents to affect both the substance and depth of learning.

Given the prevalence of relational- and engagement-related value drivers for inperson learning preferred by 20 -somethings, it seems professional learning is largely a relational and engagement-focused experience for younger learners but transitions to a more utilitarian and purpose-focused experience as learners get older. Put simply, the purpose of learning changes as learners grow in their careers and look to expand their skills and networks in ways that balance day-to-day and professional responsibilities.

Young people begin their professional learning as they begin their professional lives, in an exploratory mode that benefits from and relies on engaging in networks and fostering like-minded connections. Young people are also often coming into their professional lives from socially-driven endeavors such as on-campus college courses, team sports and organized activities. With this in mind, it stands to reason that for younger professionals in learning - as in life - high value is placed on peer relationships, group engagement and the immediate feedback loops of direct interaction. Older professionals, on the other hand, who prefer mixed modes of learning value in-person learning's benefits but are also more specific and deliberate about their learning needs. While the convenience of online learning does in fact help with navigating the pull of 
multiple of responsibilities, the self-directed nature of online learning is also beneficial to older professionals who are likely to be more purposeful about what they need to learn and who are likely to have more experience-driven clarity about how they expect to apply their learning.

Does this mean organizations and learning providers working primarily with younger professionals should focus learning efforts face-to-face delivery? To be clear, even if learning providers wanted to focus on in-person-only delivery, such an approach may no longer be plausible. As the opening lines of this dissertation state, technologymediated learning is the new normal. normal. Recall from this dissertation's Introduction that some state school systems now require high-schoolers to complete an online course before graduation, more college courses are coming online each year, and technologymediated learning for professionals has expanded across the Internet. The cost and efficiency pressures on learning businesses coupled with the prevalence of learning online makes a return to in-person-only learning for professionals highly unlikely, if not wholly inconceivable.

Also, recall from Styer's (2007) research referenced in the literature review for Learning Value, some adult learners choose online delivery precisely because the social aspects of learning do not interest them. Learners who prefer to exert direct control over their learning, who naturally possess the self-discipline and commitment to engage content sans community, and who thrive on self-driven discovery will undoubtedly find online learning a productive experience befitting their inclinations.

But if conclusions drawn from this research are accurate in illuminating young professionals' relational/engagement preference based on the value they associate with 
learning in person, one must question the sensibility of bringing more young people into online learning without attending to their overall perceptions of learning value. Indeed, this relational/engagement preference among young adult learners suggests particularly thoughtful efforts should be put forth in online learning design and delivery to insure these learners have engagement as part and parcel of technology-mediated learning.

Thus, a key implication for professional learning design and delivery is, if relationships and real-time engagement are premium drivers of learning value for young adult learners, these elements should be diligently and deliberately intertwined with learning aimed at young adults and offered as experiential options. And, this should be so even when learning is delivered solely online. For learning practitioners, this implication puts the onus on us to understand the degree to which our learning audiences find value in group and peer engagement, real-time discussions and collaboration so that we can creatively deliver on that value regardless of learning modality.

Whether via formal means such as pre-learning assessments or more informal means such as group polling, we learning providers would benefit from practicing more mindfulness about whether the learning experiences we want to insure for participants align with whether learning participants place greater value on having people in their learning process or being task-focused in their learning process. No matter the learning modality or intended outcomes, we need to know, for example, whether we are working with a collection of mostly people-driven learners so that even an online-only learning engagement is designed to include high-quality connection and collaboration. What cannot be stressed enough from this dissertation's findings is the need for learning practice to bring a greater participant-oriented mindfulness to learning design. 


\section{Ubiquitous Blend in Learning Design}

A second standout conclusion to arise from this study's findings on modality-driven learning value is the concept of ubiquitous blend. Now that learner preference and experience has illuminated unique and shared learning value across modalities, ubiquitous blend is an explanation of why and how learning practitioners should and can move away from singularly conceiving of learning as designed either for in-person learning or for online learning. Even practitioners planning to deliver in one modality or another could conceive of learning value in more expansive terms and presume a simultaneous need for each learning delivery mode's value in all learning engagements.

Recall from this study's findings that a mix of both in-person and online learning delivery was most preferred by learners in the smaller primary research group who were older than 50 as well as those who had experienced online learning. And in the larger survey test research group, a blend of modalities was the second-most preferred modality across age, gender and online learning experience. Based on respondent experience, this study also revealed learning delivery mode bias related in no small part to respondents' experiences of suboptimal learning design for online delivery.

Combining learner preferences with respondents' insight into how they value learning, the basic message of ubiquitous blend is that learners do not prefer to choose nor should they have to choose - which value set they experience in learning. As Nate Edwards, Vice President of AT\&T University, notes of learners in the organization's online professional development programs: "It's really critical that those learners have the support of a coach, peers, community of practice and anyone else who can help them 
digest the material. And where we're transitioning now is, the technology has made it such that we can be much more engaged to bring that learning to life" (Udacity, 2016).

Indeed, learning practitioners who put their minds to it could take any number of creative approaches toward a ubiquitous blend of modality value, either seeking to pull the relational and engagement advantages of in-person learning into online delivery or the self-directed control and discovery advantages of online learning into face-to-face delivery. The social bookmarking and web annotation tool Diigo, for example, helps learners build common online learning libraries to knowledge-share, engage in learning community and open additional avenues of self-driven learning discovery. Exposing learners to social bookmarking tools could drive peer-powered learning, build shared learning environments and open discovery-driven options for encountering new content.

From the perspective of ubiquitous blend, mindfulness on the part of learning providers is key to recognizing that cross-modality benefits are collectively indispensable in learning engagements. With this perspective in mind, the task at hand for learning providers is to make a standard practice out of bringing all learning value to bear in learning design. As both an explanation of learning preference and a conceptualization of learning practice, ubiquitous blend assumes an ever-present learning necessity for tapping the people-oriented benefits of in-person alongside the task-oriented benefits of online delivery. This explanatory concept offers a new frame of mindfulness and new methods learning practitioners can adopt to capture and deliver a wider range of learning value.

As noted in data analysis, respondents in this study were more vocal in their critique of poorly designed online learning experiences than similar experiences they may have had with in-person learning. Still, it is both risky and suboptimal learning practice to 
presume the presence of in-person learning's relational and engagement value simply because learners convene in a common location and sit next to one another for learning. Silo-inducing learning situations can arise in large-group face-to-face settings (e.g. 80person training programs) as much as they can in online learning.

Technology can be of service in breaking through the isolation that individual learners might experience in such face-to-face and online learning scenarios. Learning providers, for example, can bring nonverbal communication and the immediacy of interaction into learning with personal analytics like the Mood Meter emotional intelligence application and with interactive activities such as quick pulse polling with the Poll Everywhere online application for real-time feedback and engagement. Online portfolio services such as Pathbrite are yet another mechanism for direct feedback in learning environments with barriers to personal connection. Participants can showcase the transformation of their professional learning into project deliverables and receive feedback from their learning providers and from their learning peers.

Even the most perfunctory professional training such as compulsory online-only anti-harassment courses which are standard fare at most American-based companies could be designed to include the ubiquitous blend approach. Participants, for example, could participate in crowd-sourced question-and-answer forums similar to Quora.com and work collectively as peers on sharing best practices for substantive learning about real-world challenges. By leveraging technology-mediated combinations of group- and content-focused activities, learning practitioners can seed their learning environments with the relational, engagement, structure-based and discovery-oriented value learners experience across modalities. 
When learning providers bring learners together, we serve them best with proactive design and delivery of an intentionally transformational experience. Do learners want to feel connected and engaged? Would discussion and collaboration notably improve digestion of their learning content? Is there, for example, opportunity to leverage offline meet-ups, learning captains for designated support, or peer-to-peer labs for personally connected learning? What opportunities will learners have for exploration? And, does the learning structure support learner control over learning experience, encourage learners to keep their commitments, and incentivize their self-discipline? Deliberately attending to such questions can help insure learning is intentional about building relational, engagement, discovery and structural value that is ubiquitous across modalities.

\section{Absolute Proximity in Learning Delivery}

Absolute proximity is the third explanatory concept to emerge from this study's findings with implications for how providers could offer more effective learning and how organizations could more precisely assess professional learning's effectiveness.

Succinctly put, absolute proximity is a thorough blurring of the lines between work and learning such that the two contexts are indistinguishable. While similar to on-the-job training or learning by doing, absolute proximity is conceptually differentiated by a distinct technology-mediated merger of work and learning contexts that deliberately supports professionals in achieving full applicability of their learning.

Some of the perspectives from this study's participants framed online learning as an embedded learn-work experience driven by course designs that utilized their actual work and were tailored for their immediate responsibilities. Recall participants with positive online learning experiences who talked of video modules and peer collaboration 
combined with downloadable materials for applied learning that heightened learning's immediacy and relevance to their professional roles. These experiences highlighted a technology-driven approach to professional learning that intentionally blended learning into a learner's work.

The concept of absolute proximity as experienced by this study's participants is also practically reflected in recent approaches to virtual coaching discussed in the Training Transfer section of this dissertation's Literature Review. Coaches who can observe, interject and engage teachers during their real-time workflow offer the kind of learning that blurs dividing lines between learning and working, or training and transfer.

Equally compelling is the recent introduction of highly-quality 360-degree viewers and virtual reality (VR) headsets compatible with every-day smartphones. Physical movement in wearable virtual reality goes so far as to deceive the brain into thinking what is seen is real on conscious and subconscious levels, generating a sense of "visceral intimacy" (Wohlsen, 2015). This technology sends users journeying from a first-person perspective through myriad virtual worlds: scientists in training can stand on a conjured Mars, while health care providers in training can voyage neuron-by-neuron through the virtual brain of a mental patient. Wearable VR users can experience "being virtually anywhere" (Konnikova, 2015), to include learning settings where their work has immediate relevance, or work settings infused with applied experiential learning.

Another technology-enabled facilitator of absolute proximity is the combination of project-based learning design and multiplatform learning delivery. Upstart providers of online professional learning such as the edtech company Udacity are capitalizing on the joint ability of project-based design and multiplatform delivery to heighten absolute 
proximity's impact. Project-based design insures concepts in learning directly relate to activities in business. "It's not just a course and a test," notes Scott Smith, Senior Vice President of Human Resource Operations at AT\&T, a Udacity partner in certification programs for software developers. "You're actually doing a project, so it's virtual handson ... I think that's really important" (Udacity, 2016). Multiplatform delivery over smartphone, tablet and desktop computer further facilitates the learn-work merger by making it possible, as Smith says, to "be anywhere, anytime doing your learning."

From downloadable online tutorials to immersive virtual realities, technology in the current era of professional learning has altered content accessibility and physical realities. In this era, training generalization is arguably no longer necessary for learning to exert its effects. This is because in technology-mediated absolute proximity, learners do not experience training as an additional task to be done on the job or transferred to the job. Rather, they experience professional learning as indistinguishable from the job itself. The larger purpose of this dissertation's research on the value of professional learning in varied modes of delivery was to reveal and reinforce good indicators of professional learning's effectiveness. Overall, respondents held to the perspective that the most substantive measure of professional learning's effectiveness is whether learning builds new skills and changes their performance in their professional roles. With no dividing lines between what professionals learn to do and what they actually do for a living, absolute proximity as a practice could be a strong facilitator of learning effectiveness in the context of learning designed for working professionals. 


\section{Implications for Theory}

Given its focus on learning value, this study's standout theoretical implication relates to training transfer theory, which has historically represented learning value in adult professional learning. Since training transfer theory emerged in 1901, there have been no fewer than five major transfer models - Woodworth and Thorndike, 1901; Judd, 1908; Stokes and Baer, 1977; Baldwin, 1988; Laker, 1990; Holton, 1996 - aiming to uncover and confirm factors affecting how learning transitions from its original context to its intended context of practice. Findings from this dissertation did not lead to yet another theory for training transfer, nor did they diminish the relevance of transfer research.

Instead, in a departure from training transfer theory's framework for learning value, this study revealed that from the perspective of learning participants, transfer of learning from on context to another is neither the sole nor primary explainer of learning value. Just as integral are experiential elements occurring across and within learning modalities that lead learners to focus on learning's purpose as an essential expression of its value.

As mentioned in this dissertation's Grounded Theory section, this study was to be guided by learner experience toward explanation of what constitutes learning value and how that value is generated in various learning modalities. This quest for learning value was driven by a practitioner-based need for "good indicators of learning" as described by Driscoll (2005). Since the degree of training transferred has been found in research to be no better than $40 \%$ in some cases and as low as $10 \%$ in others, a key driver of this exploration was a disconcerting scarcity of representative understanding in the research canon about value in learning for professionals beyond the realm of training transfer. 
As mentioned in the Descriptive Coding section of this study's qualitative analysis, participants in this study's expected professional learning to "improve the way I'm doing my job" as an indication of its value. And, this expectation that professional learning should change professional abilities resonates well with Holton's (1996) training transfer model of learning outcomes driving notable change in individual performance. But participants also saw learning as having multiple functions in their professional and personal lives and hence valued applicability based on the potential to leverage learning for varied purposes.

Recall this study's participants who spoke of "taking away something you can use" from professional learning for a variety of purposes such as skills improvement, career change and continuous learning. These perspectives were shared in response to openended learning value-related questions that did not direct participants to discuss transfer but would have certainly allowed for a focus on transfer, had that been most important to participants. Hence, while this dissertation makes no claims to have studied training transfer, what emerged from this research was clarity about learning value that extends beyond training's transfer from one context to another.

Transfer-related research on professional learning's value has typically linked learning effectiveness with retention, improved performance and generalizability from learnings environment to work environments. In this learner perspective-focused study, professional learning's effectiveness was gauged by its range of purpose - that is, whether learning applicably improved skills, advanced careers or contributed to self-betterment. With the opportunity to define learning value as they saw fit, participants chose to focus not so much on learning's contextual shift but rather on its function in their lives. 
As participants noted from their experiences, professional learning is a multi-faceted opportunity to fill "the gaps of practical knowledge" and "practice what you've gained" while "learning how to transition into advanced roles" in one's career. For researchers unsatisfied with training transfer theory's context-based attempts to identify, explain and measure learning value - efforts that are frustrated by training transfer's persistently low rates - this study suggests potentially fruitful insights might also be found via exploration of learning's function to determine, describe and measure learning value.

On the other hand, for researchers who find resonance and utility in training transfer theory's frameworks for learning value, this study could also support attempts to expand theoretical conceptualizations of training transfer. A broader characterization of training transfer may be worth considering if it helps transfer theory accommodate aspects of learning experience related to delivery modality, which emerged in this study as relevant to defining learning value.

It is worth restating that the importance of learning transfer to the understanding of learning value is not in question here. Indeed, transfer has proven both relevant and informative for this study's key concept of absolute proximity, which connects to skillbuilding to immediate applicability. Learners recognize and value the benefits of learning proximity. Respondents in this dissertation, for example, talked of advantages for their professional development from incorporating their work assignments into functional skills learning such as financial modelling.

Hence, one of this study's potential propositions for training transfer theory is absolute proximity as an affirmative response to Clardy's (2006) question of whether transfer remains a relevant measure of learning value in technology-mediated learning 
contexts. If this dissertation has brought useful learning value conceptualizations to light, it has done so by echoing Clardy's inquiry about how to further explain and predict learning value in varied learning modalities. This study's concept of absolute proximity could contribute to further investigations of learning value in training transfer theory.

\section{Implications for Further Research}

\section{Learning Function, Proximity, Transfer \& Value}

With this study's theoretical implications in mind, researchers could take up the conversation this study has begun on learning function and absolute proximity as nextgeneration complements and supplements to learning value and training transfer.

In this study, when learning for professionals was explored from the perspectives and experiences of adult professionals, the function of learning stood out as a relevant driver of learning value. But even with multiple samples from varied populations, this single study can only encourage - as opposed to define - discussion of the relevance learning's purpose has for learning value. Additional research could do much to operationalize learning function, uncover its predictive variables and validate relationships between function and value in learning for professionals.

Researchers might also do well to delve into the learning value of absolute proximity and challenge the degree to which this concept can push transfer-as-learning-value discussions to a next explanatory level. The relevance of absolute proximity as a conceptual explanation of value in professional learning harkens back to Stokes and Baer's (1977) theoretical consideration of a learner's ability to generalize beyond the learning context as both a training outcome and as a trainable behavior. If near transfer is more likely when training reflects the workplace, full transfer is more likely with absolute 
proximity's merger of work training with the workplace. Because learners can engage in a wide array of technology-enabled activities in this fusion of learning and work, researchers could follow Stokes and Baer's theoretical example and pursue absolute proximity as both an outcome of learning designed for transfer and as a fundamental shift in learner behavior necessitated by the merger of learning and work.

\section{Learner Personality \& Learning Modality Value}

Another recommended avenue for further exploration is the influence of learning style and learner personality on perceptions and experiences of learning value in various delivery modalities. In the context of this dissertation, learners personality is used as an umbrella term for both learner temperament and learning style.

Learner temperament is understood here as emotional and behavioral tendencies influencing interpersonal communication and relationships, while learning style is understood as the varied ways learners absorb and process information. Temperament dimensions stem from extensive and varied "measures of psychological functioning" (Kelly \& Jugovic, 2001) such as the Jungian Type Survey, Myers-Briggs Personality Type Indicator, Millon Index of Personality Styles and Keirsey Temperament Sorter II. These measures cover an array of dispositions such as introversion, extroversion, agreeableness, conscientiousness, persistence, adaptability, distractibility and penchant for structure. Learning styles also include varied measures and taxonomies of cognitive exploration, from Felder and Solomon's learning styles index (Felder, 1996) to Fleming's (2006) VARK framework for identifying visual, aural, read/write and kinesthetic learners.

While this dissertation's research suggests young professionals prefer face-to-face learning's relational/engagement value, personality considerations are warranted for 
learners generally, such as those examined in Styer's (2007) meta-analysis who preferred online learning unfettered by "socialization and collaboration activities" (p.114). The influence and implications of temperament and style on learners' modality preferences, particularly learners who trend against expectations, could offer telling explanatory signals for how learning modalities generate value across personalities. For example, given Styer's reference to students who neither want nor need to participate in social aspects of instruction to be successful learners, a particularly relevant research question one could ask is the degree to which learner tendency toward introversion or extroversion affects whether preference is shown for learning in person or learning online.

Education researchers have long recognized engagement and communication preferences stemming from learner inclinations toward introversion or extroversion. In their examination of what makes for successful student-teacher interaction and impact in music education, for example, Hanson et al. (1991) identified performance dominance for learners with the kind of sensing and thinking personalities predisposed to working well with concrete, practical and procedural details and typically associated with extroversion.

This extroverted personality type also dominated education leadership, according to Hanson et al., creating systems of school governance, curriculum design and teacher evaluation with an emphasis on "the values of facts, figures, procedures, skills, drill, repetition, effort, and authority" (p.31). A main focus of the Hanson et al. research was educator awareness about how learning personalities affect classroom organization and curricula. The Hanson-Silver Learning Preference Inventory (LPI) was designed as a means of helping educators identify, reflect and plan for the challenges of managing temperamentally diverse learners in temperamentally biased learning environments. 
Continuing the thread of linking temperament to learning experience, the best-selling 2012 Susan Cain book Quiet: The Power of Introverts in a World that Can't Stop Talking sharpened current understanding and heightened the profile of introverts, whose need for processing, reflection and solitary time to mentally reenergize has long been misconstrued as a personality tic of the shy and socially averse. Cain's work raised the question of whether a proliferation of learning environments designed for collaborative and active participation inherently favored extroverted learners who tend to think out loud and benefit from group discussions while disadvantaging introverted learners who benefit from time to read, write and reflect before participating in verbal exchanges.

Potentially provocative follow-on questions raised by this dissertation and other learner-preference research work such as Styer's include whether online learning designed with a lack of relational and engagement value serves learners of particular temperaments at the expense of learners with dichotomous temperaments. Exploring the nexus between introversion and extroversion, learning modality preferences and learning value assigned to modalities from a learner perspective could produce mechanisms of learning delivery with distinctly designed paths to participation that reach more learners with greater effectiveness.

\section{Learner Motivation \& Learning Modality Value}

As seen in the literature reviewed for this dissertation, motivation is often at the center of learner-focused investigations into learning outcomes and training transfer. Researchers seek to know what moves learners to engage in and apply their learning and the degree to which intrinsic motivation (e.g. one's sense of self-efficacy) or extrinsic motivation (e.g. learner perception of instructor expertise and passion) affect learner 
performance. Despite references to motivation in literature, motivation did not feature in this dissertation's analysis for one primary reason: the subject of motivation did not emerge from the data strongly enough to be counted as a driver of learning value.

This lack of prevalent motivation-related data may have stemmed from having probed participants only about how they prefer to learning and where they find value in learning, and not inquiring as diligently about how learners do not prefer to learn and where they do not find learning value. Perhaps closer examination of learner preferences and learning value from both angles would have yielded a fuller picture of learning motivation in relation to learner modality.

Despite this study's single-sided research focus, hints of motivation's relevance to learning value did emerge in themes related to structure in learning. Learner perceptions and experiences brought to light the importance of self-discipline, commitment and control in determining value for online and face-to-face learning delivery. The types of value that learners ascribed to structure's subthemes align with several intrinsic and extrinsic motivation-related themes in previously referenced learner-focused studies such as Styer (2007) and Maxfield (2008). This alignment lends credibility to the idea of motivational themes playing a more prominent role in data on learning modality value, as long as a study's research design and questions for participants explore relationships between motivation and learning modality preferences with greater intent than this study.

\section{Learner Demographics \& Learning Modality Value}

This dissertation opened with a description of the expanding engagement learners are currently experiencing with online delivery. Youngsters presently in high and college can - and, in some cases, must - include online courses in their learning schedules. Given 
the prevalence with which younger learners are now encountering online learning delivery in secondary education, this exposure could very well shift the preferences of future young professionals toward greater openness and affinity for technology-mediated learning. Hence, consistently revisiting correlations between age and learning modality preference during the next decade could prove insightful for continued research on modality-driven learning value.

\section{Final Thoughts}

Before bringing this research endeavour to a close, a single note of caution to academics and practitioners who focus their learning research and practice primarily on young adults in college. This work does not presume to suggest how best to improve technology-mediated learning design and delivery in degree-seeking contexts such as online courses for college students. Especially given the critique in this dissertation of researchers who port findings from college contexts into professional learning without pause or preface, it would be roundly hypocritical to presume the reverse practice should be any less problematic.

The only suggestion offered here to researchers and practitioners in degree-seeking contexts would be to leverage this study's research approach more so than its results. In other words, pull college learners' perspectives and experiences into quantitatively designed studies on learning outcomes, and allow that qualitative material to speak for learners as loudly as their grades.

In the philosophical spirit of classical pragmatism, this dissertation has undertaken a practical use of adult professionals' learning experiences and the applied transformation of that experience into truths about learning value. Still, as researchers are reminded by 
Dewey (1938), the logical status of our interrogations is that they are only tentative. As learning design and delivery evolve, learner experiences should be expected to evolve and so then should truths about learning value. Thus, let this dissertation's tentative truths be part of an ongoing and evolving explanation of learning's value in online and inperson delivery. 


\section{References}

Adams, J.S. (1963). Toward an understanding of inequity. Journal of Abnormal and Social Psychology, 67, 422-463.

Adler, P. \& P. Adler (1987). Membership roles in field research. Newbury Park, CA: Sage.

http://books.google.com/books?hl=en\&lr=\&id=JBglZNsbExkC\&oi=fnd\&pg=PA3\&si $\mathrm{g}=\mathrm{qWeXXUKy} 32 \mathrm{jLBZwtjoxCOeCIIDA \& dq} \# \mathrm{v}=$ onepage $\& \mathrm{q} \& \mathrm{f}=$ false.

Åge, L-J. (2011). Grounded theory methodology: Positivism, hermeneutics, and pragmatism. The Qualitative Report, 16(6), 1599-1615. Retrieved from http://www.nova.edu/ssss/QR/QR16-6/age.pdf.

Anseel, F., W. Duyck, W. De Baene \& M. Brysbaert (2004). Journal impact factors and self-citations: Implications for psychology journals. American Psychologist, 59, 4951.

Anseel, F., F. Lievens, E. Schollaert \& B. Choragwicka (2010). Response rates in organizational Science, 1995-2008: A meta-analytic review and guidelines for survey researchers. Journal of Business Psychology, 25, 335-349.

Antonacci, D. (2009). Virtual world learning spaces: Developing a Second Life operating room simulation. EDUCAUSE Review. Retrieved from http://er.educause.edu/articles/2009/3/virtual-world-learning-spaces-developing-asecond-life-operating-room-simulation.

Ayim, M. (1974). Retroduction: The rational instinct. Transactions of the Charles $S$. Peirce Society, 10, 34-43.

Baker, S.E. \& R. Edwards (2012). How many qualitative interviews is enough? Expert voices and early career reflections on sampling and cases in qualitative research. National Centre for Research Methods. Retrieved from: http://eprints.ncrm.ac.uk/2273/4/how_many_interviews.pdf.

Baldwin, T. \& K. Ford (1988). Transfer of Training: A Review and Directions for Future Research Personnel Psychology, 41(1), 63-105.

Beecham, W. (2012). Measuring the impact of executive education. UC Davis Graduate School of Management Blog. Retrieved from http://gsm.ucdavis.edu/blogfeature/measuring-impact-executive-education.

Bogdan, R.C. \& S.K. Biklen (2007). Qualitative research for education: An introduction to theories and methods ( $5^{\text {th }}$ ed.). New York, NY: Allyn \& Bacon. 
Bonner, A. \& G. Tollhurst (2002). Insider-outsider perspectives of participant observation. Nurse Researcher, 9(4), 7-19.

Breen, L.J. (2007). The researcher 'in the middle': Negotiating the insider/outsider dichotomy. The Australian Community Psychologist, 19(1), 163-174. Retrieved from http://groups.psychology.org.au/Assets/Files/Breen 19(1).pdf.

Bryant, A. (2003). A constructive/ist response to Glaser. Forum Qualitative Sozialforschung / Forum: Qualitative Social Research, 4(1). Retrieved from http://www.qualitative-research.net/index.php/fqs/article/view/2541/3936\#g2.

Burke, L. \& H. Hutchins (2007). Training Transfer: An Integrative Literature Review. Human Resource Development Review, 6(3), 263-296.

Burnett, S. (2011). Maximizing returns on executive education. BloombergBusinessweek Online. Retrieved from http://www.businessweek.com/bschools/content/may2011/bs20110519 149428.htm.

Byrne, J.A. (2014, November 4). What Harvard Business School learned from its first online program. Poets \& Quants. Retrieved from http://poetsandquants.com/2014/11/04/what-harvard-business-school-learned-from-itsfirst-online-program/.

Cain, S. (2012). Quiet: The power of introverts in a world that can't stop talking. New York: Crown Publishers.

Cater, J.J. III, T.N. Michel \& O.E. Varela (2012). Challenges of online learning in management education: An empirical study. The Journal of Applied Management and Entrepreneurship, 17(491), 76-96.

Charlton, K. \& C. Osterweil (2005). Measuring return on investment in executive education: A quest to meet client needs or pursuit of the Holy Grail? $360^{\circ}$ The Ashridge Journal. Retrieved from http://www.ashridge.org.uk/website/content.nsf/FileLibrary/FC30125A4420D12B802 576020039C093/\$file/MeasuringROI.pdf.

Charmaz, K. (2016). A personal journey with grounded theory methodology: Kathy Charmaz in conversation with Reiner Keller. Forum Qualitative Sozialforschung / Forum: Qualitative Social Research, 17(1). Retrieved from http://www.qualitativeresearch.net/index.php/fqs/rt/printerFriendly/2541/3936.

Chejlyk, S. (2006). The effects of online course format and three components of student perceived interactions on overall course satisfaction. UMI No. 3213421, Capella University, ProQuest Dissertations \& Theses. 
Chiari, G. \& M.L. Nuzzo (2010). Constructivist Psychotherapy: A Narrative Hermeneutic Approach. New York: Routledge.

Clardy, A. (2006). Transfer of training: Literature Review. Working Paper 2006-Clardy01, Towson University, Human Resources Development Program. Retrieved from http://www.scribd.com/doc/218340997/Transfer-of-Training\#scribd.

Coghlan, D. (2003). Practitioner research for organizational knowledge: Mechanistic- and organistic- oriented approaches to insider action research. Management Learning, 34(4), 451-463.

Corbin, J. \& A. Strauss (2008). Basics of qualitative research ( $3^{\text {rd }}$ ed.). Los Angeles, CA: Sage Publications.

Creswell, J.W. (1998). Qualitative inquiry and research design: Choosing among five traditions. Thousand Oaks, CA: Sage.

(2003). Research design: Qualitative, quantitative, and mixed methods approaches. ( $2^{\text {nd }}$ ed.). Thousand Oaks: Sage.

(2007). Qualitative inquiry and research design: Choosing among five approaches ( $2^{\text {nd }}$ ed.). Thousand Oaks, CA: Sage.

Cromwell, S.E., \& J.A. Kolb (2004). An examination of work environment support factors affecting transfer of supervisory skills training in the workplace. Human Resource Development Quarterly, 15(1), 449-471.

Delfino, M., S. Manca, D. Persico \& L. Sarti (2004). Online learning: Attitudes, expectations and prejudices of adult novices. Proceedings of the IASTED International Conference Web-Based Education, 16-18 February 2004, Innsbruck, Austria. Retrieved from https://www.academia.edu/3126825/Online learning Attitudes expectations and prej udices_of adult novices.

Dewey, J. (1930). Conduct and experience in Carl Murchison (ed.), Psychologies of 1930 (pp. 409-422). Worcester, MA: Clark University Press. Retrieved from http://archive.org/stream/psychologiesof1930unse/psychologiesof1930unse djvu.txt. (1938). Logic: The theory of inquiry. NY: Henry Holt and Company, Inc. Retrieved from https://archive.org/details/JohnDeweyLogicTheTheoryOfInquiry.

Dillman, D., J. Smyth \& L. Christian (2009). Internet, Mail, and Mixed-Mode Surveys: The Tailored Design Method. New York: Wiley.

Driscoll, M.P. (2005). Psychology of learning for instruction. Upper Saddle River, NJ: Allyn \& Bacon. 
Dwyer, S.C. \& J. Buckle (2009). The space between: On being an insider-outsider in qualitative research. Research International Journal of Qualitative Methods, 8(1), 5463. Retrieved from http://ejournals.library.ualberta.ca/index.php/IJQM/article/download/2981/5198.

Felder, R. (1996). Matters of style. ASEE Prism, 6(4), 18-23. Retrieved from http://www4.ncsu.edu/unity/lockers/users/f/felder/public/Papers/LS-Prism.htm.

Fleming, N., \& D. Baume (2006) Learning Styles Again: VARKing up the right tree!, Educational Developments, 7(4), 4-7. Retrieved from http://vark-learn.com/wpcontent/uploads/2014/08/Educational-Developments.pdf.

Garland, D. \& Martin, B. (2005). Do gender and learning styles play a role in how online courses should be designed? Journal of Interactive Online Learning, 4(2), 67-81.

Glaser, B.G. \& A.L. Strauss (1967). The discovery of grounded theory: Strategies for qualitative research. New York: Aldine de Gruyter.

Goldstein, I.L. (1986). Training in organizations: Needs assessment, development, and evaluation. Pacific Grove, CA: Brooks/Cole.

Goodwin-Lee, R. (2010). The effects of program structure on dissertation writing in "Online Academia": A qualitative analysis of online doctoral student experiences. Walden University, ProQuest Dissertations \& Theses.

Goulão, M. d.F. (2013). Virtual learning styles: Does gender matter? Procedia - Social and Behavioral Sciences, 106, 3345-3354.

Graham, C.R. (2013). Emerging practice and research in blended learning. In M. G. Moore (Ed.), Handbook of distance education. ( $3^{\text {rd }}$ ed., pp. 333-350). New York, NY: Routledge. Retrieved from http://www.academia.edu/2068375/Emerging_practice and research in blended lear ning.

Greene, J.C. (2007). Mixed methods in social inquiry. San Francisco: Jossey-Bass.

Guba, E.G. (1981). Criteria for assessing the trustworthiness of naturalistic inquiries. Educational Communication and Technology, 29(2), 75-91. Retrieved from http://www.clemson.edu/ces/cedar/images/1/1a/3-Guba-Trustworthiness-1981.pdf.

Guest, G., A. Bunce \& L. Johnson (2006). How many interviews are enough?: An experiment with data saturation and variability. Field Methods, 18(1), 59-82. 
Gunawardena, C.N., J.A. Linder-VanBerschot, D.K. LaPointe \& L. Rao (2010).

Predictors of learning satisfaction and transfer of learning in a corporate online education program. American Journal of Distance Education, 24, 207-226.

Gutierrez, K. (2012). 18 mind-blowing eLearning statistics you need to know. SHiFT ELearning Company Blog. Retrieved from http://info.shiftelearning.com/blog/bid/247473/18-Mind-Blowing-eLearning-StatisticsYou-Need-To-Know.

Hanson, J.R., H.F. Silver \& R.W. Strong (1991). Square pegs: Learning styles of at-risk students. Music Educators Journal, 78(3), 30-35.

Haynie, D. (2014, January 8). U.S. News releases 2014 best online programs rankings. U.S. News \& World Report Education. Retrieved from http://www.usnews.com/education/online-education/articles/2014/01/08/us-newsreleases-2014-best-online-programs-rankings.

Herrmann, A.W. (1989). The participant observer as "insider": Researching your own classroom. Paper presented at Annual Meeting of the Conference on College Composition and Communication, Seattle, WA.

Holton, E.F. III (1996). The flawed four-level evaluation model. Human Resource Development Quarterly, 7(1), 5-25.

Holton, E.F. III (2000). What is really wrong: Diagnosis for learning transfer system change. Advances in Developing Human Resources, 8, 7-22.

Holton, E.F. III, R.A. Bates, D.L. Seyler \& M.B. Carvalho (1997). Toward construct validation of a transfer climate instrument. Human Resource Development Quarterly, $8(2), 95-113$.

Horn, M. \& H. Staker (2011). The Rise of K-12 Blended Learning. Innosight Institute, renamed the Clayton Christensen Institute in 2013: San Mateo, California.

Israel, M., C. Carnahan, K. Snyder \& P. Williamson (2012). Supporting new teachers of students with significant disabilities through virtual coaching: A proposed model. Remedial and Special Education, 34(4), 195-204.

James, W. (1890). The principles of psychology, volume 1. London: Macmillan and Co. (1907). Pragmatism: A new name for some old ways of thinking. The Project Gutenberg EBook. Retrieved from http://www.gutenberg.org/files/5116/5116-h/5116h.htm. 

- (1909). The meaning of truth: A sequel to 'Pragmatism'. The Project

Gutenberg EBook. Retrieved from https://www.gutenberg.org/files/5117/5117-h/5117$\underline{\text { h.htm. }}$.

Johnson, R.B., M.W. McGowan \& L.A. Turner (2010). Grounded theory in practice: Is it inherently a mixed method? Research in the Schools, 17(2), 65-78.

Johnson, R.B. \& A.J. Onwuegbuzie (2004). Mixed methods research: A research paradigm whose time has come. Educational Researcher, 33(7), 14-26.

Judd, C.H. (1908). The relation of special training to general intelligence. Educational Review, 36, 28-42.

Kelly, K. \& H. Jugovic (2001). Concurrent validity of the online version of the Keirsey Temperament Sorter II. Journal of Career Assessment, 9(1), 49-59.

Kerstetter, K. (2012). Insider, outsider, or somewhere in between: The impact of researchers' identities on the community-based research process. Journal of Rural Social Sciences, 27(2), 99-117. Retrieved from http://www.ag.auburn.edu/auxiliary/srsa/pages/Articles/JRSS\%202012\%2027\%202\% 2099-117.pdf.

Kim, K.J. \& T. W. Frick (2011). Changes in student motivation during online learning. Journal of Educational Computing Research, 44(1), 1-23. doi:10.2190/EC.44.1.a

Konnikova, M. (2015). Virtual reality gets real: The promises — and pitfalls - of the emerging technology. The Atlantic. Retrieved from http://www.theatlantic.com/magazine/archive/2015/10/virtual-reality-getsreal $/ 403225 /$.

Kozlowski, S.W.J. \& E. Salas (1997). A multilevel organizational systems approach for the implementation and transfer of training. In J. Kevin Ford (Ed.), Improving training effectiveness in work organizations (pp. 247-287). Hillsdale, NJ: Erlbaum.

Kuong, H.C. (2009). An exploratory case study of students' perceptions of online graduate education. Order No. 3392896, University of Northern Iowa, ProQuest Dissertations \& Theses, 220. Retrieved from http://gradworks.umi.com/33/92/3392896.html.

Laker, D.R. (1990). Dual dimensionality of training transfer. Human Resource Development Quarterly, 1 (3), 209-235.

Leech, N.L. \& A.J. Onwuegbuzie (2007). A typology of mixed methods research designs. Quality \& Quantity, 43(2), 265-275. 
Lingard, L., A. Mathieu \& W. Levinson (2008). Qualitative research: Grounded theory, mixed methods, and action research. BMJ: British Medical Journal, 337(7667), 459461. Retrieved from

http://www.researchgate.net/profile/Lorelei_Lingard/publication/23156529 Grounded theory mixed methods and action_research/links/53f269c80cf2bc0c40e99208.pdf.

Locke, E.A. (1968). Toward a theory of task motivation and incentives. Organizational Behavior and Human Performance, 3, 157-189.

London, P.A., \& D.D. Flannery (2004). Social factors that impact women's practice of breast self-examination: A challenge to the transfer of training literature. Journal of European Industrial Training, 28(7), 538-549.

Lopez, L. (2001). Teacher talk: A community of colleagues that values practical teacher knowledge through sharing experiences. ProQuest ETD Collection for FIU, Paper AAI3059786. Retrieved from http://digitalcommons.fiu.edu/dissertations/AAI3059786.

Lowenthal, P. \& B.G. Wilson (2010). Labels do matter! A critique of AECT's redefinition of the field. TechTrends, 54(1), 38-46.

Lloyd, F.R. \& D. Newkirk (2011). Rating the management gurus. BloombergBusinessweek Online. Retrieved from http://www.businessweek.com/stories/2001-10-14/rating-the-management-gurus.

Maven Magnet research firm \& UNICON's 2013 online learning conversation research. Retrieved from http://uniconexed.org/2013/research/CBS_MavenMagnet_OnlineLearning-072013.pdf.

Maxfield, R.J. (2008). Online education for nontraditional adult students: Perceptions and attitudes of emergency services workers in asynchronous learning environments. Utah State University All Graduate Theses and Dissertations, Paper 114. Retrieved from http://digitalcommons.usu.edu/etd/114.

Mercer, J. (2007). The challenges of insider research in educational institutions: Wielding a double-edged sword and resolving delicate dilemmas. Oxford Review of Education, $33(1), 1-17$.

Moore, J.L., C. Dickson-Deane \& K. Galyen (2011). e-Learning, online learning, and distance learning environments: Are they the same? Internet and Higher Education, $14,129-135$.

Morgan, D.L. (2014). Pragmatism as a paradigm for social research. Qualitative Inquiry Online. 1-9. Retrieved from http://qix.sagepub.com/content/early/2014/01/31/1077800413513733. 
Morse, J.M., M. Barrett, M. Mayan, K. Olson \& J. Spiers (2002). Verification strategies for establishing reliability and validity in qualitative research. International Journal of Qualitative Methods, 1(2), 1-19.

Myerhoff, B.G. (1978). Number our days: A triumph of continuity and culture among Jewish old people in an urban ghetto. New York: Simon and Schuster.

Palfrey, J. \& U. Gasser (2008). Born digital: Understanding the first generation of digital natives. New York : Basic Books.

Peirce, C.S. (1931-1958). Collected papers, vols. 1-6, C. Hartshorne \& P. Weiss (eds.); Vols. 7-8, A.W. Burks (ed.). Cambridge, MA: Harvard University Press.

Pettazzoni, J.E. (2008). Factors associated with attitudes toward learning in an online environment: Transactional distance, technical efficacy, and physical surroundings. UMI No. 3346551, The University of Southern Mississippi, ProQuest Dissertations \& Theses.

Rafferty, P.D. \& C.M. Anderson (2013). Are executive students satisfied with onlinelearning experiences? Implications for online training and executive education. Training \& Management Development Methods, 27(4). 6.73-6.84.

Richey, R.C. (2008). Reflections on the 2008 AECT Definitions of the Field. TechTrends. 52(1), 24-25.

Rooney, P. (2005). Researching from the inside - does it compromise validity? Level3, 3. Retrieved from http://level3.dit.ie/html/issue3/rooney/rooney.pdf.

Rouiller, J.Z. \& I.L. Goldstein (1993). The relationship between organizational transfer climate and positive transfer of training. Human Resource Development Quarterly, 4 (4), 377-399.

Rubin, H.J. \& I.S. Rubin (2012). Qualitative interviewing: The art of hearing data (3 ${ }^{\text {rd }}$ ed.). Thousand Oaks, CA: Sage.

Saldana, J. (1998). The coding manual for qualitative researchers $\left(1^{\text {st }} \mathrm{ed}\right.$.). Thousand Oaks, CA: Sage.

Sanders, T. (2014a). The online transformation of executive education: A report from the front lines. Retrieved from https://medium.com/@wellstockedmind/executiveeducations-online-transformation-f70c243e6aae.

(2014b). Cell phones vs. learning. Corporate Learning Network. Retrieved from http://aws.corporatelearningnetwork.com/tools-and-technologies/articles/cellphones-vs-learning/. 
Schiller, F.C.S. (1907). Studies in humanism. London: Macmillan and Co. Retrieved from https://archive.org/details/studiesinhumanis00schiiala.

Sheehy, K. (2012, October 24). States, districts require online ed for high school graduation. U.S. News \& World Report Education. Retrieved from http://www.usnews.com/education/blogs/high-school-notes/2012/10/24/statesdistricts-require-online-ed-for-high-school-graduation.

Stokes, T.F. \& D.M. Baer (1977). An implicit technology of generalization. Journal of Applied Behavioral Analysis. 10(2), 349-367.

Stopper, A. (2013). Building an online education portfolio. American Society for Training \& Development. Retrieved from http://www.astd.org/Publications/Newsletters/ASTD-Links/ASTD-LinksArticles/2013/04/Building-An-Online-Executive-Education-Portfolio.

Strauss, A. \& J. Corbin (1998). Basics of qualitative research: Techniques and procedures for developing grounded theory (2nd ed.). Thousand Oaks, CA: Sage.

Strauss, A. \& J. Corbin (2000). Grounded theory methodology: An overview in N.K. Denzin \& Y.S. Lincoln (eds.), Handbook of Qualitative Research ( $2^{\text {nd }}$ ed., pp. 273285). Thousand Oaks, CA: Sage.

Strübing, J. (2007). Research as pragmatic problem-solving: The pragmatist roots of empirically-grounded theorizing in A. Bryant \& K. Charmaz (eds.), The SAGE Handbook of Grounded Theory. (pp. 580-602). London, England: Sage Publications Ltd.

Styer, A. (2007). A grounded meta-analysis of adult learner motivation in online learning from the perspective of the learner. UMI No. 3249903, Capella University, ProQuest Dissertations \& Theses.

Suddaby, R. (2006). From the editors: What grounded theory is not. Academy of Management Journal, 49(4), 633-642.

Taylor, S. \& S. Keeter (2010). Millennials: A portrait of generation next. PewResearch Social \& Demographic Trends. Retrieved from http://www.pewsocialtrends.org/files/2010/10/millennials-confident-connected-opento-change.pdf.

Tedlock, B. (2000). Ethnography and ethnographic representation. In N.K. Denzin \& Y.S. Lincoln (Eds.), Handbook of Qualitative Research ( $2^{\text {nd }}$ ed., pp. 455-486). Thousand Oaks, CA: Sage.

Tracy, S.J. (2010). Qualitative quality: Eight "big-tent" criteria for excellent qualitative research. Qualitative Inquiry, 16(10), 837-851. 
Udacity (2016). AT\&T partners with Udacity to transform the skills of its workforce. Udacity for Business. Retrieved from https://www.udacity.com/business.

Unluer, S. (2012). Being an insider researcher while conducting case study research. The Qualitative Report, 17(58), 1-14. Retrieved from http://www.nova.edu/ssss/QR/QR17/unluer.pdf.

UNICON's state of the executive education industry: 2013 survey results. Retrieved from http://uniconexed.org/en/research-link.html.

U.S. Department of Education, Office of Planning, Evaluation, and Policy Development Policy and Program Studies Service's 2010 evaluation of evidence-based practices in online learning: A meta-analysis and review of online learning studies. Retrieved from http://www2.ed.gov/rschstat/eval/tech/evidence-based-practices/finalreport.pdf.

Velada, R., A. Caetano, J.W. Michel, B.D. Lyons \& M.J. Kavanagh (2007). The effects of training design, individual characteristics and work environment on transfer of training. International Journal of Training and Development, 11(4), 282-294.

Volery, T. \& D. Lord (2000). Critical success factors in online education. International Journal of Educational Management, 14(5), 216-223.

Vroom, V. (1964). Work and motivation. New York: Wiley.

Wexley, K.N. and G.P. Latham (2002), Developing and Training Human Resources in Organizations. Englewood Cliffs, New Jersey: Prentice Hall.

Wohlsen, M. (2015). Google Cardboard's New York Times experiment just hooked a generation on VR. Wired Online. Retrieved from http://www.wired.com/2015/11/google-cardboards-new-york-times-experiment-justhooked-a-generation-on-vr/.

Woodworth, R.S. \& E.L. Thorndike (1901). The influence of improvement in one mental function upon the efficiency of other functions (I). Psychological Review, 8(3), 247-261.

Yamnill, S. \& G. McLean (2001). Theories Supporting Transfer of Training. Human Resource Development Quarterly, 12(2), 95-113.

Yukselturk, E. \& S. Bulut (2009). Gender Differences in Self-Regulated Online Learning Environment. Educational Technology \& Society, 12 (3), 12-22.

Zembylas, M. (2008). Adult learners' emotions in online learning. Distance Education, 29(1), 71-87. 
${ }^{1}$ See ExecOnline, an education technology startup that "allows companies to combine the quality and engagement of in-person development with the scale, integration and measurability of online development" in executive learning and learning training, indicated on the company's website as of 15 November 2014: http://www.execonline.com/about-us/. I am personally familiar with ExecOnline, having negotiated a strategic learning partnership with the company in 2013 while working with the University of California, Berkeley's Center for Executive Education.

${ }^{2}$ Examples of executive education typical programs can be found at the majority of business schools around the world. Though schools may have brand niches, such as entrepreneurship or a global focus, a remarkable similarity of executive education offerings can nonetheless be found at most business schools. Compare, for example, program offerings at Stanford University (http://www.gsb.stanford.edu/exed/programs.html), Harvard University (http://www.exed.hbs.edu/programs/Pages/default.aspx), University of Minnesota (http://carlsonschool.umn.edu/executive-education/program-catalog) and Thunderbird School of Global Management (http://www.thunderbird.edu/executive-education/programs/open-enrollment-programs).

${ }^{3}$ The London \& Flannery statistic is troublesome in that it is not sourced in the researchers' study and there is no clear indication in their literature review or methodology of where the researchers' derived the statistic. Nonetheless, it is quoted here on the presumption that London \& Flannery's published work is reputable and because it is in line with simtheilar statistics reported in other studies. 
Greetings, and thanks very much for making time to complete this survey. The goal is to collect views, attitudes and experience related to learning as a working professional. Your responses are highly valued and protected. Your name is requested only so that well-informed and relevant questions can be asked during follow-up, if needed. No personally identifying information linking you to your answers will be shared with anyone. The insight you'll provide in the next $15 \mathrm{~min}$ or so is very much appreciated. Thanks again!

Continue »

\section{Final question}

63. Can we follow-up with you about your survey answers? If yes, plesse provide your emall address. This heips with follow-up, If needed. No personal info Inking you to your answers will be shared with anyone, anywhere, ever.

Hit "Submit" \& you're all done!

If you have any questions or comments about this survey experlence (especially if you caught any typos or found any of the questions confusing). please feel to share your feedback. You're awescme. Thank you. On, and dont forget to hit "Suomit: 
Appendix B - Survey Instrument

\begin{tabular}{|c|c|}
\hline $\begin{array}{l}\text { Demographic Questions* } \\
\text { (* indicates response required) }\end{array}$ & $\begin{array}{l}\text { Choices } \\
\text { (blank indicates open-ended question) }\end{array}$ \\
\hline What is your age bracket?* & $\begin{array}{ll}\text { 1. } & 20 \text { or younger } \\
\text { 2. } & 21-29 \\
\text { 3. } & 30-39 \\
\text { 4. } & 40-49 \\
\text { 5. } & 50 \text { or older (\& wiser) }\end{array}$ \\
\hline What is your gender? & $\begin{array}{ll}\text { 1. } & \text { Female } \\
\text { 2. } & \text { Male }\end{array}$ \\
\hline $\begin{array}{l}\text { What is your individual } \\
\text { annual income range?* }\end{array}$ & $\begin{array}{ll}\text { 1. } & \text { Less than } \$ 50 \mathrm{k} \\
\text { 2. } & \$ 50 \mathrm{k} \text { to less than } \$ 75 \mathrm{k} \\
\text { 3. } & \$ 75 \mathrm{k} \text { to less than } \$ 100 \mathrm{k} \\
\text { 4. } & \text { More than } \$ 100 \mathrm{k} \\
\text { 5. Prefer not to answer this one }\end{array}$ \\
\hline
\end{tabular}

\begin{tabular}{|c|c|}
\hline $\begin{array}{l}\text { Professional Questions* } \\
\text { (* indicates response required) }\end{array}$ & $\begin{array}{l}\text { Choices } \\
\text { (blank indicates open-ended question) }\end{array}$ \\
\hline $\begin{array}{l}\text { What phrase best describes } \\
\text { your current professional } \\
\text { situation?* }\end{array}$ & $\begin{array}{l}\text { 1. Full-time with a company or organization } \\
\text { 2. Part-time with a company or organization } \\
\text { 3. Temporary with a company or organization } \\
\text { 4. Run my own business or work independently } \\
\text { 5. Work through a placement agency } \\
\text { 6. Not a working professionally currently }\end{array}$ \\
\hline $\begin{array}{l}\text { If you are a working } \\
\text { professional, what is your } \\
\text { professional title? }\end{array}$ & \\
\hline $\begin{array}{l}\text { What is / was your current or } \\
\text { most recent professional field } \\
\text { or industry of experience?* }\end{array}$ & \\
\hline $\begin{array}{l}\text { What is / was your experience } \\
\text { level in your current or most } \\
\text { recent field or industry?* }\end{array}$ & $\begin{array}{l}\text { 5. Expert } \\
\text { 4. Highly Experienced } \\
\text { 3. Experienced } \\
\text { 2. Somewhat Experienced } \\
\text { 1. Entry-Level }\end{array}$ \\
\hline $\begin{array}{l}\text { How long have / had you } \\
\text { been in your current or most } \\
\text { recent field or industry?* }\end{array}$ & $\begin{array}{l}\text { 1. } 2 \text { or fewer years } \\
\text { 2. } 3 \text { to } 5 \text { years } \\
\text { 3. } 6 \text { to } 10 \text { years } \\
\text { 4. } 11 \text { to } 15 \text { years } \\
\text { 5. } 16 \text { or more years }\end{array}$ \\
\hline $\begin{array}{l}\text { How much professional } \\
\text { experience do you have } \\
\text { overall?* }\end{array}$ & $\begin{array}{l}\text { 1. } 2 \text { or fewer years } \\
\text { 2. } 3 \text { to } 5 \text { years } \\
\text { 3. } 6 \text { to } 10 \text { years } \\
\text { 4. } 11 \text { to } 15 \text { years } \\
\text { 5. } 16 \text { or more years }\end{array}$ \\
\hline
\end{tabular}




\section{Appendix B - Survey Instrument (cont.)}

\begin{tabular}{|l|l|}
\hline $\begin{array}{l}\text { Learning Questions* } \\
\text { (* indicates response required) }\end{array}$ & $\begin{array}{l}\text { Choices } \\
\text { (blank indicates open-ended question) }\end{array}$ \\
\hline What's your highest level & 1. Associates Degree \\
of completed formal degree & 2. Bachelors Degree \\
education?* & 3. Masters Degree \\
& 4. Professional Doctorate (e.g. JD or MD) \\
& 5. Research Doctorate (e.g. PhD, EdD) \\
6. I don't have a formal degree
\end{tabular}

\begin{tabular}{|l|l|}
\hline $\begin{array}{l}\text { Interview Set-Up Questions } \\
(* \text { indicates response required) }\end{array}$ & $\begin{array}{l}\text { Choices } \\
\text { (blank indicates open-ended question) }\end{array}$ \\
\hline $\begin{array}{l}\text { Can we follow-up with you about your } \\
\text { survey answers?* }\end{array}$ & $\begin{array}{l}1 . \text { Yes } \\
\text { 2. No }\end{array}$ \\
\hline If yes, please provide your email address & \\
\hline $\begin{array}{l}\text { What else should this survey have asked } \\
\text { you about professional learning? }\end{array}$ & \\
\hline
\end{tabular}




\section{Appendix C - Interview Questions}

\begin{tabular}{|c|c|}
\hline Interview Questions & Reasoning \\
\hline $\begin{array}{l}\text { What comes to mind when you hear } \\
\text { the term "professional learning"? }\end{array}$ & $\begin{array}{l}\text { Give explicit voice to participants' definitions of what it } \\
\text { means to learn as a professional and thereby push } \\
\text { against jargon and assumptions of shared understanding. }\end{array}$ \\
\hline $\begin{array}{l}\text { What is the primary purpose of } \\
\text { learning as a professional? }\end{array}$ & $\begin{array}{l}\text { Give explicit voice to participants' definitions of what it } \\
\text { means to learn as a professional, and explore the } \\
\text { relevance of training transfer from a learner perspective. }\end{array}$ \\
\hline $\begin{array}{l}\text { How do you expect to learn as a } \\
\text { professional? }\end{array}$ & $\begin{array}{l}\text { Capture learner-generated perspective and potentially } \\
\text { expand options beyond those offered among the answer } \\
\text { choices for the survey question: How have you learned } \\
\text { as a professional? }\end{array}$ \\
\hline $\begin{array}{l}\text { Describe your most recent } \\
\text { professional learning activities } \\
\text { (subject, where, when, duration \& } \\
\text { so on). }\end{array}$ & Give explicit voice to participants' learning experience. \\
\hline $\begin{array}{l}\text { What did you find useful about the } \\
\text { professional learning activities in } \\
\text { which you participated? }\end{array}$ & $\begin{array}{l}\text { Give explicit voice to participants' learning experience } \\
\& \text { perceptions of learning value, and explore the } \\
\text { relevance of training transfer from a learner perspective. }\end{array}$ \\
\hline $\begin{array}{l}\text { What advantages do you see for } \\
\text { (preferred learning format) that are } \\
\text { most important for you? }\end{array}$ & $\begin{array}{l}\text { Give explicit voice to participants' learning experience } \\
\& \text { perceptions of learning value. }\end{array}$ \\
\hline $\begin{array}{l}\text { What are your professional } \\
\text { development priorities? }\end{array}$ & $\begin{array}{l}\text { Explore learners' intrinsic \&/or extrinsic motivation for } \\
\text { professional learning \& pay particular attention to how } \\
\text { these motivations might tie to preferred delivery modes. }\end{array}$ \\
\hline $\begin{array}{l}\text { If you had time, money \& access to } \\
\text { your choice of professional } \\
\text { learning, how would you choose to } \\
\text { learn? }\end{array}$ & $\begin{array}{l}\text { Explore learners' intrinsic \&/or extrinsic motivation for } \\
\text { professional learning \& pay particular attention to how } \\
\text { these motivations might tie to preferred delivery modes. }\end{array}$ \\
\hline $\begin{array}{l}\text { Do you think it should be } \\
\text { mandatory that employees } \\
\text { participate in professional learning? }\end{array}$ & $\begin{array}{l}\text { Explore learners' intrinsic \&/or extrinsic motivation for } \\
\text { professional learning \& pay particular attention to how } \\
\text { these motivations might tie to preferred delivery modes. }\end{array}$ \\
\hline
\end{tabular}




\section{Appendix D - Sanders Online Learning Reflections}

\section{July 2016}

- the conversation with Udacity was incredibly helpful b/c it gave me a sense of someone out there doing online learning right; makes sense they've been as successful as they are - it's just fundamental to them that the feeling and the value of learning in person, shows up in their online learning

- I really want to interview Udacity learners about how they experience professional learning with Udacity, whether the synchronous \& offline interaction requirements are a help or a botheration or both, whether they want to be engaging others as they learning online, whether they feel they have control over their learning or expected more control - I think also Udacity is appreciating the notion of research being able to put names to their practices - in a way, it helps codify what they do, how they approach learning design and delivery - there may be a next research project there, but first, gotta finish what's in front of me

\section{June 2016}

- I want to make sure in the dissertation writing to connect survey details and interview questions as closely as possible with the data in the analysis section, to connect research approach and data outcome - also, I got to interview participants in more ways than I bargained for, in person, by text-messaging (that was fun!), and emails for other - communicating methods definitely affected outcomes, and it has to be part of the data interpretation; everything affects everything

\section{June 2016}

- even in the larger sample, younger respondents did not go at all where I thought they would with their answers about learning online; this is turning analysis upside down but also making it very interesting to sort through

- what I'm finding is they don't just praise the benefits of learning in person, they're also pretty down on what they've experienced online

- the critique echoes mine; it feels like rote learning, it feels like an impediment to learning, it feels like wasted time - now of course, I'm asking myself, did I find this critique from others b/c I was looking for it out of my own viewpoint or b/c it was there to be found? did my respondents shine a light on this problem, or did I point the light in that direction in the first place and guide them there?

- one way that I do feel comfortable is that I asked questions that were as neutral and straightforward as possible: how do you prefer to learn, what do you value about learning the way that you prefer; these are wide open questions for the respondents to fill in the blanks

- $\mathrm{i}$ just find it so obvious that we should always be asking our learners this question before we teach them; but even I don't b/c by the time my learners are in my sessions, the decision about how they're going to learn has already been made 
- what can I possibly do about it if they don't prefer to learn in the modality we're in? I need to answer this question for myself as much as for this dissertation; there has to be more that I can do as a learning practitioner

- and when I read back over my notes here on BL's learning courses, I get more than a hint of direction about how to address this; I have to design around the problems of any given modality; it's work to do this, but it's also quite possible to accomplish

- ironically, and interestingly enough, when questioned about my own learning preferences, i fall in line with my older age group despite all my internal kvetching about the shortcomings of online learning

- how is possible that older people want to learn online more than younger people? I certainly didn't think I'd feel that way, not based on online learning design I've experienced so far

- but now that I'm thinking about it along with my respondents, I find myself influenced by their perspective on control; it's control that i find most valuable about learning online - so even if have been able to somewhat manage my influence on my data, what about my data influencing me? is that also bias? or isn't this the way it's supposed to be? I expect to be influenced by my data; otherwise, how could I stay dedicated to it

\section{May 2016}

- most useful bit of information I've gotten from these group projects in instruction theory class is the reading of this confirmation in the 2007 Teacher perspective online vs blended Schrum/Burbank/Capps article

- students rating their online teacher training class: "least successful aspect of the class, according to one-fourth of the students, was the group assignments and postings. They felt that these were inconvenient and ineffective because other students would procrastinate posting, making it difficult for students to respond to each other in a timely way" (p.208)

\section{May 2016}

I don't want to make this journal about the research findings ... that's what the dissertation is actually for. But I will say that I am completely caught off guard by seeing in early survey data that young people don't prefer learning online.

Their feelings are pretty strong about learning in person. That could simply stem from the earnestness of being in one's $20 \mathrm{~s}$. But they do seem pretty serious about it, and it's worth thinking about what kind of contexts are they are $\&$ what kinds of contexts are they coming from as 20-somethings that they'd prefer to do everything with their computers and phones but not prefer to learn that way.

I've spent time with younger people where they literally do not stop staring at their phones. Maybe there's something about the way they've experienced learning online that also makes it something they wouldn't want to do if they had the choice. 
I gotta make sure I'm not projecting in that regard and let them speak for themselves in their surveys and in their interviews. It almost would be better to interview more people by email in this regard, so there's nothing in the inflection of my voice, and nothing is said in the swirl of conversation that would lead them in any one direction or another. In email, they just simply respond to the question, what do you prefer about your modality of choice, and I don't influence that answer.

Hopefully I can get some email interviews along with in-person interviews so I can compare how respondents answer and make sure my biases don't creep in and taint these conversations.

\section{May 2016}

- why are we using Bboard for discussions when the tool is not only incredibly clunky, separate discussions with multiple comment threads, it's also inaccessible once this class is over

- which just reinforces the notion that this is simply busy work, tasks we need to do to get the points we need to get to get the grade we need to receive to get the credits we need to have to get our degrees

- none of that is about learning; and these verbose word requirements $200+$ or more . . you just end up with a lot of people expounding about how they agree with you and reiterate pretty much whatever it is you wrote

- there's no substance there

- in my design of BL's online class syllabus, we put conclusions and guidance coming out of this dissertation to work, at least to the limited degree that he can

- I suggested he build a discussion based on the question how do I, and classmates are responsible for providing solutions; so learners have to identify an application challenge, and they get crowdsourced solutions

- and if you can get it out of Bboard into a tool that allows upvoting and downvoting, that would be even more helpful

- bboard discussions are inefficient, cumbersome and perfunctory

- I also suggested applied reflections in pathbrite as an alternative to quizzes, for learners who are working or have experiences with the concepts they're studying - learners could create an infographic or video or write-up about how 1 concept for each week or from each 4 wk block has been applied/put to work in their organization, either by them or others, and whether it was successful and why or why not

- I suggested a shared online learning resource that each student has to contribute to each week that lives on outside of Blackboard and is much easier to use and read and nobody has to write stupid comments about it

- again, the resources could simply get upvoted or downvoted and they should be tagged for some sort of categorization 
- I suggested he require all learners to get a diigo account and create their own individual online library and that they contribute 2 public annotated bookmarks/week related to their final projects (academic articles, online articles, multimedia annotated to explain connection/usefulness to final project)

- and I suggested he revise his rubric so that graded engagement with these tools is required to insure students become familiar and comfortable with them and can carry forward with using them long after the class is over, which contributes to the continuous learning habit of mind practice and fulfills that objective by equipping students for continuous learning

- BL also reminded me about incorporating twitter in learning sessions as a way for everyone to have a voice

- wouldn't it be cool to project the scrolling twitter feed as class is happening

- and he uses it for students to submit thoughts that he scans before going into class

- way cooler than the clunky discussion board we have to deal with in Blackboard that's also trapped in Blackboard and inaccessible once class is over

- the way (professor) has her boards set up, we don't even have access to them during the class, once they've expired for the week

- so we can't go back and access any thoughts that might be relevant to our final projects or future work

- last thing, i just read the phrase "tweetup" to describe a Q\&A conducted via twitter; you tweet questions at someone and they select which questions to answer

- social media savvy William Shatner turned me on to that one

- you could have a learner hosted tweetup and of course have a faculty hosted tweetup; 2 tweets max per answer

- the more I think about it, the lamer my online learning experience is as it's been designed by academics; it's really archaic and just embarrassing

\section{April 2016}

It occurs to me that I need to dissertation-journal about discovery-based learning. There's somewhere I read and reflected on one of our alleged experts (the elearning book p.20) saying discovery-based learning doesn't work. It's a conclusion posted in Mayer's 2004 research and apparently based on 50yrs of research. But since learning via Internet hasn't been around for 50yrs, perhaps we need to re-examine this.

And perhaps we need to be talking about discovery-driven - not discovery-based learning. I have first-hand experience of discovery-driven learning experience, enabled and mediated by technology: 
WDHB taught me, the best learning was in the serendipity. Well, the most interesting learning. And that we had to design for serendipity, for the unplanned sparks of insight that come to people when they least expected it. These sparks could be lit because learners where put in the right circumstances - with people, given tasks, in environments - that would spur their creativity in learning.

I think that's true online, too. People in industry right now are constantly yammering about collaboration. Meanwhile, group work is the most annoying aspect of both inperson and online learning.

It's serendipity, that's what we haven't really been designing for online, for sure, and that's what's needed to enrich learning with value. I need to research whether anyone else is talking about serendipity in learning.

And yes, as oxymoronic as it sounds, you can design for serendipity. Actually, if we don't design for it, we effectively snuff it out.

I connected with one of my online classmates in person last week and experienced that intensity and immediacy of connection and the quickness with which we could get to some meaningful exchange between us that could change the course of our learning - it happens most easily in person.

We're not coming anywhere close to anything like that rich immediacy in our online groups, where we're forced to do assignments that we really have no interest in doing and where tech is a connector via communication but also a barrier between people, keeping most connections focused on utilitarian outcomes.

\section{March 2016}

Attending my first webinar, and I'm not quite sure how it's different in experience from a lecture. I'm listening to someone talk and watching them click through their slides. My mic is muted, so I can't participate. I also can't see or chat with other participants, so I don't know who I'm in here with.

They just did some polls, so there's a modicum of interactivity. But overall, it's pretty passive experience. Definitely not engaging, but somewhat informative.

Best experience design aspects of this is being able to listening to recording after the session, having moderators who are monitoring the questions and comments from audience

\section{March 2016}

And the syllabus confusion continues. It occurs to me that perhaps even more so than an in-person class, the syllabus matters significantly in how learning directors communicate 
what is to be done and how learners understand what's expected of them. I'm tempted to rewrite one of these syllabi with a table of contents added, b/c really why aren't professors doing that already.

Also, thinking about these syllabi compared to the ExecOnline course I looked at, no syllabus was needed for learners to understand exactly what was expected of them and when. It seems the more you want to (micro)manage how learners perform and what learners deliver, the more instructions you need about it.

Now that I've had a second online synchronous session, wow, night and day between what it's like when you have mic privileges and what it's like when you don't. The professor today simply trusted all of us to act in a way that would help the session run effectively, and we did. And that was that. It the session was so much more smooth than us having to type all our questions and responses and follow-up questions in half-inch tall box that doesn't allow for full view of the conversation.

I thanked the professor today for allowing us mic privileges and she said (paraphrasing), "I prefer to do it this way b/c it gives the sense that we are all together, as if we were in class" - to which I totally agreed.

It was so much easier to communicate when we had the mic option. Questions, answered. Confusions, clarified. Directed responses, confirmed. Done and done.

\section{March 2016}

As I continue to wade through the syllabi nailing down what's expected, I've just had a more specific realization about why these online courses strike me as such a botheration. There is an unceasing degree of micromanaging how we explore, express and otherwise engage in these courses.

Example syllabus directions for discussion board postings:

1. Each student will post their reflection/responses to the Handbook of Research on Teaching by Sunday midnight. Your reflection should promote a critical exploration and understanding of the chapter being discussed. Students' reflection/responses to EACH question should be comprehensive and a minimum of 200 words and maximum of 400 words is required for each answer.

2. Each student will respond/comment to TWO reactions from other classmates. Your comments/responses are due on Tuesdays by 11:59 pm. I agree, disagree, etc. type of answer will not do. Please be reflective and thoughtful. A minimum of 100 words and maximum of 200 words is required.

3. AVOID limiting your responses to just the two reactions required by the instructor. Be an ACTIVE participant of your learning and enhance the class' discussions. Note: As you prepare to answer the discussion questions and react on your classmates' posting, you are expected to provide answers that follow the Bloom's Taxonomy highest order thinking (levels 4, 5, 6). 
Examples of postings that demonstrate higher levels of thinking:

"Some common themes I see between your experiences and our textbook are...." (analysis)

"These newer trends are significant if we consider the relationship between ...." (synthesis)

"The body of literature should be assessed by these standards ...." (evaluation)

Every step of the way, we're told how to perform. I feel like the syllabi are designed to train monkeys - they read as if we adult graduate students have no experience learning from the Internet. The bulk (and in the case of one course, the entirety) of our learning experience is scripted for us, down to the keystroke.

Also, it's just ridiculously out-of-touch with the student experience to expect sustained substantive engagement with each other if we're all tasked with producing hundreds of blah-blah-blah bulletin board responses that are trapped in an LMS with no export functionality and thus no access or utility for us following the class (unless we make special efforts to copy/paste DBoard posts and responses).

Last thing I'll say, for tonight, it's one thing to have a convoluted 10+-page syllabus when you're teaching an in-person course b/c students generally know that the first class is devoted in no small part to understanding the syllabus and what's expected of them. It's another inefficient and unhelpful matter entirely to have a wordy detailed syllabus for an online course and to jam explanation of its multiple deliverables into an hourlong online session where students can only request clarity via a chat box. We may be reading and writing about ideal online instructional design this semester, but we certainly aren't experiencing best-practice modeling of ideal online instructional design.

So grateful I've only had to suffer two of these online courses while going through my own process of thinking about online learning design and delivery.

\section{March 2016}

So we had our first Adobe Connect session today and it was as ridiculous as expected. We're supposed to interact, but no one had the mic except the professor. There were 27 people in this session, and the only way we can communicate is the "raising our hands" icon or the sliver of a chat box down in the right-hand corner.

At one point, the prof was doing a screen demo, and we couldn't see the screen. But no one could tell her that b/c she wasn't connected via mic to anyone in the session. There was no moderator accompanying the host/presenter. Having someone connected to the host is just basic effective online design, and it's my continued frustration with formal academic encounters related to edtech. They are either antiquated or poorly executed, but they're supposed to model how we deliver online as educators and learning practitioners. 
Another serious point of annoyance, a severe lack of self-reflectiveness on the part of professors about how they comprehend what students are trying to ask them. Because all our questions can only be asked via text, with no voice inflection and no immediate feedback adjustment to what someone is telling us they understand about our questions, we so often get professors thinking about our questions at a very surface level and not addressing them at all.

I asked about how the point system assigned to tasks translates the grade \% in the syllabus. And ultimately got some completely unhelpful and snarky comment from the professor that she wasn't going to change her grading system. I wasn't asking her to change anything, just make it comprehensible. I just had to give up on the whole discussion b/c she clearly couldn't hear me -- \#1 b/c I couldn't actually talk to her, and \#2 $\mathrm{b} / \mathrm{c}$ it is simply much, much easier to filter the written words of someone through your own filters of understanding and misconstrue what's being said.

I completely get why people think online learning is lame. Mostly, b/c it is.

\section{March 2016}

I'm finally experiencing someone else's online courses from a faculty advisor perspective. Already my opinions are forming, and it's best to capture and noodle on them now before they harden into imperceptible bias in my dissertation research.

First week of classes, and it's been so annoying to deal with these online courses. The syllabi are ridiculously convoluted and contradictory - at once boasting way too many pages $(10+)$ and hundreds of words but not still not enough pertinent detail. The professors don't even seem to know what they've put in the syllabi, and I've spent days trying to figure out what's due when and how. To the credit of one professor, she also created a 2pg Weekly Synopsis that clearly laid out what was to be done by when.

The other professor did something similar, but only after uploading a seriously confusing 15 pg syllabus, which eventually came down but not before I wasted a lot of time trying to understand it.

And, even her corrected 10pg syllabus still put the week-by-week summary at the end. This, really, is what students need at the start of a 10pg syllabus, not at the end or in a separate doc.

Especially when students are being graded, they need to know their deliverables up front. Why professors think it sensible to bury what matters most at the end of 10+pgs of wordy detail is beyond my comprehension. Perhaps it is because professors have either forgotten or have never learned to think and design from the learner's perspective.

Both classes are requiring synchronous sessions in this first week. Which obliterates one of the few indirect learning benefits of online delivery. One professor at least attempted 
to figure out what evening time would work best for the working teachers in her class. But she nonetheless insists that we must interact, without explaining why and what we're supposed to get out of sitting in Adobe Connect sessions, raising our virtual hands to speak one at a time.

For those of us who miss these synchronous sessions, we have to listen to the session and write a summary about it. Frankly, as an adult in a doctoral program, I abhor assignments given to adult students that require us to prove we were paying attention. We are not undergrads, and this isn't high school.

It seems no matter how skilled traditional teachers and professors may be at using online tools, they're still bringing an old-school mindset to their learning design and, especially, their expectations about needing to prompt and control student performance. Based on my experience this week, I hold out no hope that either of these classes will inspire any new thinking or ideas about how I might design and integrate tech into my teaching. 


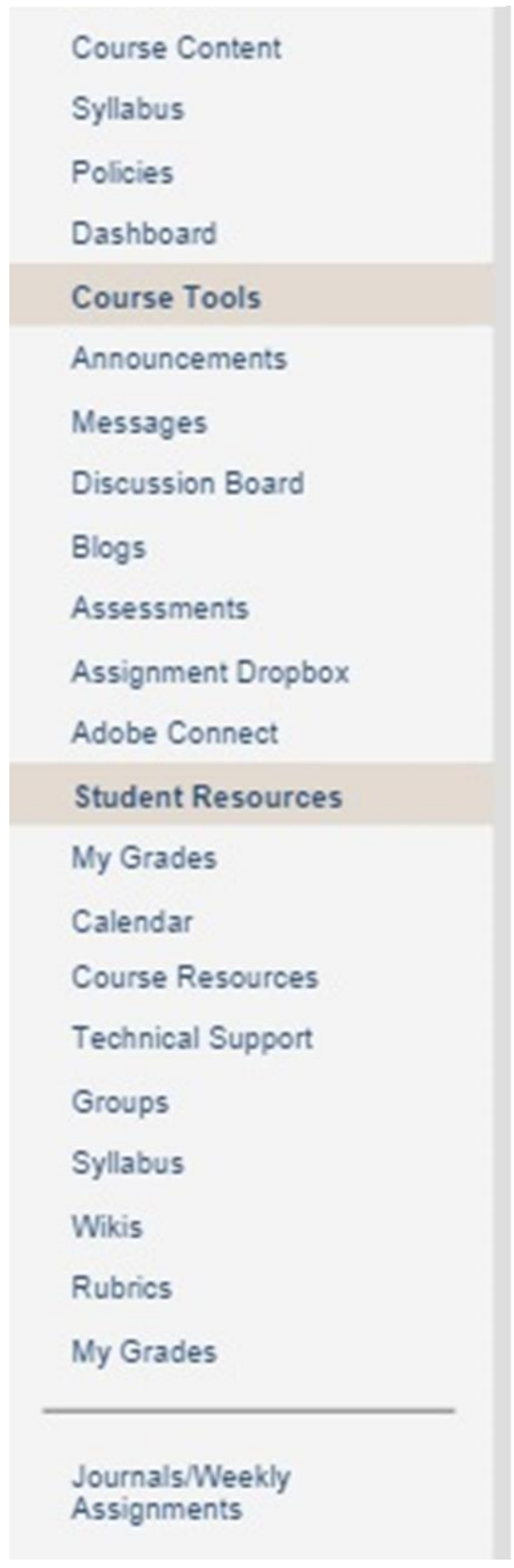

Also, this whole nonsense about how we must interact for the sake of interacting ... tell us that we have synchronous sessions so we can experience how to run them. Tell us we have synchronous sessions so we can experience the technology. But for the love of good sense, don't tell us we have synchronous sessions because we need to "interact" when all we're really doing is sitting and staring at our computers all at the same time.

Something E. said when I mentioned that we also have to do group work in these courses: "If you're introverted, it's already a botheration to do group work; and it's a lot more botheration to do group work if you're not in front of people"

As wordy as the syllabi have been, the DBoard layouts have been just as convoluted. One of the classes has $20+$ primary links in the main nav.

Does nobody designing these courses and LMS platforms use web sites on the Internet? How is it OK to put $20+$ links in the navigation, some of them literally repetitive and more than a few of them winding their way back to similar destinations?

This just wastes so much time and energy and is not in any conducive to establishing an effective learning environment.

I just can't even write about this anymore tonight, it's just such poor design. 


\section{Appendix E - Sanders Bracketing Interview}

February 2016

\section{Sanders Professional Learning Survey}

\begin{tabular}{|l|l|}
\hline $\begin{array}{l}\text { Learning Questions* } \\
\text { (* indicates response required) }\end{array}$ & $\begin{array}{l}\text { Choices } \\
\text { (blank indicates open-ended question) }\end{array}$ \\
\hline $\begin{array}{l}\text { What's your highest level } \\
\text { of completed formal degree } \\
\text { education?* }\end{array}$ & $\begin{array}{l}\text { Associates Degree } \\
\text { Bachelors Degree } \\
\text { Masters Degree } \\
\text { Professional Doctorate (e.g. JD or MD) } \\
\text { Research Doctorate (e.g. PhD, EdD) } \\
\text { I don't have a formal degree }\end{array}$ \\
\hline $\begin{array}{l}\text { How much professional } \\
\text { learning have you had } \\
\text { outside of a formal } \\
\text { degree?* }\end{array}$ & $\begin{array}{l}\text { None } \\
\text { Less than } 10 \text { hours in the past } 5 \text { years } \\
\text { Less than } 10 \text { hours in the past year } \\
\text { More than } 10 \text { hours in the past year } \\
\text { More than 10 hours in the past } 6 \text { months }\end{array}$ \\
\hline $\begin{array}{l}\text { How important is } \\
\text { professional learning to } \\
\text { you?* }\end{array}$ & $\begin{array}{l}\text { Not important } \\
\text { Somewhat important } \\
\text { Important }\end{array}$ \\
\hline $\begin{array}{l}\text { How have you learned as a } \\
\text { professional?* (choose all } \\
\text { that apply) }\end{array}$ & $\begin{array}{l}\text { Significantly important } \\
\text { Extremely important } \\
\text { Attending conferences } \\
\text { Participating in creative learning tours } \\
\text { Researching \& reading on my own } \\
\text { Working with a mentor / coach } \\
\text { Exploring other companies / organizations } \\
\text { Attending university or extension courses } \\
\text { Participating in employee training programs } \\
\text { Taking online courses } \\
\text { Affiliating with professional associations } \\
\text { Doing my job } \\
\text { Other [open answer] }\end{array}$ \\
\hline $\begin{array}{l}\text { What's your preferred } \\
\text { learning format?* }\end{array}$ & $\begin{array}{l}\text { In-person } \\
\text { Online (Computer, Mobile or Tablet) } \\
\text { I like a mix of in-person \& online } \\
\text { I don't have a learning preference }\end{array}$ \\
\hline
\end{tabular}




\section{Sanders Professional Learning Interview}

What comes to mind when you hear the term "professional learning"?

I think about how I want to grow as a professional. How I can do my job better. How I can be a better communicator. How I can learn the latest techniques and approaches for being a more effective learning facilitator. I expect learning to help make me more effective.

\section{What is the primary purpose of learning as a professional?}

Hmm, I guess I kinda just answered that question. The point of learning as a professional is to deliver more effectively in my work. But also, I think I would add that it's also to make me better personally, too. Like, to help me work well with my colleagues and my bosses. So not just to deliver for my clients or learners in my programs but also to be the kind of person that other people can work well with and rely on because I have myself together personally.

\section{How do you expect to learn as a professional?}

I know because learning is my business, I have maybe a different bar. But I expect to be learning all the time, from my interactions with people to the $\mathrm{PhD}$ courses I take to the learning programs I design and deliver. I feel kind of driven by curiosity, a need to know why things are so and how things are connected and how things work in the world. So I'm kind of learning everywhere, and any given situation can be a learning situation for me professionally or personally.

Describe your most recent professional learning activities (subject, where, when, duration). I'm a PhD student in Education with a focus on technology and learning for professionals. So pretty much every working hour of my life the past 3 yrs has been a professional learning activity.

Follow-up question: Can you drill down on a learning experience to be more specific and answer your own questions?

$\mathrm{OK}$, recently I was in an online class for online instructional design as part of the last semester of my $\mathrm{PhD}$ coursework. It was a few months long and included a lot of instructional design project deliverables and exams. The exams where incredibly annoying because they felt like busywork, like as if we were all undergrads who needed to be micro-managed to insure we were doing our learning chores.

The deliverables made more sense to me because I saw them as indicative of the kind of work I'd be doing in the field. In fact, I ended up including my deliverables in this class in my work portfolio. But the exams felt juvenile and really, really annoyed me. I can't stress that enough.

What did you find useful about professional learning activities in which you participated? My PhD has definitely changed how I think about learning in that it's made me think about learning all the time. But honestly, I feel like I might not know the details of what's useful until I actually start putting my PhD to work. Maybe what I can say right now is there's a level of expertise I can feel confident about having. And, I'm more resourceful and have more depth in terms of how I think about learning.

What advantages do you see for (preferred format) that are most important for you? Well, for face-to-face learning, I do like that it requires me to focus because I have to be in a place and committed to participating. But it doesn't always feel worth my time and effort to get somewhere and be around a bunch of other people. The online courses I've taken, I kind of feel the same way about them. But when I think about learning online as exploring on my own, then it really makes more sense. 
Follow-up question: What about exploring online qualifies as learning for you? Being online, it's amazing to me how much information and knowledge and ideas and content I have access to now. I have to wonder, who would I have become if I'd had this much information at my disposal when I was a kid?! It's incredible. My family is not educated - my Dad finished $8^{\text {th }}$ grade $\&$ my Mom completed high school. No one in my family had gone to college when I was a kid, and I really mean no one. Not on either side of my family, in any generation. My generation was the first to start going to college, and only a handful of us went. My parents got me an encyclopedia set when I was a kid, but that was about all they knew to do for my learning.

Now, any question I ever have, I go online and someone out there has probably already asked it and answered it. And if that's not the case, I can still find so many sources of information to help put together my own ideas. It's like taking my brain on an adventure and expanding what I can think about and how I can think about it. That's what learning is to me.

\section{What are your professional development priorities?}

It's interesting, this is a tough question for me. It's so open-ended and could go in so many directions. I don't really understand how to answer it. So I definitely wonder what my research respondents are going to say. I guess right now, I'd say my priorities are to become a thoughtleader and expert on education technology and learning for adult professionals. It's a high-level answer. I'm sure I'll develop more detailed, objective-oriented answers to this once I'm back out in the field working. But for now, since my PhD is at the heart of my professional development, those high-level priorities are most top-of-mind for me.

\section{If you had time, money $\&$ access to your choice of professional learning, how would you choose to learn?}

I can't even believe I'm writing this considering how long this $\mathrm{PhD}$ process has been, but if I didn't have to work, I'd probably do another PhD. But more like how it's done in Europe, where you don't do courses, just reading and researching. I like doing the deep dive, being immersed in a question and putting together the answers. The more I research, the more questions I have. So yeah, I think it'd be this long-form learning of the $\mathrm{PhD}$, that's what I would do.

Do you think it should be mandatory that employees participate in professional learning? Absolutely. But there's no way I'm not biased in this regard. I develop \& design \& deliver learning for a living. Of course I think everyone should learn. I believe in the transformative power of learning, and I believe learning has the potential to move us toward our better selves. So yes, I'm definitely a supporter of mandatory learning.

Follow-up question: Since you plan to interview your participants over the phone and over email, Do you think doing this interview over email affects your answers you provided? Absolutely. I had more time to consider and re-consider my responses. Maybe I would've not had certain thoughts or said certain things if I'd just had to answer quickly in the moment. So yeah, that's a good point. The interviews I do over email will definitely be different than the ones I do in person. There's sort of this faster back-and-forth that happens in person and different ideas are being created as a result of the conversation. Interviewing online doesn't have that instant exchange, but it does allow for more deliberate consideration of ideas and sort of a more thoughtful engagement between people.

Now that I think about it, it's probably the same with learning, right? 


\section{Appendix F - Relevant Technology Software and Services}

\section{Google Cardboard: https://vr.google.com/cardboard/}

Google Cardboard is a virtual reality (VR) platform developed by Google for use with a head mount for a smartphone. Named for its fold-out cardboard viewer, the platform is intended as a low-cost system to encourage interest and development in VR applications.

\section{- Cardboard get CARDBoARd APPS developers manufacturers googleVR}

\section{Google Cardboard}

Experience virtual reality in a simple,

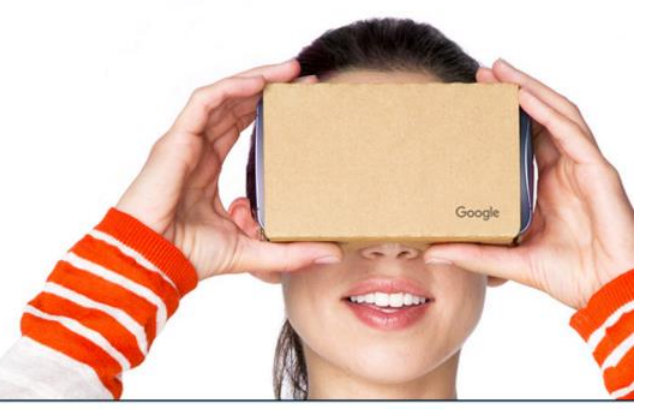




\section{Appendix F - Relevant Technology Software and Services (cont.)}

Mood Meter: http://moodmeterapp.com/

When students experience a range of emotions, how does it impact how they think and what they do? The Mood Meter app was conceived by Marc Brackett, Ph.D. and Robin Stern, Ph.D. from the Yale Center for Emotional Intelligence to encourage student mindfulness of changes in emotions through the day. The app allows end-users to identify, label and track emotions as steps toward cultivating emotional intelligence.

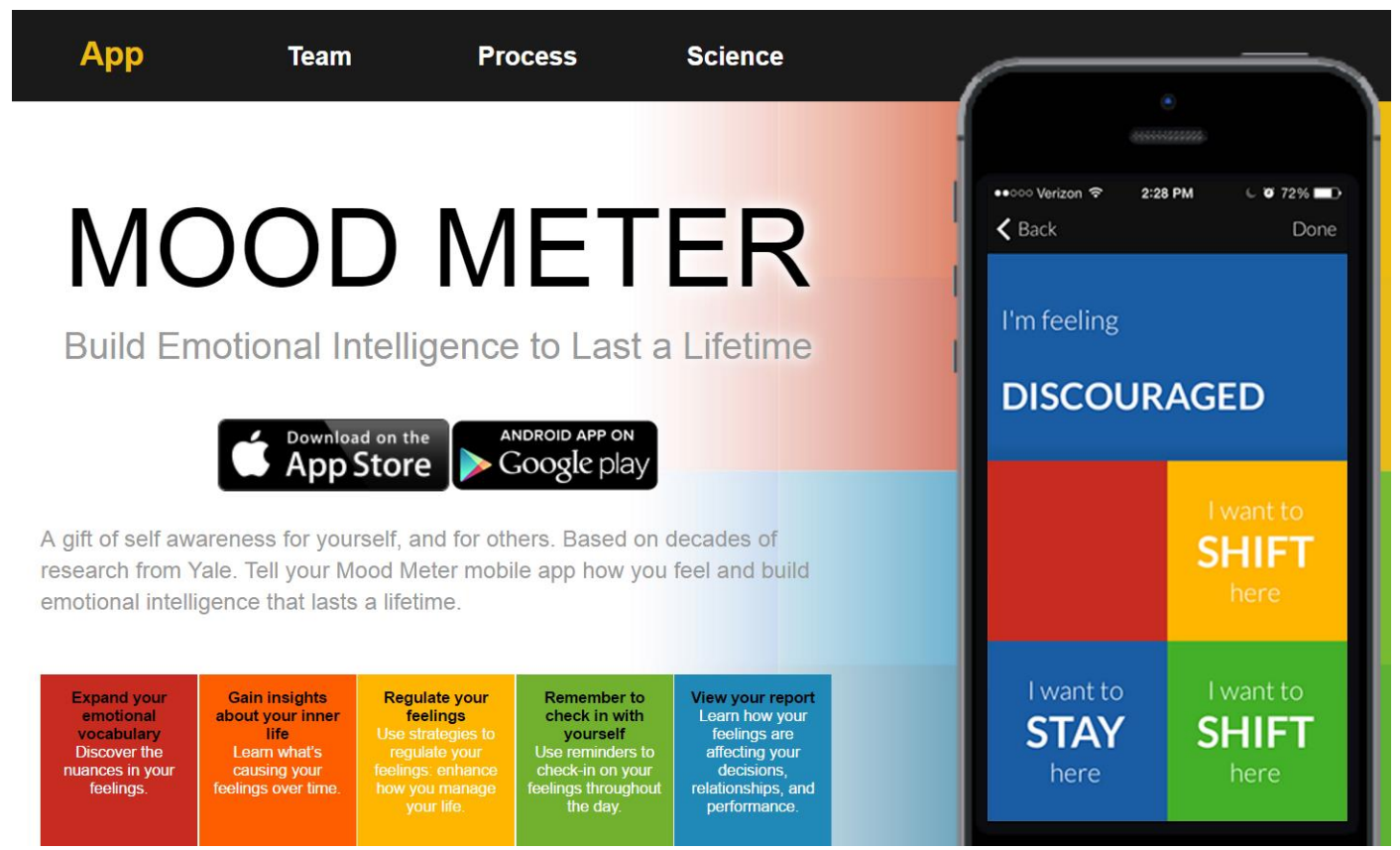




\section{Appendix F - Relevant Technology Software and Services (cont.)}

\section{Pathbrite Online Portfolios: https://pathbrite.com/}

Pathbrite is a cloud-based portfolio platform that allows end-users to aggregate and showcase digital content they have created, skills they have achieved and concepts they have mastered. The portfolio platform supports individual and group assessments of skills and knowledge. Pathbrite's portfolio platform is leveraged by K-12 schools, institutions of higher education and companies to support student and employee success.

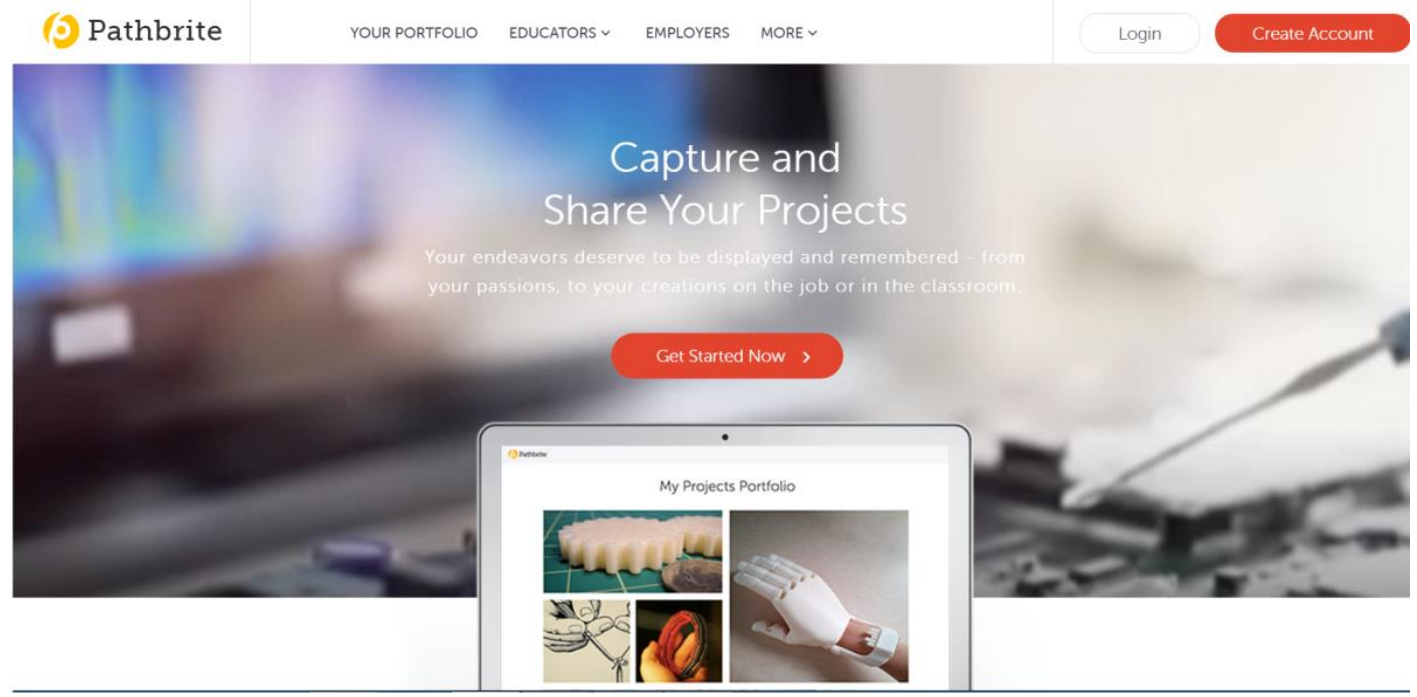




\section{Appendix F - Relevant Technology Software and Services (cont.)}

Poll Everywhere: https://www.polleverywhere.com/

Poll Everywhere allows lecturers, instructor and presenters to insert real-time polling into presentation decks or web sites. The application works well for live audiences using mobile and internet-connected devices. People participate in polls by voting via mobilefriendly web pages, sending text messages or using Twitter. Additional uses include texting comments to a presentation, texting questions to a presenter and responding to group discussions via the web and mobile devices.

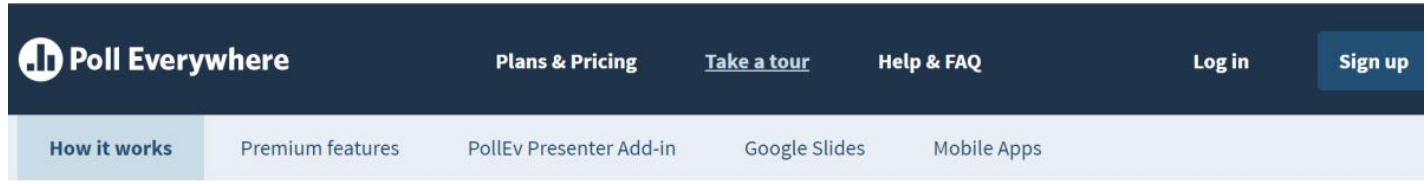

\section{This is how it works}

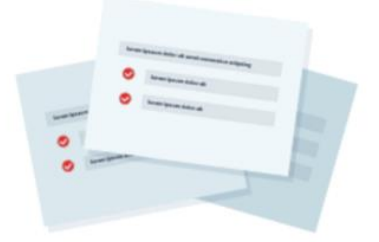

Ask your audience a question with the Poll Everywhere app

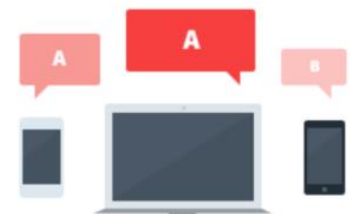

Audience answers in real time using mobile phones, Twitter, or web browsers

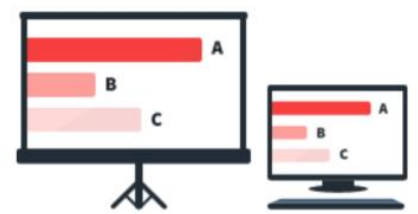

See your response live on the web or in a PowerPoint presentation 


\section{Appendix F - Relevant Technology Software and Services (cont.)}

Quora.com: https://www.quora.com/

Quora is a question-and-answer community that aims to share and grow the world's knowledge by crowdsourcing answers to an unlimited array of questions. A user who signs on to Quora either via an email address or social media (e.g. Facebook) log-in can post questions of any kind or answer questions of any kind. Along with crowd-sourced Q\&A, the site also features questions answered directly by luminaries and experts in science, politics and across a variety of industries.

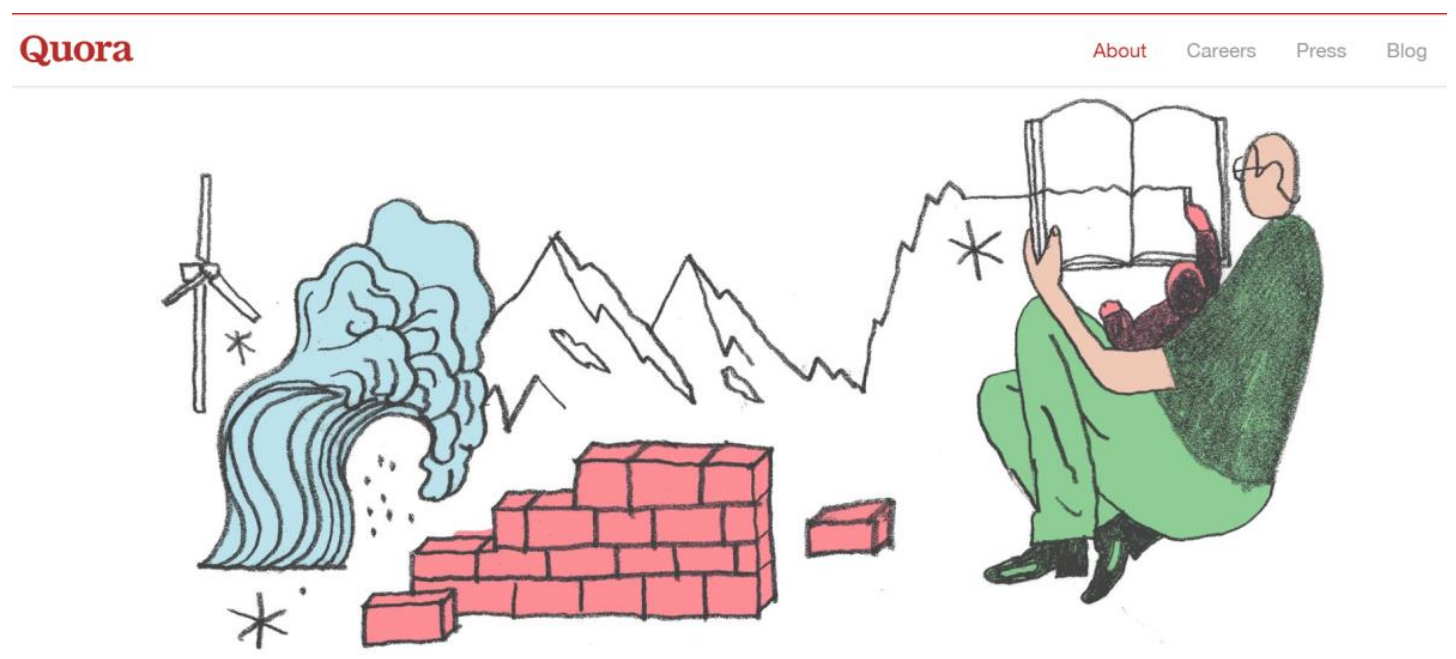

Gather Around a Question

The heart of Quora is questions - questions that affect the world, 


\section{Appendix G - Sanders IRB Exempt Approval}

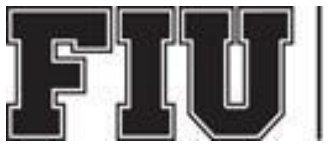

FLORIDA

INTERNATIONAL

UNIVERSITY
Office of Research Integrity

Research Compliance, MARC 414

\section{MEMORANDUM}

To: Dr. Thomas G. Reio, Principal Investigator

CC: File

From: Eliza Gomez, M.Ed., Coordinator, Research Integrity fet

Date: May 18, 2016

Protocol Title: "A Value-Driven Exploration of Online \& In-Person Learning for Professionals"

The Florida International University Office of Research Integrity has reviewed your research study for the use of human subjects and deemed it Exempt via the Exempt Review process.

IRB Protocol Exemption \#: IRB-16-0192 IRB Exemption Date: $\quad$ 05/18/16 TOPAZ Reference \#: $\quad 103552$

As a requirement of IRB Exemption you are required to:

1) Submit an Event Form and provide immediate notification of:

- Any additions or changes in the procedures involving human subjects.

- Every serious or unusual or unanticipated adverse event as well as problems with the rights or welfare of the human subjects.

2) Submit a Project Completion Report Form when the study is finished or discontinued.

Special Conditions: N/A

For further information, you may visit the IRB website at http://research.fiu.edu/irb. 
VITAE

TAMMY SANDERS

$1998-2000$

B.A., Anthropology

Mills College

Oakland, California

$1999-2000$

Online Director \& Managing Producer

WGBH Educational Media Foundation

$2001-2002$

Boston, Massachusetts

M.A., Anthropology of Media

University of London, School of Oriental and African

Studies

London, England

2002-2004

2004-2006

$2007-2010$

2011

$2011-2013$

Cross-Cultural Communications \& Professional Skills

Trainer

Berlitz International Language Schools

Berlin \& Stuttgart, Germany

MBA, International Management

Middlebury Institute of International Studies at Monterey,

Fisher School of Business

Monterey, California

Strategic Learning Facilitator \& Business Development

Partner

WDHB Consulting Group

Berkeley, California

Learning Designer, Director \& Facilitator

Independent Learning Projects

United States \& Europe

Learning Director \& Business Developer

University of California, Berkeley's Center for Executive

Education

Berkeley, California 
Ph.D., Education, McKnight Doctoral Fellow

Florida International University

Miami, Florida

2014

Startup \& Entrepreneurial Culture, Summer Intensive Startup Institute

Boston, Massachusetts

2014-Now

Learning Director \& Research Scholar

Ronin Institute for Independent Scholarship

San Francisco Bay Area, California \& Miami, Florida 